Portland State University

PDXScholar

Fall 1-1-2012

\title{
The Crossover Effects of Supervisor Work-Family Positive Spillover on Employee Sleep Deficiency: Moderating Effects of Family Supportive Supervisor Behaviors (FSSB)
}

Tori Laurelle Crain

Portland State University

Follow this and additional works at: https://pdxscholar.library.pdx.edu/open_access_etds

Part of the Family, Life Course, and Society Commons, Industrial and Organizational Psychology Commons, Social Psychology Commons, and the Work, Economy and Organizations Commons Let us know how access to this document benefits you.

\section{Recommended Citation}

Crain, Tori Laurelle, "The Crossover Effects of Supervisor Work-Family Positive Spillover on Employee Sleep Deficiency: Moderating Effects of Family Supportive Supervisor Behaviors (FSSB)" (2012). Dissertations and Theses. Paper 895.

https://doi.org/10.15760/etd.895

This Thesis is brought to you for free and open access. It has been accepted for inclusion in Dissertations and Theses by an authorized administrator of PDXScholar. Please contact us if we can make this document more accessible: pdxscholar@pdx.edu. 
The Crossover Effects of Supervisor Work-Family Positive Spillover on Employee Sleep Deficiency: Moderating Effects of Family Supportive Supervisor Behaviors (FSSB)

by

Tori Laurelle Crain

A thesis submitted in partial fulfillment of the requirements for the degree of

\author{
Master of Science \\ in \\ Psychology
}

Thesis Committee:

Leslie Hammer, Chair

Todd Bodner

Orfeu Buxton

Charlotte Fritz

Portland State University

2012 
(C) 2012 Tori Laurelle Crain 


\begin{abstract}
The majority of literature on the work-family interface has focused on, and provided evidence of, the conflict associated with engagement in both work and family roles (Eby, Casper, Lockwood, Bordeaux, \& Brinley, 2005). Research examining the positive aspects of work and family participation remains limited. The current study investigated how work-family positive spillover is transferred between members of the supervisoremployee dyad and subsequently how this affects employee sleep outcomes. It was hypothesized that work-to-family affective positive spillover experienced by supervisors would crossover to employees and increase their experiences of work-to-family affective positive spillover. In turn, this would allow for better employee sleep. It was also proposed that these relationships would depend on the level of employee perceptions of family-supportive supervisor behaviors (FSSB), such that higher levels of FSSB would result in higher levels of employee positive spillover and better employee sleep. As part of a larger study, survey data were collected in a sample of 696 workers supervised by 180 managers in the information technology sector. Contrary to expectations, results indicated that supervisor positive spillover was negatively related to employee positive spillover. Furthermore, FSSB moderated the association between supervisor positive spillover and employee sleep duration, such that the relationship between supervisor positive spillover and employee sleep duration was positive under high levels of FSSB, but negative under low levels of FSSB. Again, this finding was contrary to expectations. Alternative explanations are discussed.
\end{abstract}




\section{Acknowledgements}

I would like to acknowledge my thesis committee for their guidance, suggestions, and enthusiasm. Each member's expertise has proved extremely valuable in the development of this manuscript. I am especially grateful to my advisor, Dr. Leslie Hammer, for providing me with continual support and assistance over the course of this project. I would also like to thank my cohort for their helpful feedback. Finally, I would like to acknowledge my roommates, friends, and family members for their encouragement and support. 
Table of Contents

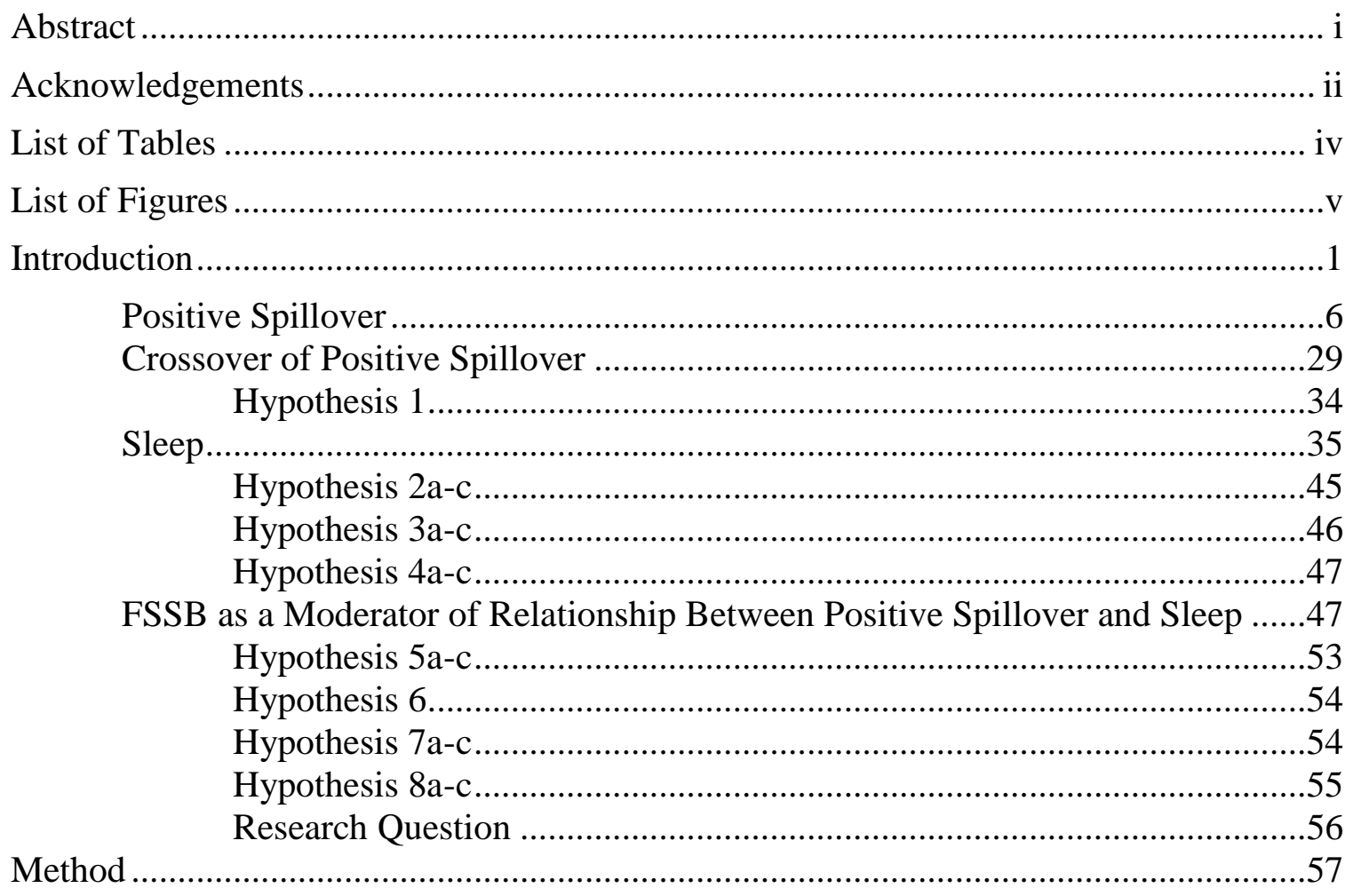

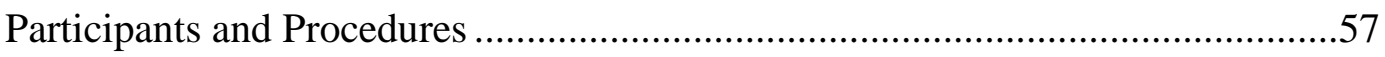

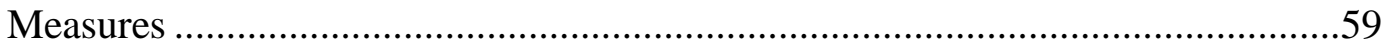

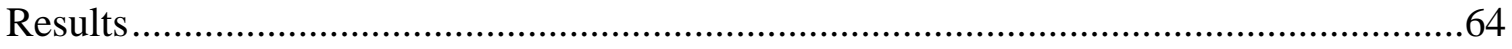

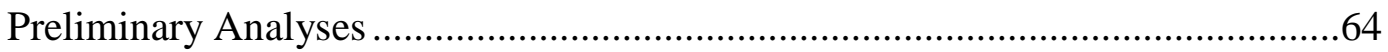

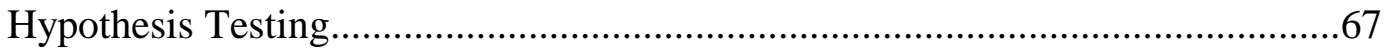

Direct Effects and Mediation ..............................................................68

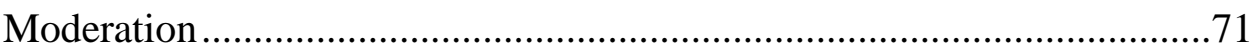

Moderated Mediation...................................................................76

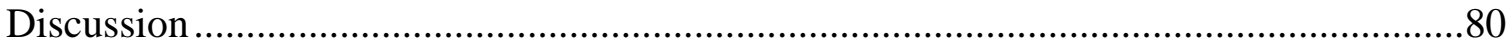

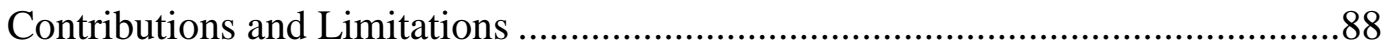

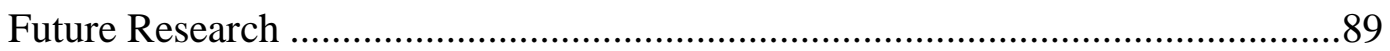

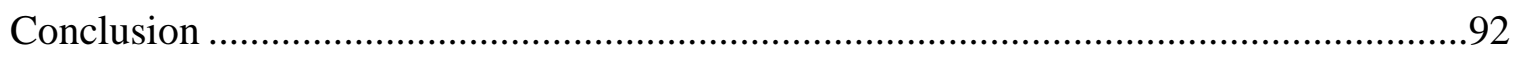

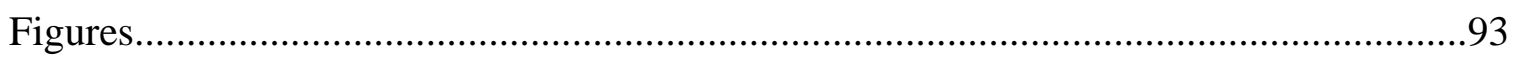

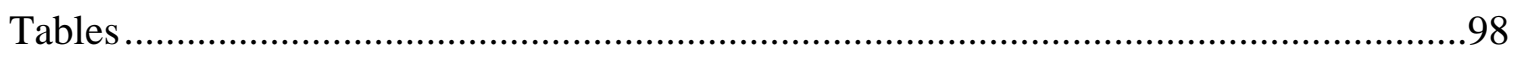

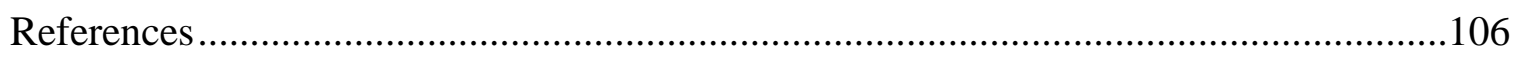

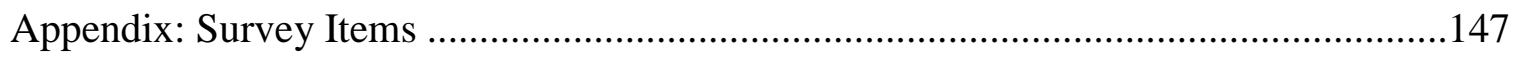


List of Tables

Table 1: Correlations between Study Variables .98

Table 2: Hypothesis 1: Multilevel Regression Results for Association Between Supervisor Positive Spillover and Employee Positive Spillover.....

Table 3: Hypothesis 2a-c: Multilevel Regression Results for Association Between Supervisor Positive Spillover and Employee Sleep Outcomes

Table 4: Hypotheses 3a-c: Multilevel Regression Results for the Association Between Employee Positive Spillover and Employee Sleep Outcomes

Table 5: Hypothesis 5a-c: Multilevel Regression Results for Moderating Effects of FSSB between Supervisor Positive Spillover and Employee Sleep Outcomes .103

Table 6: Hypothesis 6: Multilevel Regression Results for Moderating Effects of FSSB between Supervisor Positive Spillover and Employee Positive Spillover .104

Table 7: Hypothesis 7a-c: Multilevel Regression Results for Moderating Effects of FSSB between Employee Positive Spillover and Employee Sleep Outcomes .105 


\section{POSITIVE SPILLOVER AND SLEEP}

List of Figures

Figure 1: Theoretical Model of Moderated Mediation .

Figure 2: Results of Moderated Mediation for Sleep Insufficiency.

Figure 3: Results of Moderated Mediation for Sleep Duration .95

Figure 4: Results of Moderated Mediation for Insomnia Symptoms... .96

Figure 5: Graph of Employee Positive Spillover by FSSB Interaction on Employee Sleep

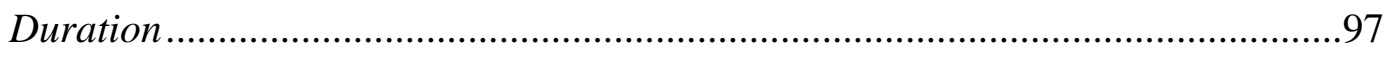




\section{Introduction}

Several social and demographic trends have contributed to a growing interest in the work-family interface. The U.S. workforce is seeing increasing numbers of female workers, working mothers with young children, working single parents, and men and women who are assuming caregiving responsibilities for parents as well as children (e.g., Bond, Galinsky, \& Swanberg, 1998; Bond, Thompson, Galinsky, \& Prottas, 2003; Fields \& Casper, 2001; Hammer, Colton, Caubet, \& Brockwood, 2002; Neal \& Hammer, 2007; US Bureau of Labor and Statistics, 2006). Furthermore, the nature of today's work is also changing with a shift towards a 24/7 economy, a focus on capitalistic values and lean production, and increasingly service-based work (e.g., Bond et al., 1998; Tetrick \& Quick, 2003). It is these developments that have fueled much of the research on the intersection between work and family. However, scholars in this area are becoming increasingly aware that the social and psychological complexities of the work-family interface extend beyond the conflict that is experienced by members of the workforce assuming both work and family responsibilities.

The majority of literature on the work-family interface has focused on, and provided evidence of, the conflict associated with engagement in both work and family roles (Eby, Casper, Lockwood, Bordeaux, \& Brinley, 2005). High levels of work-family conflict have negative consequences such as decreased job and life satisfaction, increased turnover intentions, increased psychological strain, increased rates of depression, and increased rates of burnout (e.g., Eby et al., 2005). However, some research has examined positive outcomes, as opposed to conflict, associated with this dual participation (e.g., 
McNall, Nicklin, \& Masuda, 2010). Currently, there is still limited empirical research examining the mutually beneficial effects that work and family can have on one another. Results to date show that affective commitment, job satisfaction, family satisfaction, life satisfaction, physical health, and mental health are increased when individuals experience the enriching effects that work and family can have on each other (e.g., Crain \& Hammer, forthcoming; McNall et al., 2010; Parasuraman \& Greenhaus, 2002; Zimmerman \& Hammer, 2010). Work-family researchers contend that by focusing on conflict, we do not understand the work-family interface in its entirety (e.g., Parasuraman \& Greenhaus, 2002; Rothbard, 2001; Voydanoff, 2004b).

Drawing on positive psychology (e.g., Seligman 1998; Seligman \& Csikszentmihalyi, 2000), organizational researchers have introduced the construct of work-family positive spillover as a means for understanding the positive and reciprocal effects that work and family have on each other (Edwards \& Rothbard, 2000; Hanson, Hammer, \& Colton, 2006). Work-family positive spillover can be defined as the transfer of affect, skills, behaviors, and values from work to family domains or from family to work domains, allowing for beneficial outcomes in the receiving domain (Hanson et al., 2006). With the conceptual development of positive spillover, growing awareness of the positive connections between work and family has been mounting.

Limited research has shown that the effects of positive spillover may crossover to another member of a dyad. The majority of crossover studies have focused on the transmission of strain, while the process of positive crossover has remained largely unexamined (Crain \& Hammer, forthcoming; Westman, 2001). However, crossover 
effects of positive spillover on spouses' depression have been found between members of dual-earner couples in the expected direction, such that positive spillover is strongly related to decreases in spouses' depression (Hammer, Cullen, Neal, Sinclair, \& Shafiro, 2005). The majority of crossover and spillover-crossover research has examined spousal dyads (Westman, Vinokur, Hamilton, \& Roziner, 2004). Thus far, only one study has examined the crossover effects of positive spillover within a supervisor-employee dyad, demonstrating a positive relationship (Carlson, Ferguson, Kacmar, Grzywacz, \& Whitten, 2011). Furthermore, this study uniquely examined the transfer of positive spillover in supervisors to positive spillover in employees, rather than examining the effects of supervisor positive spillover on other employee outcomes.

As has been suggested by Greenhaus and Powell (2006), engaging in multiple roles may lead to the generation of resources allowing individuals to better cope with stress and stress-related outcomes. In keeping with this explanation, data suggests that positive spillover does in fact have a positive relationship with mental and physical health (e.g., McNall et al., 2011). Consequently, the crossover of positive spillover should also result in positive health outcomes for employees when resources are transferred from supervisor to employee.

One particular health outcome that has rarely been examined in work-family research is sleep. Furthermore, sleep-related variables have largely been neglected in the occupational health and Industrial/Organizational Psychology literature (e.g., Krauss, Chen, \& DeArmond, 2003). Some studies have found a negative relationship between work-family conflict and sleep-related variables (e.g., Britt \& Dawson, 2005; Sekine, 
Chandola, Martikainen, Marmot, \& Kagamimori, 2006; van Amelsvoort, Jansen, Swaen, van den Brandt, \& Kant, 2004). However, only two studies have tested and found a positive relationship between positive spillover and sleep (Sanz-Vergel, Demerouti, Mayo, \& Moreno-Jimenez, 2011; Williams, Franche, Ibrahim, Mustard, \& Layton, 2006). Given the associations between poor sleep and health-related problems (e.g., Buxton \& Marcelli, 2010; Buxton, Pavlova, Reid, Wang, Simonson, \& Adler, 2010; Centers for Disease Control and Prevention, 2011; NHLBIWG, 1999), individuals' well-being may greatly benefit from increases in positive spillover and subsequent improved sleep. Furthermore, poor sleep has been linked to organizational variables such as job satisfaction (Scott \& Judge, 2006), absenteeism (Jacquinet-Salford, Lang, Fouriaud, Nicoulet, \& Bingham, 1993; Spector \& Jex, 1998), turnover (Shimizu et al., 2005), and occupational accidents (e.g., Akerstedt, Fredlund, Gillberg, \& Jansson, 2002; Nakata et al., 2005; Raggatt, 1991). The positive effects of spillover on employee sleep may hold numerous beneficial outcomes for both employee well-being and organizational success. Additionally, previous studies in this area that have included sleep-related variables have not used a comprehensive measure of sleep or multiple measures of different sleep components. Rather, organizational researchers, such as Williams et al. (2006) and Sanz-Vergel et al. (2011), have relied primarily on self-report scales measuring sleep quality. Moreover, researchers in the sleep field have generally examined sleep duration, sleep quality reports, or the presence or absence of specific sleep disorders (Buxton et al., in press). Recently, a concept termed "sleep deficiency" has been suggested (National Center on Sleep Disorders Research, 2011) as a 
comprehensive evaluation of sleep and is marked by "the presence of insufficient sleep quantity and/or inadequate sleep quality, such as a sleep disorder, and reflects unmet sleep need that further results in suboptimal health, performance, or well-being" (Buxton et al., in press). This concept takes into account measures of sleep insufficiency, sleep duration, and insomnia (Buxton et al., in press; Sorenson et al., 2011). The development of sleep deficiency was motivated by the need to measure the different components, and combinations of components, that result in insufficient sleep. The components of sleep deficiency have been found to be associated with higher rates of pain, work interference, and functional limitations (Buxton et al., in press), in addition to inadequate physical activity, low supervisor and coworker support, harassment at work, low decision latitude, low people-oriented culture, and poor safety and ergonomic practices (Sorenson et al., 2011). In order to truly understand how work-family variables affect employee sleep, the comprehensive measurement of sleep is essential.

Work-family scholars have called for future research to examine more complex models exploring the linkages between work and family by incorporating the role of potential moderators within the positive spillover process (e.g., Heller \& Watson, 2005). Supervisor support has been related to increases in work-to-family positive spillover (Bhargava \& Baral, 2009; Taylor, Delcampo, \& Blancero, 2009; Hammer, Kossek, Yragui, Bodner, \& Hanson, 2009; Thompson \& Prottas, 2005). Additionally, the presence of supervisors that are supportive of employees' work and family demands has been related to increases in employees' sleep duration (Berkman, Buxton, Ertel, \& Okechukwu, 2010). Because past research indicates that support from supervisors does 
in fact act as a resource for employees (O'Driscoll et al., 2003; Thomas \& Ganster, 1995), I propose that the buffering hypothesis of supervisor social support can be extended to the crossover of supervisor positive spillover on employee positive spillover and subsequent employee outcomes.

The proposed study will address these gaps in the literature by examining the crossover of positive spillover from supervisor to employee and its effect on employee sleep outcomes. Specifically, the role of family supportive supervisor behaviors (FSSB) in the crossover process of positive spillover is determined. It is also hypothesized that this crossover process is related to employee sleep insufficiency, sleep duration, and the presence of insomnia symptoms. This basic theoretical model is shown in Figure 1. The following section will review background literature on work-family positive spillover, followed by an explanation of the crossover of positive spillover. Then, sleep as an outcome variable and FSSB as a moderator will be examined.

\section{Positive Spillover}

The positive psychology movement has grown in a reaction to the traditional field of psychology which has emphasized a disease model of human nature focused on psychological illness and dysfunction. Formative work on optimism and happiness (Seligman, 1998; Seligman \& Csikszentmihalyi, 2000) has developed into the branch of positive psychology, or the study of positive emotions, strengths, character, and virtues in people, groups, and institutions (Crain \& Hammer, forthcoming). Positive psychology argues that a focus on pathology and healing has left us without an adequate understanding of what conditions lead to flourishing, civic engagement, and a life worth 
living (Seligman \& Csikszentmihalyi, 2000). More recently, Seligman (2008) proposed a new field of psychology altogether: positive health psychology. This field parallels positive psychology with a focus on physical health rather than illness. The positive health psychology movement is also evident within organizational research and the area of work and family, where constructs such as positive spillover have emerged to explain how a combination of work and family responsibilities can lead to beneficial outcomes.

Research on the positive aspects of work and family indicates that participation and engagement in both work and non-work domains may enrich an individual's resources, rather than deplete them (Kirchmeyer, 1992a), therefore making it essential to distinguish the construct of positive spillover from work-family conflict. Work-family conflict occurs when an individual's participation in his or her work role interferes with participation in his or her family role, or vice versa (Greenhaus \& Beutell, 1985). Correlations between work-family conflict and work-family positive spillover are low, with a mean correlation of -.02 (Greenhaus \& Powell, 2006). Thus, it is assumed that work-family conflict and work-family positive spillover are distinct constructs, meaning that a high level of one does not indicate the absence of the other (Hanson et al., 2006). Similarly, it has been shown that different antecedents predict positive spillover and work-family conflict (Grzywacz \& Butler, 2005) suggesting that individuals can experience high levels of both conflict and positive spillover simultaneously. In fact, a study conducted by Innstrand, Langballe, and Falkum (2010) showed that across eight different occupational groups, those experiencing the most positive spillover were also among those experiencing the most conflict, regardless of gender. Work-family positive 
spillover is associated with work and non-work outcomes, such as job performance, affective commitment, and work satisfaction, home performance, home commitment, home satisfaction, and global life satisfaction, above and beyond the effects of workfamily conflict (van Steenbergen, Ellemers, \& Mooijart, 2007).

Organizational research has begun to address the need for understanding the positive aspects of work and family participation by building off of the early theoretical work of Sieber (1974), Marks (1977), Thoits (1983), and Crouter (1984). For example, research has focused on the constructs of work-family facilitation (Grzywacz, Almeida, \& McDonald, 2002; Grzywacz, Carlson, Kacmar, \& Wayne, 2007) and work-family enrichment (Greenhaus \& Powell, 2006; Carlson, Kacmar, Wayne, \& Grzywacz, 2006), in addition to work-family positive spillover (Crouter, 1984; Edwards \& Rothbard, 2000; Kirchmeyer, 1992b). Other closely related terms that have been proposed include workfamily compatibility (Barnett \& Baruch, 1985; Barnett \& Hyde, 2001), work-family enhancement (Greenhaus \& Parasuraman, 1999), and work-family synergy (Beutell \& Wittig-Berman, 2008). Although operationalized slightly differently, these constructs are closely related (Masuda, McNall, Allen, \& Nicklin, 2012). Facilitation refers to the extent to which involvement in one life domain provides developmental (e.g., skills, knowledge), affective (e.g., moods, attitudes), capital (e.g., economic, social, health assets), or efficiency gains (e.g., enhanced focus, attention) that contribute to functioning in the other domain (Wayne, Grzywacz, Carlson, \& Kacmar, 2007). Enrichment refers to the degree to which experiences in one role improve the quality of life in the other role, 
through the transfer of resources or positive affect from one role to the other (Greenhaus \& Powell, 2006).

Hanson and colleagues (2006) have developed and validated a work-family positive spillover scale to measure the benefits involved with the transfer of affect, skills, behaviors, and values between work and family domains with the condition that positive outcomes are experienced in the receiving domain. It has been suggested that future research develop a nomological network explaining the relationships between these distinct but related concepts as difficulties arise when attempting to synthesize the past research on positive aspects of the work-family interface (McNall et al., 2010). Zimmerman and Hammer (2010) propose work-family positive spillover as a metaconstruct encompassing the relationships and mechanisms that allow work and family to benefit one another. Per this interpretation, I will refer to the separate constructs generally as the single unifying concept of work-family positive spillover in the remainder of this text.

Edwards and Rothbard (2000) suggested there are four specific types of workfamily positive spillover: mood, values, skills, and behaviors. By the authors' definition, the spillover of mood occurs when mood in one domain affects mood in the other domain. Positive interactions in one domain increase positive mood, thereby increasing the probability of later positive interactions being experienced in the opposite domain. Positive interactions with children or coworkers, for example, bring about intrinsic and extrinsic rewards which also enhance mood. Although the spillover of mood is generally unintentional, especially when it is felt mood rather than expressed mood, intent does 
regulate the degree to which felt moods are actually expressed. Depending on the domain, certain roles carry expectations regarding the expression of mood (Ashforth \& Humphrey, 1993; Rafaeli \& Sutton, 1987). As such, researchers contend that individuals will regulate the expression of moods to comply with role expectations.

In understanding the other three types of positive spillover, Edwards and Rothbard (2000) offer two pathways by which values, skills, and behaviors can be transferred to the opposite domain: mediation or direct effect. For example, work and family are socializing forces that form an individual's general life values, which in turn shape those values that are specific to a domain. This implies that general life values mediate the causal path between work and family values. Additionally, values originating in one domain can directly spill over to influence values in the other domain. Similarly, the learning of skills in one domain influences an individual's general knowledge, which then influences knowledge in a specific domain. Specific skills can also be directly transferred between roles. Lastly, behaviors developed in one domain become permanent habits that then influence the second domain, or directly affect behaviors in the second domain.

Drawing on the work of Edwards and Rothbard (2000), Hanson et al. (2006) have created a multidimensional scale of work-family positive spillover that is composed of three dimensions of positive spillover: behavior-based instrumental positive spillover, value-based instrumental positive spillover, and affective positive spillover. The behavior-based instrumental dimension is composed of items relating to both skills and behaviors. Each of these three types occurs in the family-to-work direction and in the 
work-to-family direction. The authors recommend that future research treats each type of positive spillover as a separate construct as a way to advance theoretical development.

Some earlier work has been conducted to establish which types of affect, skills, behaviors, and values can be transferred between domains when work-family positive spillover occurs. For example, the affective states of excitement, enthusiasm, and happiness may transfer from work to family or from family to work contexts (Williams \& Alliger, 1994). Such skills as multitasking and interpersonal communication learned in one role can have beneficial effects in another role (Crouter, 1984; Ruderman, Ohlott, Panzer, \& King, 2002). Regarding behavior, teachers' disciplinary style has been shown to spill over to the home domain and influence behavior (Ispa, Gray, \& Thornburg, 1984). Lastly, values that parents promote in the home may be transferred from the work domain. These values include autonomy, curiosity, consideration, and obedience (Kohn, 1963; Pearlin \& Kohn, 1966). Despite these initial efforts, there is a need for construct clarification, theoretical work, and further measurement development to uncover exactly which types of affect, skills, behavior, and values are spilling over (Greenhaus \& Powell, 2006; Gryzwacz \& Butler, 2003; Hammer, Bauer, \& Grandey, 2003; Wayne, Musisca, \& Fleeson, 2004).

Role theory. Research on the work-family interface has drawn primarily on role theory for establishing a theoretical framework underpinning the construct of positive spillover. This theory assumes that roles are established by the expectations that others set with regard to appropriate behavior when assuming that role (Kahn, Wolfe, Quinn, Snoek, \& Rosenthal, 1964). The behaviors that are expected of individuals at home may 
be very different from the roles that are expected of individuals at work. For example, managerial tactics effective in the workplace may not be warranted or welcomed when interacting with family members. To address this phenomenon, Katz and Kahn (1978) proposed that conflict occurs when differing roles are incompatible and Greenhaus and Beutell (1985) have clarified that work-family conflict is a form of this inter-role tension.

In contrast, research on positive spillover has sought to establish the positive effects of engaging in multiple roles. Sieber (1974) proposed a theory of role enhancement suggesting that when individuals participate in multiple roles, they accumulate resources and skills that can be utilized across their different responsibilities regardless of the role. Sieber suggested that positive outcomes of role accumulation include role privileges, overall status security, resources for enhancement and role performance, and enrichment of the personality and ego gratification. Recent metaanalytic evidence does support positive spillover, as it is marked by role accumulation, being associated with various positive outcomes (McNall et al., 2010).

Social identity theory. In addition to role theory, social identity theory has been foundational to the establishment of positive spillover as a construct. This theory posits that individuals hold a set of social identities determined both by themselves and by others in society who send role expectations (Mead, 1934; Stryker, 1968). Out of social identity theory emerged the scarcity and enhancement hypotheses. Goode (1960) proposed that individuals have a fixed number of resources and the greater number of roles maintained by that individual, the more resources expended. This "scarcity" leads to a greater potential for conflict and strain. The scarcity hypothesis assumes that the 
ability to meet all role demands is not normal or common practice, so individuals will make efforts to protect and maintain resources, thereby decreasing strain to tolerable levels.

Alternatively, Marks (1977) put forward the more comprehensive enhancement hypothesis, arguing that the scarcity hypothesis does not always hold true. Some individuals may report a scarcity of personal resources and experiences of role overload, while other individuals in the same settings do not. In an attempt to explain this, the enhancement hypothesis suggests that multiple roles can in fact increase the number of resources available to an individual, allowing for enhanced self-esteem (Marks, 1977; Marks \& MacDermid, 1996; Sieber, 1974; Thoits, 1983). Mirroring this effect, human physiology indicates that human activity produces energy on the cellular level while simultaneously consuming energy. This metaphor for the work-family interface suggests that in similar way, engagement in multiple roles may simultaneously use and generate resources. People who engage in multiple roles derive feelings of meaningfulness and this in turn may allow for a decrease in stressors or for increases in coping skill behaviors. Employed men and women holding multiple roles have reported rewards and benefits of multiple role participation such as decreased psychological distress, increased job satisfaction (Pictromanoco, Manis, \& Frohardt-Lane, 1986), and improved health (Collijn, Appels, \& Nijhuis, 1996). It is essential that research examine the ways in which engagement in multiple roles serves to both deplete and increase resources.

Theory of work-family enrichment. Based on this work by early theorists, Greenhaus and Powell (2006) more recently proposed a model for work-family 
enrichment. Enrichment is the extent to which experiences in one role improves the perceived quality of life or effectiveness in the other role. The enrichment model assumes bidirectionality in that resource gains can be acquired in either the work or family domain, consequently improving performance in the opposite domain. Previous research demonstrates that work-to-family and family-to-work positive spillover are conceptually distinct constructs because of their associations with different antecedents and outcomes (e.g., Grzywacz, 2000; Grzywacz \& Marks, 2000; Wayne, Musisca, \& Fleeson, 2004). For example, it has been shown that there is a positive relationship between decision latitude at work and work-to-family positive spillover, while there is a positive relationship between family-related social support and family-to-work positive spillover (Grzywacz \& Marks, 2000).

According to Greenhaus and Powell (2006) a resource is "an asset that may be drawn on when needed to solve a problem or cope with a challenging situation" (p. 80). Under this theory, role experiences offer five categories of resources that may be acquired by an individual: skills and perspectives (e.g, interpersonal skills, coping skills, respecting individual differences), psychological and physical resources (e.g., selfefficacy, hardiness, optimism), social-capital resources (e.g., networking, information), flexibility (e.g., flexible work arrangements), and material resources (e.g., money). The acquiring of these assets then allows for the improved performance in the opposite role. For example, new parents may learn multitasking skills while caring for their children that may then allow them to carry new skills into the work context. Additionally, flexible work arrangements may allow individuals to take children or aging parents to doctors' 
appointments during work time without resulting in imposed punishment from supervisors or management.

This framework asserts that enrichment is experienced either through an instrumental path or an affective path. Performance is increased by means of the instrumental path when individuals have the belief that engagement in one role has directly increased their ability to perform in the opposite role. Enhanced performance occurs by way of the affective pathway when an increase in resources in one role enhances mood, spilling over and permitting for increased functioning in the other role. Greenhaus and Powell (2006) also suggest the relationship between work resources and family performance is moderated by the salience of family, such that the positive relationship between work resources and family performance is strengthened when family is especially salient. Correspondingly, the salience of work moderates the relationship between family resources and work performance, such that the positive relationship between family resources and work performance is enhanced under high levels of work saliency.

Resource-gain-development theory. Based on the concepts of positive organizational scholarship (Cameron, Dutton, \& Quinn, 2003), ecological systems theory (Bronfenbrenner, 1979), and conservation of resources theory (Hobfoll, 1989), Wayne, Grzywacz, Carlson, and Kacmar (2007) have suggested a model for understanding the theoretical relationships between work-family positive spillover and its antecedents and outcomes. The authors propose that personal characteristics and environmental resources enhance system functioning which ultimately facilitates the spillover process. An 
individual is likely to experience this enhancement when he or she possesses personal characteristics (e.g., trait positive affectivity) that promote positivity and allow the individual to more easily experience positive emotions and pursue developmental opportunities. These individuals have a greater tendency towards increasing their gains in a domain, which will consequently spill over into the opposite domain. Important personal characteristics may include positive affectivity, self-efficacy, and work identity. In addition, environmental resources promote positive experiences and the acquisition of gains above and beyond personal characteristics. Environmental resources can be classified into three categories: energy resources (i.e., enriched jobs, developmental opportunities), support resources (i.e., coworker and supervisor support, supportive work environment), and condition resources (i.e., job prestige). When accessible, these resources enable positive spillover by promoting positive environments.

The acquisition of resources is contingent upon their availability and an individual's ability to obtain and maintain the resources. Despite being readily available, some individuals may be better skilled than others at exploiting the resources in ways that promote greater developmental opportunities. These individuals are likely to experience more benefits. The authors contend that demand characteristics, such as gender and social class, directly affect the availability of resources. Demand characteristics are projected to act as moderators in the relationship between environmental resources and positive spillover. The authors suggest that a promotion of performance in the work and family roles can crossover to other members within the system (Wayne et al., 2009). These individuals can then also report positive outcomes, as they experience enhanced 
gains. For example, spouses may report increases in marital quality in the family domain.

Antecedents of positive spillover. Despite work-family positive spillover being established in the organizational literature, limited research has been conducted on the predictors and outcomes related to this construct (Zimmerman \& Hammer, 2010). Findings on antecedents of the construct are reviewed below.

Characteristics of the individual and environment that facilitate the acquisition and transfer of resources from one domain to the other are likely to be antecedents of positive spillover (Carlson et al., 2006). To date, there is a limited list of variables that have been suggested as non-work-related and work-related antecedents to positive spillover. According to Greenhaus and Powell (2006) these non-work and work-related antecedents are resources generally acquired from the originating domain. For example, marital role commitment is more likely to be related to family-to-work positive spillover while coworker support is more likely to be related to work-to-family positive spillover.

Non-work-related antecedents. Most research on non-work-related predictors of positive spillover has focused on family-related variables. For example, family salience and one's relationship with family correlate with both directions of positive spillover, and family mutuality, or the cooperation of family members sharing in responsibilities, correlates with work-to-family positive spillover (Carlson et al., 2006). Other family factors such as family role quality (Pedersen, Minnotte, Kiger, \& Mannon, 2009), psychological involvement in the family, marital role commitment (Allis \& O’Driscoll, 2008; Graves, Ohlott, \& Ruderman, 2007), and family cohesion (Stevens, 
Minnotte, Mannon, \& Kiger, 2007) have been suggested as antecedents of family-towork positive spillover. In a study by Stevens et al. (2007), relationship satisfaction was related to positive family-to-work spillover for men, while satisfaction with the housework arrangement was related to women's family-to-work positive spillover. In a study examining emotional labor conducted by Yanchus, Eby, Lance, and Drollinger (2010), positive affective responses to family mediated the relationship between surface acting, or managing one's observable expressions, in family and family-to-work positive spillover.

Many studies to date have focused on the positive spillover experienced by parents. Zimmerman (2009), found that parents having a child under the age of 18 in the household experienced more positive affective outcomes in the work domain. Child care role quality has a positive relationship with family-to-work spillover (Brockwood, 2002). Similarly, time spent parenting has a negative relationship with positive spillover (Kirchmeyer, 1992b; 1993). Another study found that age of one's first child and the presence of a paid domestic helper were negatively related with family-to-work positive spillover in a sample of Chinese parents (Lu, Siu, Spector, \& Shi, 2009), although having an elderly domestic helper was positively associated. Higher levels of family-to-work positive spillover have also been found with the ability for a woman's partner to leave work to care for children (Pedersen et al., 2009). Innstrand, Langballe, Espnes, Aasland, and Falkum (2010) concluded that work-to-home positive spillover did not vary by family structure (i.e., two-parent families, childless couples, single parents, and single 
individuals without children), although childless couples reported the most home-to-work positive spillover.

Family support has also been examined in relation to the enriching effects of engagement in both work and family roles. Support from one's spouse and support from other family members is related to positive spillover in the family-to-work direction (Cinamon \& Rich, 2010; Grzywacz \& Marks, 2000; Hakanen, Peeters, \& Perhonemiemi, 2011; Karatepe \& Bekteshi, 2008; Lu et al., 2009; Siu et al., in press; Srivastava, Srivastava, \& Srivastava, 2009; Voydanoff, 2005; Wadsworth \& Owens, 2007) and the work-to-family direction (Cinamon \& Rich, 2010; Hakanen et al., 2011; Lu et al., 2009). It has also been found that supportive family experiences are significantly and positively related to the occurrence of positive spillover (Aryee, Srivivas, \& Tan, 2005). Supportive partners seem to act as buffer for individuals' job-related stress (Kinnunen, Feldt, Geurts, \& Pulkkinen, 2006), while the relationship between work experiences and psychological distress can be buffered by experiences in the family (Barnett, 1994).

In addition to family factors, other non-work variables have also been associated with positive spillover. For example, household rewards have been related to family-towork positive spillover (Voydanoff, 2005), while family-to-work positive emotional spillover has been correlated with engagement in sports, recreation, and physical fitness (Hecht \& Boies, 2009). It has also been suggested that research on the positive benefits of simultaneous engagement in work and family domains be extended to determine the role of community in these relationships (Voydanoff, 2005b). Family-to-work positive spillover has been positively associated with a strong sense of community (Voydanoff, 
2004a; 2005), while both directions have been linked to support from friends (Voydanoff, 2004a; Wadsworth \& Owens, 2007). In a study by Hecht and Boies (2009), volunteering was positively related to emotional work-family positive spillover, while volunteering intensity was related to positive behavioral work-family positive spillover.

Most research on positive spillover that has focused on the role of health has done so by classifying health as an outcome variable. However, Hill et al. (2007) conducted a qualitative study with data from the IBM 2004 Global Work and Life Issues Survey which examined the antecedents of positive spillover. In this study, participants reported physical and psychological health as resulting from work benefits, which in turn positively affected home life. For example, one mother reported that working from home allowed her to sleep more in the mornings. Additionally, physical and psychological resources acquired in the home helped with renewal of health and positively influenced work for participants.

Work-related antecedents. Multiple occupational variables have been suggested to be predictive of positive spillover. Positive correlations have been found between both directions of positive spillover and job salience (Carlson et al., 2006) and work engagement (Siu et al., in press). Furthermore, job role quality has been found to be positively related to work-to-family positive spillover for both husbands and wives (Brockwood, 2002), although individuals with higher job-performance-based self-esteem experience lower home-to-work positive spillover (Innstrand, Langballe, Espnes, Aasland, \& Falkum, 2010). A study by King, Botsford, and Huffman (2009) found that perceived advancement in the workplace is related to family-to-work positive spillover. 
Individuals experience less work-to-family and family-to-work positive spillover when they have a lower skill level (Butler et al., 2005), experience more job demands (Karimi \& Nouri, 2009), and more work-family strain (Mulvaney et al., 2011). Positive spillover has also been positively related to the presence of contribution, a component of leadermember exchange determined by the degree to which an employee perceives a mutual obligation to benefit their leader when their leader is beneficial to them (Culbertson, Huffman, \& Alden-Anderson, 2010). Similarly, a positive work climate has been qualitatively linked with positive spillover (Devine et al., 2006).

One's preference for managing work and family demands may also determine the degree to which positive spillover is experienced. Utilizing a person-environment fit approach, Chen, Powell, and Greenhaus (2009) examined the association between congruence and positive spillover. Congruence refers to the degree to which an employee's work-family boundary management preference matches the conditions or resources offered by their work environment for work-family boundary management. Congruence was positively related to work-to-family instrumental positive spillover, but was also negatively related to work-to-family affective positive spillover.

Opportunities for learning and job satisfaction may also contribute to positive spillover as work domain antecedents. Positive spillover may be facilitated by enriched jobs (Wayne et al., 2007), developmental career opportunities (Beutell \& Wittig-Berman, 2008; Carlson et al., 2006; Voydanoff, 2004a; Wayne et al., 2007), a sense of personal accomplishment (Stevanovic \& Rupert, 2009), and work pride (Voydanoff, 2004a). Kwan, Mao, and Zhang (2010) found that protégés' personal skill development was 
associated with their own work-to-family positive spillover. Additionally, role modeling affected their positive spillover through personal skill development. Individuals who perform organizational citizenship behaviors are more likely to experience work-tofamily positive spillover, and this relationship is mediated by personal skill development (Kwan \& Mao, 2011). In a sample of dentists, job resources, such as craftsmanship, direct and long-term results, and pride in one's profession, were related to both directions of positive spillover (Hakanen et al., 2011). While Judge and Ilies (2004), found job satisfaction to be associated with the spillover of positive mood, especially for those individuals high on trait positive affectivity, Ilies, Wilson, and Wagner (2009) found an interaction between work-family integration and job satisfaction, such that employees with a high level of job satisfaction and a high level of integration had higher spousal ratings of positive home affect. Therefore, job satisfaction may spill over from work to home and result in more positive affective states that are observable to others. Stevens et al. (2007) found a relationship between family-to-work spillover and emotion-work satisfaction. Qualitative findings have linked job satisfaction (Devine et al., 2006) with positive spillover.

Characteristics of one's occupation may influence the degree to which individuals experience positive spillover. Those who are given less decision latitude (Butler, Grzywacz, Bass, \& Linney, 2005; Grzywacz \& Marks, 2000) and have less autonomy (Carlson et al., 2006; Grzywacz \& Butler, 2005; Innstrand, Langballe, Espnes, et al., 2010; Karimi \& Nouri, 2009; Srivastava et al., 2009; Voydanoff, 2004a) have been found to experience decreases in both directions of positive spillover. Findings suggests a 
relationship between a low level of pressure at work and less positive spillover from work to family for men, but not for women (Grzywacz \& Marks, 2000). Similarly, greater substantive complexity and intellectual capacity required by the job seems to be related to positive spillover (Grzywacz \& Butler, 2005). Increases in workload have been associated with decreases in work-to-home positive spillover (Innstrand, Langballe, Espnes, et al., 2010), while conversely, working hours have been positively associated with work-to-family positive spillover (Karimi \& Nouri, 2009). However, flexibility has been linked with positive spillover in qualitative studies (Devine et al., 2006; Poppleton, Briner, \& Kiefer, 2008). It has been suggested that emotional labor may have an effect on the experienced benefits of work and family. Seery, Corrigall, and Harpel (2008) found a negative relationship between work-to-family spillover and surface acting. Other-focused job-related emotional labor, in the form of relationship management, was positively related to both directions of positive spillover. Similarly, Yanchus et al. (2010) found positive affective responses to work to mediate the relationship between surface acting and deep acting at work and work-to-family positive spillover.

Research in this area also points to the association between material resources and engaging in work and family roles. In a recent study, it was found that income adequacy facilitated positive affective outcomes in the family domain (Zimmerman et al., 2009). Additionally, employees receiving workplace benefits also seem to experience increased positive spillover (Srivastava et al., 2009).

A number of social and social support factors within the workplace have been examined as antecedents of positive spillover. For example, Grzywacz and Butler (2005) 
found the extent to which an individual's job requires social interactions, or social skills, to be positively related to spillover. In a recent study, it was also concluded that team resources such as team cohesion, familiarity, and similarity enhance both directions of positive spillover (Hunter, Perry, Carlson, \& Smith, 2010). Workplaces with a supportive culture have also been associated with women's family-to-work positive spillover (Pedersen et al., 2009), while organizational social support has been related to both directions of positive spillover (Wadsworth \& Owens, 2007). Supervisor support and coworker support have also been found to be related to increases in positive spillover (Cinamon \& Rich, 2010; Grzywacz \& Marks, 2000; Karatepe \& Bekteshi, 2008; Siu et al., in press; Srivastava et al., 2009; Thompson \& Prottas, 2006; Wadsworth \& Owens, 2007), as has supervisor family support (Beutell \& Wittig-Berman, 2008; Hammer et al., 2009) and employee-supervisor relationship quality (Carlson et al., 2006). Zimmerman and Hammer (2010) suggest that these findings are indicative of supervisors and coworkers acting as resources in the work domain, allowing for increases in positive spillover in the family domain. Informal workplace practices, such as a familysupportive culture, are more essential to experiences of work and family than formal organizational practices (Wayne, Randel, \& Stevens, 2006).

Numerous antecedents of positive spillover have been explored in the workfamily literature. Specifically, non-work variables such as family, parental, and community factors have been associated with work-to-family and family-to-work positive spillover. Opportunities for learning, job satisfaction, organizational support and other work factors relate to positive spillover in similar ways. Although such antecedents 
POSITIVE SPILLOVER AND SLEEP

were not included in the present investigation, these findings suggest that certain nonwork and work factors may increase individuals' experiences of positive spillover, ultimately decreasing sleep deficiency.

Outcomes of positive spillover. Outcomes associated with positive spillover have typically fallen into the categories of non-work-related factors, work-related factors, and health and well-being factors. However, positive spillover is primarily predictive of job performance or individual well-being outcomes (Greenhaus \& Powell, 2006).

Studies have suggested that the originating role has a stronger effect on outcomes compared to the receiving role (e.g., Carlson, Hunter, Ferguson, \& Whitten, in press; McNall, et al., 2010; Shockley \& Singla, 2011; Wayne et al., 2004; 2006). For example, being a parent is likely to be more related to family satisfaction, than being an employee is.

Non-work-related outcomes. Non-work-related factors have been linked with positive spillover, although few studies on this topic exist. In a longitudinal, multisource, multimethod study, Ilies et al. (2009) explored the effect of work-life integration and the spillover of daily job satisfaction into the work domain. Results indicated that employees' daily job satisfaction ratings were related to partner evaluations of the employees' affective states at home. According to Heller and Watson's (2005) withinsubject analyses, afternoon job satisfaction predicted marital satisfaction at night and vice versa. A recent meta-analysis supported previous findings in that family-to-work and work-to-family positive spillover is related to family satisfaction (McNall et al., 2010). These results with family satisfaction were also found by Hanson and colleagues (2006). 
Furthermore, as both directions of positive spillover increase, so does overall life satisfaction (Hill, 2005; Karatepe \& Bekteshi, 2008; Stevanovic \& Rupert, 2009; van Steenbergen et al., 2007). One's engagement with his/her partner has also been shown to increase when both directions of positive spillover are experienced (Innstrand et al., 2009), as well when as perceived family support is high (Stevanovic \& Rupert, 2009).

Work-related outcomes. Research suggests that individuals and organizations may also experience benefits of positive spillover in the workplace. For example, positive spillover has been negatively related to turnover intentions (Wayne et al., 2006) and absenteeism (van Steenbergen \& Ellemers, 2009), and has been positively associated with affective commitment (Karatepe \& Kilic, 2009; Karatepe \& Magaji, 2008; McNall et al., 2010; Mulvaney et al., 2011). Participating in family roles allows for the accumulation of personal resources such as self-esteem and skills that then spill over into the work domain and increase an individual's ability to meet his or her work demands (Kirchmeyer, 1992b). Mixed findings exist with regard to the relationship between positive spillover and job satisfaction. While meta-analytic evidence suggests that both directions of positive spillover are positively related to job satisfaction (McNall et al., 2010), other studies have only found this relationship with work-to-family positive spillover (Carlson et al., in press; Karatepe \& Kilic, 2009; Lourel, Ford, Gamassou, Gueguen, \& Hartmann, 2009). Hanson et al. (2006) found that job satisfaction was significantly and positively related to both directions of their positive spillover measure. Rogers and May (2003) examined longitudinal data from married couples to determine that marital satisfaction was positively related to job satisfaction. 
Many studies have also included job performance as an outcome variable. Both directions of positive spillover have been associated with increases in self-rated performance (Karatepe \& Bekteshi, 2008; Karatepe \& Kilic, 2009) and objective performance (van Steenbergen \& Ellemers, 2009). A study by Carlson and colleagues (2011) found that work-to-family positive spillover experienced by employees resulted in increased job performance as rated by both the employee and his/her supervisors. In contrast, job dedication, a dimension of contextual performance, has been negatively associated with positive spillover (Carlson, Witt, Zivnuska, Kacmar, \& Grzywacz, 2008). However, in this same study, supervisors' appraisal of their employees' family-to-work positive spillover was positively related to the supervisors' appraisal of both job dedication and interpersonal facilitation. A more recent study explored the mechanisms behind these relationships and showed that the relationship between work-to-family positive spillover and performance was fully mediated by positive mood and partially mediated by job satisfaction (Carlson, Kacmar, Zivnuska, Ferguson, \& Whitten, 2011).

Health and well-being outcomes. In addition to non-work and work outcomes, positive spillover has been associated with various health outcomes and health behaviors. As was previously mentioned, meta-analytic findings suggest that both family-to-work and work-to-family positive spillover have a positive relationship with overall physical and mental health (McNall et al., 2010). Similarly, positive spillover is related to positive well-being, a construct that encompasses feelings such as enthusiasm, contentedness, and motivation (Allis \& O’Driscoll, 2007), and psychological well-being (Carlson et al., 2006). Stoddard and Madsen (2007) found a relationship between family-to-work 
positive spillover and overall health and mental-emotional health. Hanson et al. (2006) found that there was a relationship between the availability of resources to an individual at home and more positive reports of mental health. Similarly, with a unique sample of caregivers aged 60 and over, Rozario, Morrow-Howell, and Hinterlong (2004) demonstrated that productive roles working or volunteering is associated with better selfrated health. Those experiencing positive spillover are also at lower risk for mental illness, problem drinking (Grzywacz \& Bass, 2003), and depression (Franche et al., 2006; Grzywacz \& Bass, 2003; Mulvaney et al., 2011). Hammer et al. (2005) found that positive spillover experienced by employees was significantly related to a decrease in their spouse's depressive symptoms one year later. Both directions of positive spillover have also been negatively related to psychological distress (Haar \& Bardoel, 2008; Schneewind, Kneeb, \& Kupsch, 2010) and global stress (Schneewind et al., 2010), while work-to-family positive spillover has been related to individual stress (Hill, 2005). Lagged negative effects have been found between positive spillover and burnout (Innstrand, Langbelle, Espnes, Falkum, \& Aasland, 2008). Individuals experiencing more family-to-work positive spillover are less likely to report multiple chronic health problems (Grzywacz, 2000), while lowered cholesterol levels and BMI have been related to positive spillover one year later (van Steenbergen \& Ellemers, 2009). Results from a study conducted by Williams et al. (2006) showed a significant relationship between family-to-work positive spillover and sleep quality.

Fewer outcomes of positive spillover have been established than antecedents. Out of the studies that have been conducted on this topic, non-work factors including family 
and life satisfaction seem to result from the experiencing of positive spillover. Work outcomes, primarily job satisfaction and job performance, have also been explored. Lastly, multiple studies have examined the link between positive spillover and physical and mental health. However, only one study has included a sleep variable (Williams et al., 2006). Given the results from the Williams et al. (2006) study, in addition to other promising findings showing the relationship between positive spillover and health outcomes reviewed above, more research is necessary to determine the effects of positive spillover on sleep outcomes.

\section{Crossover of Positive Spillover}

Crossover represents a complementary level of analysis to spillover, in that it allows the researcher to understand how experiences are transmitted on the interindividual level. Crossover is a dyadic transmission process whereby one person's experience affects the experience of another person in the same social environment (Bolger, DeLongis, Kessler, \& Wethington, 1989). While spillover is a within-person, across domains transmission process between roles, crossover is a transmission process between members of a dyad (Bakker, Westman, \& van Emmerik, 2009). Crossover was originally proposed to explain the contagion of stressors or strain between the spousal dyad (Bolger et al., 1989).

Crossover theory. Westman and Vinokur (1998) described three primary mechanisms by which the strain crossover process takes place. These include direct crossover via empathetic reactions, common stressors experienced by both members of a dyad, and indirect crossover via interpersonal conflict. The first explanation suggests that 
crossover occurs by a direct transmission process from one member of the dyad to the other. Because crossover effects have been seen in closely-related partners, transmission occurs when the strain of one partner evokes a distressing, empathetic response in the other. The second explanation suggests that the crossover is a spurious effect in that the two members of the dyad are merely subject to the same stressors within the same environment, such as a stressful life event. Here, transmission does not actually occur, but rather shared environmental conditions have similar effects on both members. According to the third explanation, crossover is an indirect, active process where crossover is mediated by the partners' interaction with each other. When one partner experiences strain, they are likely to react by creating interpersonal conflict with the other partner, thereby causing the other partner to experience strain. In their study (Westman \& Vinokur, 1998), the authors tested these three mechanisms and found that correlations between depressive symptomology in each partner were primarily the result of common stressors and crossover via negative social interactions, providing support for the second and third forms of crossover.

The majority of research on crossover has focused on direct transmission effects, or empathetic reactions. Theories of social learning (e.g., Bandura, 1997; Stotland, 1969) are in alignment with this specific crossover mechanism. They suggest that emotional transmission occurs through conscious processing of information. By witnessing another's emotion or behavior and imagining themselves in another's position, individuals come to experience the same emotions that are modeled for them. 
The majority of crossover research has examined the strain that is transferred between spouses. Hammer, Allen, and Grigsby (1997) and Westman and Etzion (2005) found that work-family conflict has strong crossover effects for both male and female members of dual-earner couples. More recently, Bakker et al. (2008) found strong support for a model hypothesizing that male and female job demands and consequent work-to-family conflict contributes to partners' home demands, family-to-work conflict, and exhaustion. Both partners' job involvement and career priority has been suggested to crossover and lead to males' work-family conflict (Greenhaus, Parasuraman, Granrose, Rabinowitz, \& Beutell, 1989). Negative crossover effects within the spousal dyad have also been found for anxiety (Westman, Etzion, \& Horovitz, 2004), burnout (Westman \& Etzion, 1995), psychological distress (Barnett, Raudenbush, Brennan, Pleck, \& Marshall, 1995), depression (Howe, Levy, \& Caplan, 2004), adjustment (Takeuchi, Yun, \& Teslu, 2002), marital dissatisfaction (Westman et al., 2004), family dissatisfaction (Parasuraman, Greenhaus, \& Granrose, 1992), work involvement (Karambayya \& Reilly, 1992), psychological health (Jones \& Fletcher, 1993), mental and physical health complaints (Gorgievski-Duijvesteijn, Giesen, \& Bakker, 2000), and perceived health (Westman, Keinan, Roziner, \& Benyamini, 2008).

Work-family researchers have argued that the definition and investigation of crossover should be broadened to include the crossover of positive experiences or positive feelings (e.g., Westman, 2001; Westman et al., 2004). Westman et al., (2009) suggest that empathy may involve positive emotions, in addition to negative emotions. In this way, positive emotions can be transferred between two members of a dyad by means 
of an empathetic reaction. Some evidence exists for crossover contributing to greater well-being for the receiving individual within a spousal dyad. Beehr, Johnson, and Nieva (1995) recruited members of the police force and their spouses to participate in a study on stress and coping. Results indicated that spouses generally tend to use similar coping strategies. Furthermore, spouses' use of coping was negatively related to police ratings of divorce potential and suicidal thoughts, while use of religiosity as a coping strategy had beneficial effects on spousal strains for both members. Hammer et al. (2005) examined the role of the crossover of work-family positive spillover on spousal depression. Significant longitudinal effects were found for a spouse's positive spillover being more strongly related to their partner's decreased depression than were the effects of one's own positive spillover. The crossover of positive experiences between husbands and wives has also been found with work engagement (Bakker \& Demerouti, 2009; Bakker et al., 2005), vigor (Westman, Etzion, \& Chen, 2009), and life satisfaction (Demerouti, Bakker, \& Shaufeli, 2005; Prince, Manolis, \& Minetor, 2007).

While the majority of the research on crossover has examined the spousal or partner dyadic transmission process, researchers have called for crossover to be examined in the workplace (e.g., Westman et al., 2004). However, only a few studies have begun to investigate this phenomenon. For example, in a sample of Dutch high school teachers, individuals experienced more burnout when they possessed a high susceptibility to burnout and had a high degree of exposure to other coworkers with student- and workrelated problems (Bakker \& Schaufeli, 2006). Bakker, Emmerik, and Euwema (2006) found evidence for the crossover of team-level work engagement (i.e., vigor, dedication, 
and absorption) to individual members of the work teams. The interactions between team members facilitated optimism, positive attitudes, and proactive behaviors. The crossover of burnout between human service professionals such as intensive care nurses (Bakker, Le Blanc, \& Schaufeli, 2005) and general practitioners (Bakker, Shaufeli, Sixma, \& Bosveld, 2001) has also been established. In line with role theory, Bakker et al. (2009) and Westman et al. (2001) have suggested that crossover research be extended to those individuals within the organization that are role senders. As such, Westman and Etzion (1999) demonstrated effects for the supervisor-employee dyad with job-induced tension crossing over from principles to teachers in Israeli elementary schools.

Recent work-family positive spillover research has incorporated a spillovercrossover perspective into study design, whereby it is assumed that first spillover occurs between work and home domains, and then crosses over to the other person within the dyad (Bakker, Demerouti, \& Burke, 2009; Bakker, Demerouti, \& Dollard, 2008).

This phenomenon was also demonstrated by Carlson et al. (2011) in a study that uniquely focused on both supervisor-employee dyads and the crossover of positive experiences. It was hypothesized that supervisor work-family positive spillover would crossover to employees through employee perceptions of schedule control and familysupportive organizations. Significant mediation results were found for the crossover of supervisor work-to-family positive spillover via schedule control to employee work-tofamily positive spillover, which ultimately resulted in increased ratings of employee job performance by both the supervisor and the employee. No mediation effects were found for perceptions of family-supportive organizations. Because only two mediation 
mechanisms were tested, perceptions of supportive work-family organizations and perceptions of schedule control, the authors suggest that future research include additional mechanisms aiding in the crossover process from supervisor to employee.

The current research attempts to expand our understanding of crossover by examining the crossover of positive experiences between supervisors and employees. In line with Westman's (2001) crossover theory, it is expected that crossover will occur by means of a direct transfer of positive spillover from supervisor to employee, as supervisors in this context are role senders. Drawing on social learning theory, Kelly and Barsad (2001) in their discussion of the sharing of emotions between individuals, suggest that modeling is a powerful process for emotional reactions in others. In this way, supervisors, given that they possess a certain amount of authority and give cues to their employees about what roles are appropriate, are likely to act as effective modelers of the positive spillover process for their employees. Employees witnessing supervisors experiencing positive spillover are likely to imagine themselves in their supervisor's position, thereby conjuring similar affective experiences through empathy. Thus, the following is hypothesized:

Hypothesis 1: Supervisor affective work-to-family positive spillover will be positively related to employee affective work-to-family positive spillover. Just as positive emotions play a significant role in the positive spillover process, past research indicates that they are also likely implicated in experiences of increased health. As a result, a connection can be made between the positive affect that is generated by the positive spillover process and certain beneficial health outcomes. The 
following section reviews background literature on improved sleep as an outcome of affective positive spillover.

\section{Sleep}

It is widely understood that pathology is not the only precursor to an individual experiencing disrupted sleep. Lifestyle and societal demands on the sleep-wake schedule additionally contribute to sleep health (American Sleep Disorders Association, 1997). Inadequate sleep is experienced by a majority of the population at alarming rates. According to a recent survey of 74,571 individuals in 12 states, 35\% report getting less than seven hours of sleep on average daily (Centers for Disease Control and Prevention, 2011). This same study found that $48 \%$ of participants reported snoring, $38 \%$ report unintentionally falling asleep during the day at least once during the past month, 5\% reported nodding off or falling asleep while driving in the last, month. Considering the extent to which average members of the population experience sleep deficiency, fatigue has momentous consequences for individuals and organizations. However, sleep has not been a typical variable included in organizational research, in terms of individual or organizational well-being.

According to the National Transportation Safety Board (NTSB), fatigue accounts for $30-40 \%$ of all US truck accidents, while fatal, fatigue-related accidents have a $30 \%$ occurrence rate (NTSB, 1999). The NTSB (1990) also determined that the Exxon Valdez accident of 1989 was due to sleep loss and extended duty hours. Still others have suggested that catastrophes such as the Chernobyl nuclear plant meltdown was a product of human error related to fatigue (e.g., Mitler et al., 1988). Additionally, Rajaratnam and 
colleagues (2011) have found that a large proportion of police officers in North America have a sleep disorder, which has in turn affected their health, safety, and performance. Recently, the Federal Aviation Administration has responded to multiple accounts of air traffic controllers sleeping while on duty by changing scheduling practices in an effort to address excessive fatigue (Harris, 2011). The most recent case occurred at Reno-Tahoe International Airport where a sleeping controller did not respond to radio or telephone calls for 16 minutes from a medical flight carrying an ill patient (Williams, 2011).

Insufficient sleep. Insufficient sleep, a relatively new term, is marked by the presence of not feeling refreshed after a night's sleep (Buxton et al., in press; Sorenson et al., 2011). The majority of organizational research that has included a sleep variable has generally examined sleep quality (Buysse et al., 1989), a somewhat related construct, while other studies have included non-restorative sleep as an outcome variable (e.g., Knudsen et al., 2007). Shift work has been shown to be associated with decrements in sleep quality (Costa, 1996). In a sample of female hospital workers, those who experienced gastrointestinal, joint, back, or muscle symptoms also experienced lowered sleep quality (Edell-Gustafsson, Kritz, \& Bogren, 2002). Psychological detachment from work and control has been positively related to sleep quality (Sonnentag \& Fritz, 2007). Similarly, an intervention designed to increase employees' recovery experiences, such as psychological detachment from work, relaxation, mastery experiences, and control during off-job time, increased sleep quality one week and two weeks after the training program (Hahn, Binnewies, Sonnentag, \& Mojza, 2011). Role conflict has been positively 
associated with non-restorative sleep, while job autonomy has been negatively associated (Knudsen et al., 2007).

Sleep quality is also associated with diabetes (e.g., Buxton et al., 2010;

Cappuccio, D’Elia, Strazzullo, \& Miller, 2010), hypertension (e.g., Gottlieb et al., 2006) and cardiovascular disease (e.g., Mallon, Broman, \& Hetta, 2002; Wingard \& Berkman, 1983). Additionally, the inclusion of sleep-related variables in organizational research indicates that sleep quality is associated with increased job satisfaction (Scott \& Judge, 2006), decreased turnover (Shimizu et al., 2005), and decreased absenteeism (JacquinetSalford, et al., 1993; Spector \& Jex, 1998).

Sleep duration. Sleep duration refers to the length of time that one sleeps during the night. It tends to be measured from the time that lights are turned off until the time that the individual gets out of bed (Buysse et al., 1989; Sorenson et al., 2011). In a study of United States Army senior leaders, Huffman, Adler, Calhoun, and Castro (2001) determined that operational demands and stress were associated with reduced sleep time, as measured by actigraphy. Similarly, in study conducted by Buxton et al. (2009), lack of job strain and increases in supervisor support were related to increases in self-reported adequate sleep. Additionally, adequate sleep mediated the relationship between these workplace experiences, job strain and supervisor support, and healthful eating choices. Dahlgren et al. (2006) found that overtime work was associated with decreased sleep time.

Other organizational research has linked work schedules and job stressors with short sleep duration. Specifically, shift workers experience decrements in sleep quantity 
(Costa, 1996), resulting in daytime fatigue (Luna, French, \& Mitcha, 1997; Tepas \& Carvalhais, 1990). Primarily, decreased sleep time is associated with an increase in accidents (e.g., Akerstedt et al., 2002; Connor et al., 2002) and occupational injuries (e.g., Melamed \& Oksenberg, 2002; Nakata et al., 2005). In general, cognitive performance is decreased under conditions of sleep loss (e.g., Angus \& Heslegrave, 1985; Belenky et al., 2003; Jacques, Lynch, \& Samkoff, 1990; Philibert, 2005; Thomas et al., 2000; Van Dongen, Maislin, Mullington, \& Dinges, 2003).

Short sleep duration is also related to such health outcomes as elevated body mass index (e.g., Kohatsu et al., 2006), weight gain (e.g., Patel \& Hu, 2008), and obesity (e.g., Buxton \& Marcelli, 2010; Gangwisch, Malaspina, Boden-Albala, \& Heymsfield, 2005; Taheri, Lin, Austin, Young, \& Mignot, 2004). Sleep duration is also associated with diabetes (e.g., Buxton \& Marcelli, 2010; Buxton et al., 2010; Cappuccio et al., 2010), hypertension (e.g., Gottlieb et al., 2006) and cardiovascular disease (e.g., Buxton \& Marcelli, 2010; Mallon, Broman, \& Hetta, 2002; Wingard \& Berkman, 1983). Furthermore, short sleep duration has been linked with premature mortality (e.g., Mallon, Broman, \& Hetta, 2002; Wingard \& Berkman, 1983).

Poor sleep. Poor sleep is a term used to describe difficulty falling asleep or maintaining sleep throughout the night, and is often referred to as insomnia symptoms (Sorenson et al., 2011). Insomnia is highly prevalent with population estimates ranging from $3.9 \%$ to $22.1 \%$ (Roth et al., 2011). Other research indicates that lost work performance due to insomnia may account for up to $\$ 63.2$ billion dollars per year in the United States (Kessler et al., 2011). 
Using data from two national surveys in the United States and Sweden, Karasek (1979) found that male workers with jobs low in decision latitude and high in demands were likely to report exhaustion after work, trouble awakening in the morning, and insomnia or disturbed sleep. As part of the Helsinki Heart Study, researchers found strong main effects for job demands and job control on insomnia in a large sample of male employees (Kalimo, Tenkanen, Harma, Poppius, \& Heinsalmi, 2000). It has also been found that individuals have a greater risk of insomnia with increased job strain and decreased job control and social support (Nomura, Nakao, Takeuchi, \& Yano, 2009). In a study of nurses, it was found that a pay reduction was associated with increased insomnia (Greenberg, 2006). However, the degree of insomnia did not change for nurses whose supervisors received training in interactional justice both immediately after the training and 6 months later. Role conflict and has been associated with initiating sleep, while repetitive tasks have been associated with difficulty initiating and maintaining sleep (Knudsen et al., 2007).

Regarding psychological health, insomnia has been also been associated with depression (e.g., Riemann, Berger, \& Voderholzer, 2001; Walsh et al., 2011). Multiple studies have found an association between experiences of insomnia and burnout (e.g., Grossi et al., 2005; Melamed et al., 1999; Soderstrom, Ekstedt, Akerstedt, Nilsson, \& Axelsson, 2004; Vela-Bueno et al., 2008). In a sample of physicians, sleeping problems were related to higher levels of intentions to change one's profession, while job control attenuated this positive association (Heponiemi et al., 2009). 
Sleep deficiency. While the majority of previous studies have measured sleep quality (e.g., Costa, 1996) or quantity (e.g., Dahlgren, Kecklund, \& Akerstedt, 2006), sleep problems or insomnia (Heponiemi, Kouvonen, Vanska, Halilia, Sinervo, Kivimaki, \& Elovainio, 2009) have also been evaluated. However, this research has neglected to view sleep as a multicomponent construct and has instead only measured individual aspects of sleep. As previously mentioned, Buxton et al. (in press) and Sorenson et al. (2011) have both argued that a self-report scale measuring the different components of sleep separately and in constellation is necessary. Thus, they have proposed the new concept of sleep deficiency as a means for integrating the three components of sleep insufficiency, sleep duration, and insomnia symptoms. Sleep deficiency has been found to be associated with higher rates of pain, work interference, and functional limitations (Buxton et al., under review), in addition to inadequate physical activity, low supervisor and coworker support, harassment at work, low decision latitude, low people-oriented culture, and poor safety and ergonomic practices (Sorenson et al., 2011).

Mood as Information theory and sleep. Schwarz and Clore (1983) first proposed Mood as Information theory to explain the informative and directive functions of momentary affective states. The informative function of mood may be especially helpful in determining the effect of positive mood on health behaviors, such as sleep. Past research indicates that individuals rely on their emotions to provide them with information as to how well they are functioning in everyday life (Schwarz \& Clore, 1996). 
Schwarz and Clore (1983) found that individuals use their momentary mood states in developing judgments about their general well-being. For example, participants that recalled a positive experience, rather than a negative experience, and those that were studied on sunny days, rather than rainy days, made more positive general judgments about their happiness and life satisfaction. It seems that positive affective states signal to individuals that the environment is safe, while negative affective states signal to individuals that some aspect of the environment is threatening or needs changing (Schwarz \& Clore, 1996). Individuals experiencing more positive affective states may therefore experience less stress and worry over potential problematic environmental factors, influencing their ability to attain adequate and sufficient sleep.

Similarly, one's assessment of their health status and patterns of health behavior may be influenced by the valence of their momentary emotions. Drawing on the Mood as Information theory (Schwarz \& Clore, 1986), Salovey, Rothman, and Steward (2000) have suggested that positive emotional experiences affect physical health through the influence of emotion on judgment. Salovey and Birnbaum (1989) found that happy individuals, when compared to sad individuals, perceived themselves as better able to engage in health promoting behaviors. Furthermore, they had more confidence that such behaviors would relieve illness. It seems that in addition to indications of general happiness and life satisfaction, positive emotions also improve one's general self-efficacy and prompt understanding that positive health behaviors will be effective. As such, individuals who experience the positive spillover of affect between work and family domains generate more positive emotions, which in turn may lead them to engage in 
healthy sleep behaviors under the assumption that such behavior is beneficial. In line with this reasoning, Cohen, Doyle, Turner, Alper, and Skoner (2003) found that positive affect is related to increases in both sleep quality and sleep efficiency.

Work-family research and sleep outcomes. Sleep is one particular health outcome which has rarely been used in organizational research, but is especially relevant to the study of work and family. However, some studies have found a relationship between work-family conflict and sleep-related constructs. Sekine et al. (2006) found a relationship between high levels of work-family conflict and poor sleep quality. Similarly, Britt and Dawson (2005) found a negative relationship between hours of sleep and soldiers' work-family conflict. A study conducted by Lallukka, Rahkonen, Lahelma, and Arber (2010) examined the effects of work-family conflict on sleep complaints. Results indicated that work-family conflict was strongly associated with sleep complaints for both men and women in the sample, after controlling for unhealthy behaviors, obesity, health status, depression, and medications. Although important in understanding the influence of sleep on the work-family interface, these studies have focused only on the conflict associated with participation in work and family roles. Additionally, they have not employed sleep as a major outcome variable.

Berkman et al. (2010) explored the relationships between the work-family interface and sleep duration. Specifically, the researchers examined whether employees with supportive managers experienced an increase in sleep duration in a sample of 393 employees and 45 managers working in four extended care facilities. Employee sleep was assessed using objectively measured actigraphy methods to determine mean minutes 
POSITIVE SPILLOVER AND SLEEP

of sleep per day over seven days. Separate qualitative data from employees' supervisors, in the form of semi-structured interviews, were also analyzed. Managers were given a work-family balance score based on their openness and creativity in dealing with their employees' work and family demands. Results from this study showed that managers' attitudes and practices were related to employees' health. Employees who had managers scoring higher on support for work-family balance slept almost 30 minutes longer on average than employees with managers scoring lower on support for work-family balance. This study suggests that managers' support for work and family issues is a critical factor in promoting employee health, especially sleep.

To date, two studies have been conducted to determine the explicit relationship between work-family positive spillover and sleep outcomes (Sanz-Vergel et al., 2011; Williams et al., 2006). With a sample of 273 ambulance workers from Spain, SanzVergel and colleagues (2011) examined the moderating role of sleep quality, as measured by the Pittsburgh Sleep Quality Index (Buysse et al., 1989), on the relationship between work-family positive spillover and psychological strain. Results indicated that sleep quality moderated this relationship only for the home-to-work direction of positive spillover.

In another study conducted by Williams et al. (2006), sleep quality was utilized as a dependent variable. A sample of 168 Canadian female healthcare workers completed questionnaires on depressive symptomology, general health, work conditions, workfamily spillover, sleep quality, and sociodemographic information. Sleep quality was measured using the Pittsburgh Sleep Quality Index (Buysse et al., 1989). Positive work- 
to-family and family-to-work spillover was assessed using the Work-Family Spillover Scale (Grzywacz \& Marks, 2000).

Williams et al. (2006) found evidence for the beneficial effects of positive spillover on sleep. After controlling for age, family income, general health, depressive symptomology, work situation, and number of children, positive family-to-work spillover was associated with better sleep quality. Although work-to-family positive spillover was not a significant predictor of sleep quality in the hierarchical regression analysis, there was a significant bivariate association between work-to-family positive spillover and sleep quality. The authors interpret their findings in light of the idea that positive spillover is typically associated with the availability of resources. Because family-towork spillover was found to predict sleep quality, it is suggested that the presence of resources in the family domain spill over into the work domain and facilitate the recovery process, thereby resulting in better sleep quality. Although this was the first study to examine the relationship between work-family positive spillover and sleep outcomes, the findings suggest that the effect of work-family positive spillover on sleep is a promising avenue for future organizational research.

Drawing on past research which indicates that work-to-family positive spillover has been associated with job performance (e.g., Carlson et al, 2008), job effort (Wayne et al., 2004), and organizational citizenship behaviors (e.g., Balmforth \& Gardner, 2006), it is likely that supervisors who experience high levels of positive spillover are more effective leaders in the workplace, allowing for better interactions with employees and a more positive organizational climate. Employees in turn may experience less worry 
POSITIVE SPILLOVER AND SLEEP

around workplace issues and fewer conflicts between work and family, thereby improving their ability to attain sufficient and adequate sleep. Thus, based on theory and previous research, the following is hypothesized:

Hypothesis 2a: Supervisor work-to-family affective positive spillover will be negatively related to employee sleep insufficiency.

Hypothesis $2 b$ : Supervisor work-to-family affective positive spillover will be positively related to employee sleep duration.

Hypothesis 2c: Supervisor work-to-family affective positive spillover will be negatively related to employee insomnia symptoms.

Although Williams et al. (2006) did not find employee work-to-family positive spillover to significantly predict employee sleep quality, the scale used to measure positive spillover did not contain an affective subdimension. Additionally, the authors' results did not support previous positive spillover literature, in that beneficial outcomes should be experienced in the receiving domain as a result of the spillover process (Hanson et al., 2006). As such, affective work-to-family positive spillover, rather than affective family-to-work positive spillover, should be related to increases in well-being in the non-work domain. Work-to-family positive spillover then should be predictive of sleep.

Additionally, Mood as Information theory (Schwarz \& Clore, 1983) proposes that the positive affect generated through positive spillover gives individuals indication that their environment is generally safe or positive, promoting adequate sleep. Individuals who perceive their environment to be favorable may be less likely to experience stress, 
worry, or ruminate about the day's negative experiences. This in turn should decrease experiences of feeling unrefreshed upon awakening (i.e., sleep insufficiency), in addition decreasing experiences of difficulty initiating or maintaining sleep (i.e., insomnia symptoms).

Furthermore, Salovey et al.'s (2003) proposition that positive affect increases selfefficacy around health behaviors, in addition to Cohen et al.'s (2003) findings on positive affect and sleep, suggests that employee positive spillover should be associated with decreases in sleep insufficiency and increases in sleep duration because individuals experiencing positive spillover are more likely to be motivated to engage in healthy sleep habits. These individuals may have more confidence that sleep can prevent or relieve illness, and may make greater efforts to attain sufficient sleep. Thus, based on theory and previous research, the following is hypothesized:

Hypothesis 3a: Employee work-to-family affective positive spillover will be negatively related to employee sleep insufficiency.

Hypothesis 3b: Employee work-to-family affective positive spillover will be positively related to employee sleep duration.

Hypothesis 3c: Employee work-to-family affective positive spillover will be negatively related to employee insomnia symptoms.

Although Carlson et al. (2011) found evidence of an indirect effect whereby positive spillover crossed over from supervisors to employees through schedule control, they did not test the effect of employee positive spillover on any health or well-being outcomes. However, Williams et al. (2006) found the relationship between positive 
spillover and sleep quality. Based on the findings of Carlson et al. (2011) and Williams et al. (2006), I propose that these relationships can be tested within a mediation framework, whereby supervisor positive spillover is related to employee sleep outcomes through employee positive spillover. The following is hypothesized:

Hypothesis 4a: Employee work-to-family affective positive spillover will mediate the relationship between supervisor work-to-family affective positive spillover and employee sleep insufficiency.

Hypothesis $4 b$ : Employee work-to-family affective positive spillover will mediate the relationship between supervisor work-to-family affective positive spillover and employee sleep duration.

Hypothesis 4c: Employee work-to-family affective positive spillover will mediate the relationship between supervisor work-to-family affective positive spillover and employee insomnia symptoms.

The following section will review background literature on family-supportive supervisor behaviors.

\section{FSSB as a Moderator of the Relationship between Positive Spillover and Sleep}

Demographic changes in the labor force, in addition to changes in the nature of work, have resulted in organizations implementing policies to support employees' family demands (e.g., Glass \& Fujimoto, 1995; Goodstein, 1994; Ingram \& Simmons, 1995; Kelly, 2006; Kelly \& Dobbin, 1999; Miliken, Martins, \& Morgan, 1998; Osterman, 1995). However, these formal workplace supports by themselves are inadequate for addressing the increases in work and family demands that workers are experiencing 
(Allen, 2001; Kossek, 2005). Hammer et al. (2007) have referred to supervisors as the "linking pin" between the availability of formal workplace supports for work and family and the informal workplace culture and climate.

Leader-Member Exchange theory. Leader Member Exchange theory posits that supervisors and their employees develop an interpersonal relationship through the social exchanges that take place within the work setting (Graen \& Cashman, 1975). Within these exchanges, each party offers something that is not only valuable, but also equitable or fair (Graen \& Scandura, 1987). As such, employees' roles within these dyadic relationships can be characterized by two categories: in-group and out-group (Dienesch \& Liden, 1986). The in-group relationship is characterized by high degree of trust, interaction, support, and formal or informal rewards (Dienesch \& Liden, 1986), signifying a high quality leader-employee relationship. The study of supportive supervision is particularly relevant to Leader-Member Exchange theory.

Supportive supervisors. In agreement with Leader-Member Exchange theory, supervisors are one potential source of social support for employees. The enforcement of family-friendly policy use is often left up to the discretion of supervisors, which may dissuade employees from utilizing such supports for fear of punishment from supervisors (Glass \& Fujimoto, 1985; Raabe, 1990). Alternatively, employees who believe their organization and supervisor to be supportive of family should feel more comfortable using available benefits (Allen, 2001). Because of this, informal supervisor support for employees managing both work and family demands may have more of an effect on 
employee well-being than formal workplace supports for family (e.g., Allen, 2001;

Behson, 2005; Kossek \& Nichol, 1992).

Past research indicates that support from supervisors does in fact act as a resource for employees, helping to mitigate the negative effects of work and family stressors (O’Driscoll et al., 2003; Thomas \& Ganster, 1995). Supervisor support has been related to lower levels of work-family conflict (e.g., Anderson, Coffey, \& Byerly, 2002; Frone, Yardley, \& Markel, 1997; Frye \& Breaugh, 2004; Goff, Mount, \& Jamison, 1990; Lapierre \& Allen, 2006; Thomas \& Ganster, 1995; Thompson, Beauvais, \& Lyness, 1999; Thompson \& Prottas, 2005). Additionally, those employees with supportive supervisors experience less work distress (e.g., Frone, Russell, \& Cooper, 1997), decreased turnover intentions (e.g., O’Neill et al., 2009; Thompson et al., 1999; Thompson \& Prottas, 2005), decreased absenteeism (e.g., Goff et al., 1990), increased job satisfaction (e.g., Thomas \& Gangster, 1995; Thompson \& Prottas, 2005), increased organizational commitment (e.g., O’Neill et al., 2009), longer sleep duration, less risk for cardiovascular disease (Berkman et al., 2010), more adequate sleep (Buxton et al., 2009), and are more likely to not be sleep deficient (Buxton et al., in press; Sorenson et al., 2011). It has also been found that supervisor support is related to increases in work-tofamily positive spillover (e.g., Bhargava \& Baral, 2009; Taylor, Delcampo, and Blancero, 2009; Thompson and Prottas, 2005).

Family supportive supervisor behaviors. Because of the considerable evidence demonstrating the importance of supervisor support in managing work and family demands, researchers have called for the classification of specific behaviors utilized by 
family supportive supervisors (Hammer et al., 2007; Hammer, Kossek, Yragui, Bodner, \& Hanson, 2009). Family supportive supervisor behaviors (FSSB) are those behaviors exhibited by supervisors that are perceived to be supportive of employees' work and family demands (Hammer et al., 2007). Family supportive supervisors empathize with an employee's desire to seek balance between work and family responsibilities (Thomas \& Gangster, 1995). Hammer et al. (2009) developed and validated a Family Supportive Supervisor Behaviors Scale based in Social Support Theory (Cohen \& Wills, 1985). This measure consists of four dimensions: emotional support, instrumental support, role modeling behaviors, and creative work-family management.

The first dimension, emotional support, refers to perceptions of supervisors showing care and concern for employees and their family responsibilities. In this way, employees generally feel comfortable in discussing their family-related issues with supervisors and their supervisors show respect, sensitivity, and sympathy towards the employees. Second, supervisors displaying instrumental support respond to employees' work and family demands through day-to-day management transactions. These supervisors are reactive and provide routine resources to employees, such as flexible scheduling practices, so that employees may better manage their conflicting responsibilities. Third, role modeling behaviors refers to supervisors modeling for their employees how to effectively integrate work and family roles. Employees perceive these supervisors as attempting to manage work and family responsibilities, resulting in beneficial work-life outcomes. Fourth, creative work-family management refers to those proactive steps that supervisors take to restructure work with employees' work and 
family responsibilities in mind, in addition to the organization's goals. Employees perceive these supervisors as being especially strategic and creative in their efforts. While instrumental support is typically initiated in response to an employees' request, creative work-family management is innovative and calculated. For example, a supervisor exhibiting this type of management may institute cross-training within the organization as a method of improving organizational outcomes while taking employees' work and family demands into account.

Hammer et al. (2009) found that their FSSB measure was significantly and positively related to affective work-family positive spillover. Specifically, a relationship was found between work-to-family affective positive spillover and role modeling behaviors. Significant positive relationships were also found between family-to-work positive spillover and all four dimensions of the measure.

FSSB was developed to measure supervisor support for family, specifically. However, "family" is a general term that can have a wide range of interpretations. Past research has used a definition of family similar to 'spouse and children' or 'kin in the household' (Rothausen, 1999). Due to recent societal and demographic changes, this traditional view of family is no longer representative of the population in the United States and there has been a call to extend these definitions beyond marriage, biological, and adoptive ties (Rothausen, 1999). Researchers have suggested that the definition of family should include all individuals who meet the needs or functions traditionally thought to have only been met by actual biological family members (Bogan, 1991). As such, FSSB can be used to measure supervisor support for family in the more general and 
inclusive form of the word that has recently been proposed, capturing support for demands resulting from individuals' relationships with spouses, partners, children, parents, friends, etc.

Given the four dimensions, Hammer et al.'s (2009) construct of FSSB is closely aligned with models of leader-member exchange. In accordance with Dienesch and Liden's (1986) description of quality leader-member exchanges, so too does quality family-supportive supervision call for a high degree of trust in that supervisors may accommodate employees' family demands under the condition that employees meet performance expectations. Furthermore, a high degree of interaction with employees is required for supervisors to exhibit emotional and role modeling behaviors. Instrumental support and emotional support also seems to be representative of the informal and formal rewards suggested by Dienesch and Liden (1986).

Drawing on past research that points to the buffering effect of social support (Johnson \& Hall, 1988), in addition to findings indicating that family-specific supervisor support is related to increases in employees' sleep duration (Berkman et al., 2010), FSSB may have moderating effects on the associations between supervisor and employee positive spillover and sleep outcomes. Therefore, the hypothesized relationships between supervisor positive spillover, employee positive spillover, and sleep outcomes may be further enhanced by the presence of support for work and family shown by supervisors.

The relationship between supervisor positive spillover and employee sleep outcomes may be facilitated when supervisors are also exhibiting high levels of FSSB. Supervisors experiencing high levels of positive spillover are likely to be more effective 
in the workplace and when working with employees. As previously mentioned, this may be beneficial for employee sleep outcomes. However, this effect may be enhanced when the supervisor is also supportive of work and family. Thus, the following is hypothesized: Hypothesis 5a: FSSB will moderate the effect of supervisor affective work-tofamily positive spillover on employee sleep insufficiency, such that the negative relationship between supervisor positive spillover and employee sleep insufficiency will be stronger when FSSB is high.

Hypothesis 5b: FSSB will moderate the effect of supervisor affective work-tofamily positive spillover on employee sleep duration, such that the positive relationship between supervisor positive spillover and employee sleep duration will be stronger when FSSB is high.

Hypothesis 5c: FSSB will moderate the effect of supervisor affective work-tofamily positive spillover on employee insomnia symptoms, such that the negative relationship between supervisor positive spillover and employee insomnia symptoms will be stronger when FSSB is high.

Although Carlson et al. (2011) found job control to mediate the crossover of positive spillover from supervisor to employee, they did not find perceptions of family supportive organizations to mediate the relationship. As suggested by Hammer et al. (2007), the supervisor has latitude in deciding whether he or she will enact the organization's work-family culture. FSSB may be a more appropriate construct to be considered as part of the process of crossover because it is specific to one's supervisor. I propose that in addition to a direct crossover process, the transfer of positive spillover 
will be facilitated by the presence of FSSB. Those supervisors who experience work-tofamily positive spillover in their own lives will be more likely to exhibit FSSB, thereby providing employees with additional resources to manage work and family demands, and a greater opportunity to experience their own positive spillover. Given the literature on social support as a moderator, the following is hypothesized:

Hypothesis 6: FSSB will moderate the effect of supervisor affective work-tofamily positive spillover on employee affective work-to-family positive spillover, such that the positive relationship between supervisor positive spillover and employee positive spillover will be stronger when FSSB is high.

Although direct effects of employee positive spillover on sleep outcomes were previously hypothesized, FSSB may also facilitate these relationships. Supervisors who exhibit more FSSB make it easier for employees to attend to both work and family demands. This should logistically allow employees to better schedule work and family responsibilities allowing for longer sleep duration, in addition to decreasing the strain that may impact sleep. Thus, the following is hypothesized:

Hypothesis 7a: FSSB will moderate the effect of employee affective work-tofamily positive spillover on employee sleep insufficiency, such that the negative relationship between employee positive spillover and employee sleep insufficiency will be stronger when FSSB is high.

Hypothesis 7b: FSSB will moderate the effect of employee affective work-tofamily positive spillover on employee sleep duration, such that the positive 
POSITIVE SPILLOVER AND SLEEP

relationship between employee positive spillover and employee sleep duration will be stronger when FSSB is high.

Hypothesis 7c: FSSB will moderate the effect of employee affective work-tofamily positive spillover on employee insomnia symptoms, such that the negative relationship between employee positive spillover and employee insomnia symptoms will be stronger when FSSB is high.

Many researchers have encouraged the inclusion and evaluation of both moderators and mediators within the same research study, as complex models may more accurately reflect relationships among variables (e.g., Baron \& Kenny, 1986;

MacKinnon, 2008). The relationships mentioned thus far will be additionally examined in an overall moderated mediation framework, such that a high level of FSSB is proposed to enhance the strength of the overall mediation.

Hypothesis 8a: FSSB will moderate the mediating effects of supervisor positive spillover on employee sleep insufficiency through employee positive spillover, such that the mediating effect will be enhanced under high levels of FSSB.

Hypothesis 8b: FSSB will moderate the mediating effects of supervisor positive spillover on employee sleep duration through employee positive spillover, such that the mediating effect will be enhanced under high levels of FSSB.

Hypothesis 8c: FSSB will moderate the mediating effects of supervisor positive spillover on employee insomnia symptoms through employee positive spillover, such that the mediating effect will be enhanced under high levels of FSSB. 
In addition to examining the abovementioned hypotheses in a moderated mediation with the individual components of sleep insufficiency, sleep duration, and insomnia symptoms, additional analyses will assess these relationships using a new composite measure of sleep deficiency. Drawing on past literature and theory cited above, the following research question will be tested:

Research Question: Does FSSB moderate the mediating effects of supervisor positive spillover on employee sleep deficiency through employee positive spillover, such that the mediating effect will be enhanced under high levels of FSSB? 
Method

\section{Participants and Procedure}

The present investigation used baseline data from a larger intervention study conducted by the Work, Family, \& Health Network (WFHN). By using a range of methods to collect data at the organization, work site, manager, employee, and family levels, the WFHN study aims to increase understanding of the importance of workplace practices and policies to work, family, and health outcomes (see Bray et al., under review; King et al., 2012). At the core of the larger study's design is a survey-based study which forms the basis for the present investigation.

The current research utilized a sample of managers and employees from multiple sites within the information technology division of a large firm in the Midwestern United States. The organizational site was selected based on its size, its large information technology workforce, and the ability to logistically support data collection. Because the company has a centralized organizational structure, recruitment involved discussions and agreements took place with top leadership over all work units in this division. Managers of a particular work unit were then informed of their unit's participation and questions were answered. Specifically, work teams consisting of 4 or more employees were identified, with a team consisting of employees who report to the same front-line manager. Note that the teams may include employees located in different buildings or even different US cities, but members work closely together doing similar work on particular projects. Next, individual employees and managers at these sites consented voluntarily to participate in the data collection. Managers and employees in the company 
were eligible to participate if they were located in the two metro areas where data collection occurred and were classified as employees (rather than as independent contractors). In addition, one study group was excluded because their employees were represented by collective bargaining agreements. Because the larger study included an intervention design, there was concern that this group would not be able to fully implement the intervention due to existing work rules.

Trained field interviewers administered face-to-face computer-assisted personal interviews (CAPI) with team supervising managers and employees beginning in September 2009 and ending in September 2010. Supervisors and employees completed a 60 minute interview at the worksite and received a \$20 incentive.

Two hundred twenty-one managers completed the CAPI out of a possible 256 for an $86.3 \%$ response rate. Of the total 221 managers, $66 \%$ were male and $34 \%$ were female. Eighty percent were White, the average employee age was 46 years $(S D=7.82)$, $90 \%$ were married or cohabitating, and $62 \%$ had children living in the home.

Additionally, 823 employees completed the CAPI out of a possible 1182 for a $69.6 \%$ response rate. Of the total 823 employees, $61 \%$ of the employees were male and $39 \%$ were female. Seventy-one percent were White, the average employee age was 46 years $(S D=8.38), 79 \%$ were married or cohabitating, and $56 \%$ had children living in the home.

For the current analysis, we analyzed groups of employees supervised under the manager that they directly report to. This allowed for the inclusion of random effects at the team level, although the focus of the present analyses was on individual level variables from managers and employees. The analyses were based on 696 employees 
POSITIVE SPILLOVER AND SLEEP

nested within 180 direct supervisors, thereby excluding managers who did not have any direct reports who completed the CAPI, in addition to employees who did not have managers that completed the CAPI. Managers supervised between one and 16 employees.

\section{Measures}

A subset of measures from the larger survey was used for this study. All measures are listed in Appendix A. With the exception of supervisor affective work-to-family positive spillover, all items were measured at the employee level (Level 1).

Work-to-family positive spillover. Positive spillover was measured at the employee level (Level 1) and at the supervisor level (Level 2) using the four item affective work-to-family positive spillover subscale developed and validated by Hanson et al. (2006). Items were rated on a scale from 1 (strongly disagree) to 5 (strongly agree), with higher scores indicating greater positive spillover. This subscale measures the extent to which positively valenced affect is transferred from the originating domain of work to the receiving domain of family ( 4 items, alpha $=.86$ for employees and alpha $=.88$ for supervisors). A sample item reads, "Having a good day at work allows you to feel positive with your family.”

Family supportive supervisor behaviors-Short Form (FSSB-SF). FSSB were measured at the employee level (Level 1) using a four item scale developed and validated by Hammer, Kossek, Bodner, and Crain (under review). Items were rated on a scale from 1 (strongly disagree) to 5 (strongly agree), with higher scores indicating greater FSSB. The four scale items measure four subordinate dimensions: emotional support, 
role modeling behaviors, instrumental support, and creative work-family management. The emotional support item measures the extent to which the employee reports his or her supervisor asks about and assists with their work and family demands. The items is, "Your supervisor makes you feel comfortable talking to him/her about your conflicts between work and non-work." Role modeling behaviors refers to the extent to which the employee reports his or her supervisor to demonstrate work-life integration through modeling behaviors while at work. The item is, "Your supervisor demonstrates effective behaviors in how to juggle work and non-work issues." Instrumental support is the extent to which the employee reports his or her supervisor responds to his or her workfamily needs in day-to-day management transactions. The item is, "Your supervisor works effectively with employees to creatively solve conflicts between work and nonwork." Creative work-family management refers to the employee's report of the extent to which his or her supervisor proactively initiates the restructuring of work to facilitate employees' effectiveness at work and at home. The item is, "Your supervisor organizes the work in your department or unit to jointly benefit employees and the company." The overall reliability for the scale is .88 .

Sleep insufficiency. Sleep insufficiency was measured using one item from the Pittsburgh Sleep Quality Index Questionnaire (Buysse, Reynolds, Monk, Berman, \& Kupfer, 1989). As a measure of sleep insufficiency, participants were asked, "How often during the past four weeks did you get enough sleep to feel rested upon waking up?" Items were rated on a scale from 1 (never) to 5 (very often), with higher scores indicating greater sleep insufficiency. 
Sleep duration. Sleep duration was measured using two items from the Pittsburgh Sleep Quality Index Questionnaire (Buysse et al., 1989). As a measure of sleep duration, participants were asked, "Over the past four weeks, what time did you usually turn the lights off to go to sleep?" and, "Over the past four weeks, what time did you usually get out of bed?" A sleep duration score (i.e., the number of hours slept) was computed from these two times indicated by the participants.

Insomnia symptoms. Insomnia symptoms were measured using two items from the Pittsburgh Sleep Quality Index Questionnaire (Buysse et al., 1989). As a measure of insomnia symptoms, participants were asked, "During the past four weeks, how often could you not get to sleep within 30 minutes?" and, "During the past four weeks, how often did you wake up in the middle of the night or early morning?" Items were rated on a scale from 1 (never) to 4 (three or more times a week), with higher scores indicating more insomnia symptoms.

Sleep deficiency. The items for sleep insufficiency, duration, and insomnia symptoms were combined to create the dichotomous composite sleep deficiency variable (Buxton et al., in press; Sorenson et al., 2011). Individuals were sleep deficient if they reported one or more of the following: insufficient sleep duration ( $<6$ hours/day), inadequate sleep quality (never feeling rested upon waking up), and/or the presence of insomnia symptoms three or more times per week. Individuals who were sleep deficient were coded with 1 while individuals who were not sleep deficient were coded with 0 .

Control variables. Several control variables were considered for use in this study based on previous findings. Potential control variables included age, gender, 
marital status, number of children, race, chronic conditions, apnea, health behaviors, psychological distress, regular night work, and hours worked. The need to control for gender arises from studies indicating women experience more positive spillover than men (e.g., Grzywacz et al., 2002; Powell \& Greenhaus, 2010). The number of children one has is positively related to positive spillover (e.g., Kinnunen et al., 2006), in addition to being married (Grzywacz et al., 2002). Additionally, age has been negatively related with sleep quality and duration (e.g., Reyner, Horne, \& Reyner, 1995), and those experiencing sleep deficiency are more likely to be older than those reporting no deficiency (Sorenson et al., 2011). Gender has been related with both sleep quality and duration with women experiencing poorer sleep (e.g., Reyner, Horne, \& Reyner, 1995), as has race with Black individuals experiencing poorer sleep than White, Hispanic, or individuals from other races (e.g., Mezick et al., 2008). Chronic conditions were considered as a control variable because of the negative relationships that have been found amongst sleep duration and obesity, diabetes, hypertension, and cardiovascular disease (e.g., Buxton \& Marcelli, 2010; Cappuccio et al., 2010). Sleep apnea is associated with both arousals and fragmented sleep (e.g., Guilleminault, van den Hoed, \& Mitler, 1978). Individuals experiencing frequent sleep insufficiency are more likely to report physical inactivity, smoking behavior, and alcohol use (e.g., Strine \& Chapman, 2005), resulting in the potential need to control for health behaviors. Furthermore, psychological distress has been reported by individuals experiencing sleep problems (e.g., Steptoe, O’Donnel, Marmot, \& Wardle, 2008). Shiftwork is also commonly reported with disturbed sleep (e.g., Akerstedt, 2003), and overtime work has been 
associated with shorter sleep duration (e.g., Dahlgren, Kecklund, \& Akerstedt, 2006).

Those working 40 hours a week or more are likely to be sleep deficient when compared with those who work less (Sorenson et al., 2011). 


\section{Results}

Multilevel modeling (MLM) with maximum likelihood estimation was used to examine the proposed hypotheses. Multilevel modeling allows intercepts and slopes at a lower level to vary between higher level units, permitting the researcher to understand relationships at different levels and to examine cross-level relationships (Tabachnik \& Fidell, 2007). This method takes into account dependencies in the data by estimating variance associated with group (e.g., one's workgroup supervised by a manager) differences in average response (intercepts) and group differences in associations (slopes) between predictors and dependent variables (e.g., group differences in the relationship between supervisor positive spillover and employee sleep) (Tabachnik \& Fidell, 2007). Thus, multilevel data can be analyzed without violating the assumptions of independence.

\section{Preliminary Analyses}

Prior to analysis, the proposed predictors, outcomes, and control variables were examined through various analyses in SPSS for accuracy of data entry, missing values, and to determine if the assumptions of multivariate analysis were met. Because of the large number of second-level units, all first level predictors were combined over the second-level units rather than being screened within the second-level units.

Scale scores were created for employee and supervisor work-family positive spillover and FSSB using mean imputation if at least $75 \%$, but not all, of the items were answered per scale. Otherwise, all scales and items were subject to listwise deletion if $75 \%$ of valid item responses were not present. The ratio of cases to independent variables was substantial given the three predictors and 696 cases. 
The data were then examined for evidence of univariate outliers. One outlier on the employee variable of hours worked per week was removed from the data set and treated as a missing value. This outlier had a value of five when the other values ranged from 30 to 78 hours worked in a typical week at that job. Multivariate outliers were also checked for using a residuals analysis, Mahalanobis' Distance, Cook's D, and centered leverage values. No multivariate outliers were found.

The data were then assessed for the assumptions of normality and linearity using both univariate and multivariate methods, while homoscedasticity of residuals was assessed with multivariate methods. Out of the dependent variables, employee positive spillover was substantially skewed in the negative direction and showed signs of positive kurtosis. Corresponding pairwise scatterplots indicated non-linearity. After reflection, logarithmic transformations were conducted, improving both skewness and kurtosis statistics. Modeling with and without transformed values for employee positive spillover did not reveal results that differed substantively. Thus, the original untransformed values are reported for ease of interpretation. All other variables were found to meet the assumptions satisfactorily.

When interactions are included in multiple regressions, issues of multicollinearity may surface unless IVs have been centered (Tabachnik \& Fidell, 2007). The supervisor and employee positive spillover, FSSB, and positive spillover by FSSB interaction terms were mean centered to create five new centered variables.

Because each parameter to be estimated in a multi-level model reduces statistical power (Tabachnik \& Fidell, 2007), preliminary analyses were conducted to determine 
which control variables should be included in the models. After dummy coding of categorical variables, separate multilevel regressions of employee and supervisor age, hours worked, race, gender, marital status, and number of children, and employee chronic conditions, apnea, health behaviors (smoking, drinking, and exercise), psychological distress, and regular night work, on sleep insufficiency, sleep duration, and insomnia symptoms were conducted. Analyses indicated that all proposed control variables were related to either the predictors or the dependent variables. Because interactions were modeled, multiple regressions of the control variables on each of the three dependent variables were run to determine if multicollinearity was present. The diagnostics of a tolerance statistic and variance inflation factor indicated that multiple proposed control variables and were causing collinearity issues ${ }^{1}$. Because of this, the variables from this list that were most strongly motivated by theory were retained. Employee gender, number of children, marital status, hours worked per week, work schedule, apnea symptoms, and psychological distress were used in the analyses.

The intraclass correlation (ICC) is used to determine whether MLM is an appropriate method of analysis due to dependency within the data. The ICC is the "ratio of variance between groups at the second level of the data hierarchy to variance within those groups" (Tabachnik \& Fidell, 2007, pp. 822). Higher values of the ICC indicate that errors are correlated as a result of the grouping of the data. ICCs were computed for sleep insufficiency (.03), duration (.02), insomnia (.03), and employee positive spillover

\footnotetext{
${ }^{1}$ For example, when sleep insufficiency was regressed on all control variables, fast food consumption per week resulted in a tolerance statistic of .48 and a variance inflation factor of 2.07 while employee age had a tolerance statistic of .69 and a variance inflation factor of 1.46 .
} 
POSITIVE SPILLOVER AND SLEEP

(.06). Despite these relatively low ICCs, multilevel modeling was used as a conservative approach to analyzing the data.

Table 1 shows descriptive statistics and inter-correlations among all study variables, without accounting for dependency in the data. Supervisors and employees experienced similar levels of positive spillover. On average, supervisors who reported higher levels of positive spillover worked with employees who reported lower levels of positive spillover $(r=-.10, p<.01)$. Employee positive spillover was not significantly related with sleep insufficiency $(r=.03, p=.39)$, duration $(r=-.01, p=.83)$, or insomnia $(r=.00, p=.93)$. The relationship between employee positive spillover and FSSB was not significant but was in the anticipated direction $(r=.06, p=.08)$, while the relationship between supervisor positive spillover and employee reports of FSSB was also non-significant but was not in the expected direction $(r=-.01, p=.87)$. On average, employees who reported higher levels of FSSB also reported lower levels of sleep insufficiency $(r=-.12, p<.01)$.

\section{Hypothesis Testing}

Two-level multilevel models assessed the mediation effects of supervisor workfamily positive spillover on employee sleep insufficiency, sleep duration, and insomnia symptoms through employee positive spillover, while controlling for employee gender, number of children, marital status, hours worked per week, work schedule, apnea symptoms, and psychological distress. Three separate models were used to test each of the sleep outcomes. It was expected that employee positive spillover would mediate this 
relationship, showing a positive relationship with sleep duration and a negative relationship with sleep insufficiency and insomnia symptoms.

Additionally, the current study hypothesized that FSSB would moderate the mediating effect of supervisor positive spillover through employee positive spillover on employee sleep outcomes. Each path of the mediation model was hypothesized to be moderated by FSSB, such that a stronger positive relationship between employee positive spillover and beneficial sleep outcomes would be seen under conditions of high FSSB. A summary of the results for the three models tested can be found in Figures 2, 3, and 4.

First-level units were employee gender, number of children, marital status, hours worked per week, work schedule, ratings of apnea symptoms, psychological distress, employee work-family positive spillover, and employee reports of FSSB. The secondlevel units were ratings of supervisor work-family positive spillover. All employees were nested under the supervisor that they directly reported to. Multilevel modeling was implemented through SPSS MIXED MODELS, Version 19. To help with convergence issues, only the intercepts were permitted to vary randomly across supervisors.

Direct Effects and Mediation. To test hypotheses 1, 2a-c, 3a-c, and 4a-c, a causal steps strategy was used (Baron \& Kenny, 1986). Additionally, to test Hypotheses $4 a-c$, analyses for regressions and mediated effects were conducted according to recommendations for multilevel mediation by MacKinnon (2008) for testing the indirect effect. The mediated, or indirect, effect equals the product of parameter $a$, the beta coefficient from the regression of the mediator on the IV, and parameter $b$, the beta coefficient from the regression of the DV on the mediator. This value was then divided 
by the standard error and compared to tabled values of the normal distribution to determine statistical significance.

Hypothesis 1 proposed that supervisor positive spillover would be positively related to employee positive spillover. The model with supervisor positive spillover was significantly better than the model including intercept and controls, $\chi^{2}(1, N=696)=$ $1397.76-1107.54=290.22, p<.001$. However, controlling for supervisor, a significant negative relationship was found between supervisor positive spillover and employee positive spillover, $\beta=-.09, S E=.04, t(132.57)=-2.44, p=.01$. Supervisors who tend to experience higher levels of positive spillover have employees who tend to experience lower levels of positive spillover. Thus, hypothesis 1 was not supported. Results can be found in Table 2.

Hypotheses $2 a$-c proposed that supervisor positive spillover would be negatively related to employee sleep insufficiency, positively related to sleep duration, and negatively related to insomnia symptoms. The model for sleep insufficiency with supervisor positive spillover was a significantly better fit than the model including the intercept and controls, $\chi^{2}(1, N=696)=2050.43-1732.55=317.88, p<.001$. However, the relationship between supervisor positive spillover and sleep insufficiency was positive and non-significant, $\beta=.05, S E=.05, t(131.54)=1.03, p=.31$. The model for sleep duration with supervisor positive spillover was a significantly better fit than the model including the intercept and controls, $\chi^{2}(1, N=696)=2181.36-1808.84=372.52$, $p<.001$. However, the relationship between supervisor positive spillover and sleep duration was positive and non-significant, $\beta=.03, S E=.06, t(157.80)=.48, p=.63$. 
The model for insomnia symptoms with supervisor positive spillover was a significantly better fit than the model including the intercept and controls, $\chi^{2}(1, N=694)=1805.01-$ 1517.22 $=287.79, p<.001$. However, the relationship between supervisor positive spillover and insomnia symptoms was positive and non-significant, $\beta=.03, S E=.05$, $t(152.66)=.53, p=.60$. Thus, hypotheses $2 a-c$ was not supported. Results can be found in Table 3.

Hypotheses $3 a-c$ proposed that employee positive spillover would be negatively related to employee sleep insufficiency, positively related to sleep duration, and negatively related to insomnia symptoms. The model for sleep insufficiency with employee positive spillover was not a significantly better fit than the model including the intercept and controls, $\chi^{2}(1, N=696)=2050.43-2053.70=.01, p=.92$. The relationship between employee positive spillover and sleep insufficiency was not significant, $\beta=-.01, S E=.05, t(819.70)=-.10, p=.92$. The model for sleep duration with employee positive spillover was not a significantly better fit than the model including the intercept and controls, $\chi^{2}(1, N=696)=2181.36-2181.33=.03, p=.86$. The relationship between employee positive spillover and sleep duration was positive and non-significant, $\beta=.01, S E=.06, t(820.19)=.18, p=.86$. The model for insomnia symptoms with employee positive spillover was not a significantly better fit than the model including the intercept and controls, $\chi^{2}(1, N=694)=1805.01-1804.31=.70, p$ $=.40$. The relationship between employee positive spillover and insomnia symptoms was negative and non-significant, $\beta=-.04, S E=.04, t(820.94)=-.83, p=.41$. Thus, hypotheses $3 a-c$ were not supported. Results can be found in Table 4 . 
Hypotheses 4a-c proposed that employee positive spillover would mediate the relationship between supervisor positive spillover and employee sleep outcomes within a causal steps framework. However, because no relationship was found between supervisor positive spillover and employee sleep insufficiency in step 1, employee positive spillover did not mediate the relationship between supervisor positive spillover and employee sleep insufficiency in a causal steps framework. A test of indirect effects further supported the absence of mediation when sleep insufficiency was the dependent variable $(a b=.00, Z=.06, p=.95)$. Additionally, because no relationship was found between supervisor positive spillover and employee duration, employee positive spillover did not mediate the relationship between supervisor positive spillover and employee sleep duration in a causal steps framework. A test of indirect effects further confirmed the absence of mediation when sleep duration was the dependent variable $(a b=.00, Z=-.02$, $p=.98)$. Lastly, because no relationship was found between supervisor positive spillover and employee insomnia symptoms, employee positive spillover did not mediate the relationship between supervisor positive spillover and employee insomnia symptoms in a causal steps framework. A test of indirect effects further confirmed the absence of mediation when insomnia symptoms was the dependent variable $(a b=.00, Z=-.47, p=$ .64). Thus, hypotheses 4a-c was not supported.

Moderation. Hypotheses $5 a-c$ proposed that FSSB would moderate the relationship between supervisor positive spillover and employee sleep outcomes. To test hypotheses $5 a-c$, the sleep outcome variables (level-one variables) were regressed on supervisor positive spillover (level-two variable), FSSB (level-one variable), and the 
supervisor positive spillover by FSSB interaction term (cross-level interaction term).

Results can be found in Table 5. The model for sleep insufficiency with the supervisor positive spillover by FSSB interaction term was not a significantly better fit than the model including the intercept, controls, supervisor positive spillover, and FSSB, $\chi^{2}(1, N$ $=692)=1728.07-1727.87=.20, p=.65$. Sleep insufficiency was not significantly predicted by FSSB when evaluated at the grand mean of supervisor positive spillover ( $\beta$ $=-.05, S E=.03, t(647.55)=-1.79, p=.07)$, supervisor positive spillover when evaluated at the grand mean of employee FSSB ratings $(\beta=.05, S E=.05, t(129.62)=1.04, p=$ $.30)$, or the supervisor positive spillover by FSSB interaction $(\beta=-.02, S E=.05$, $t(607.87)=-.46, p=.65)$. The relationship between supervisor positive spillover and employee sleep insufficiency does not differ significantly under conditions of low versus high levels of FSSB. Thus, hypothesis $5 a$ was not supported.

The model for sleep duration with the supervisor positive spillover by FSSB interaction term was a significantly better fit than the model including the intercept, controls, supervisor positive spillover, and FSSB, $\chi^{2}(1, N=692)=1807.25-1796.20=$ $11.05, p<.001$. Sleep duration was not significantly predicted by FSSB when evaluated at the grand mean of supervisor positive spillover $(\beta=.00, S E=.03, t(668.95)=-.06, p=$ .95 ) or supervisor positive spillover when evaluated at the grand mean of employee FSSB ratings $(\beta=.03, S E=.06, t(159.94)=.50, p=.62)$, but was significantly predicted by the supervisor positive spillover by FSSB interaction $(\beta=.18, S E=.05, t(636.56)=3.34, p=$ .001). Under conditions of low FSSB, there was a negative relationship between supervisor positive spillover and employee sleep duration. Under conditions of high 
FSSB, there was a positive relationship between supervisor positive spillover and employee sleep duration. Thus, hypothesis $5 b$ was not supported. The interaction graph is Figure 5.

The model for insomnia symptoms with the supervisor positive spillover by FSSB interaction term was not a significantly better fit than the model including the intercept, controls, supervisor positive spillover, and FSSB, $\chi^{2}(1, N=690)=1514.87-1514.54=$ $.33, p=.57$. Insomnia symptoms were not significantly predicted by FSSB when evaluated at the grand mean of supervisor positive spillover $(\beta=-.03, S E=.02, t(670.46)$ $=-1.09, p=.29$ ), supervisor positive spillover when evaluated at the grand mean of employee FSSB ratings $(\beta=.03, S E=.05, t(152.65)=.53, p=.60)$, or the supervisor positive spillover by FSSB interaction $(\beta=-.03, S E=.04, t(640.80)=-.57, p=.57)$. The relationship between supervisor positive spillover and employee insomnia symptoms does not differ significantly under conditions of low versus high levels of FSSB. Thus, hypothesis $5 c$ was not supported.

Hypothesis 6 proposed that FSSB would moderate the relationship between supervisor positive spillover and employee positive spillover. To test hypothesis 6 , employee positive spillover (level-one variable) was regressed on supervisor positive spillover (level-two variable), FSSB (level-one variable), and the supervisor positive spillover by FSSB interaction term (cross-level interaction term). The model for employee positive spillover with the supervisor positive spillover by FSSB interaction term was not a significantly better fit than the model including the intercept, controls, supervisor positive spillover, and FSSB, $\chi^{2}(1, N=692)=1118.94-1118.54=.40, p=$ 
.53. Employee positive spillover was not significantly predicted by FSSB when evaluated at the grand mean of supervisor positive spillover $(\beta=.03, S E=.02, t(683.28)$ $=1.65, p=.10$ ), was significantly predicted by supervisor positive spillover when evaluated at the grand mean of employee FSSB ratings $(\beta=-.09, S E=.04, t(132.57)=-$ $2.44, p=.02$ ), and was not significantly predicted by the supervisor positive spillover by FSSB interaction $(\beta=-.02, S E=.03, t(656.61)=-.63, p=.53)$. The relationship between supervisor positive spillover and employee positive spillover does not differ significantly under conditions of low versus high levels of FSSB. Thus, hypothesis 6 was not supported. Results can be found in Table 6 .

Hypotheses $7 a-c$ proposed that FSSB would moderate the relationship between employee positive spillover and employee sleep outcomes. To test hypotheses $7 a-c$, employee sleep outcomes (level-one variables) were regressed on employee positive spillover (level-one variable), FSSB (level-one variable), and the employee positive spillover by FSSB interaction term (cross-level interaction term). Results are shown in Table 7. The model for sleep insufficiency with the employee positive spillover by FSSB interaction term was not a significantly better fit than the model including the intercept, controls, supervisor positive spillover, and FSSB, $\chi^{2}(1, N=692)=2051.16-2048.25=$ 2.91, $p=.12$. Sleep insufficiency was not significantly predicted by FSSB when evaluated at the grand mean of employee positive spillover $(\beta=-.02, S E=.02, t(777.09)$ $=-1.02, p=.31$, employee positive spillover when evaluated at the grand mean of employee FSSB ratings $(\beta=-.01, S E=.05, t(819.70)=-.10, p=.92)$, or the employee positive spillover by FSSB interaction $(\beta=.07, S E=.04, t(820.04)=1.71, p=.09)$. The 
relationship between employee positive spillover and employee sleep insufficiency does not differ significantly under conditions of low versus high levels of FSSB.

The model for sleep duration with the employee positive spillover by FSSB interaction term was not a significantly better fit than the model including the intercept, controls, employee positive spillover, and FSSB, $\chi^{2}(1, N=692)=2177.01-2177.00=$ $.01, p=.92$. Sleep duration was not significantly predicted by FSSB when evaluated at the grand mean of employee positive spillover $(\beta=.04, S E=.03, t(787.19)=1.64, p=$ .10), employee positive spillover when evaluated at the grand mean of employee FSSB ratings $(\beta=.01, S E=.06, t(820.19)=.18, p=.86)$, or the employee positive spillover by FSSB interaction $(\beta=.01, S E=.04, t(820.49)=.12, p=.91)$. The relationship between employee positive spillover and employee sleep duration does not differ significantly under conditions of low versus high levels of FSSB.

The model for insomnia symptoms with the employee positive spillover by FSSB interaction term was not a significantly better fit than the model including the intercept, controls, employee positive spillover, and FSSB, $\chi^{2}(1, N=690)=1803.02-1801.51=$ $1.51, p=.22$. Insomnia symptoms were not significantly predicted by FSSB when evaluated at the grand mean of employee positive spillover $(\beta=.01, S E=.02, t(795.21)=$ $.30, p=.76$ ), employee positive spillover when evaluated at the grand mean of employee FSSB ratings $(\beta=-.04, S E=.04, t(820.94)=-.83, p=.41)$, or the employee positive spillover by FSSB interaction $(\beta=.04, S E=.03, t(810.63)=1.23, p=.22)$. The relationship between employee positive spillover and employee insomnia symptoms does 
not differ under conditions of low versus high levels of FSSB. Thus, hypotheses $7 a-c$ were not supported.

Moderated Mediation. Hypothesis $8 a-c$ proposed that FSSB would moderate the mediating effects of supervisor positive spillover on employee sleep through employee positive spillover. Because no mediating effects were found, tests of indirect effects were not conducted to assess the strength of mediation under different levels of FSSB. Thus, hypotheses $8 a-c$ were not supported.

Research Question Analyses. A multilevel logistic regression analysis was conducted to evaluate the relationships between the likelihood of being sleep deficient and supervisor positive spillover, employee positive spillover, FSSB, and the interaction terms. However, multilevel regressions were used to analyze those models with employee positive spillover as the dependent variable. The main outcome variable was sleep deficiency, with $1=$ the presence of deficiency (never feeling rested upon awakening, $<6$ hours of sleep per night, or the presence of insomnia symptoms), and $0=$ no presence of sleep deficiency. Analyses were conducted in Mplus (Muthén \& Muthén, 1998-2010) due to its ability to analyze multilevel models with categorical outcome variables.

To test step one of the mediation, sleep deficiency was regressed on manager positive spillover and the control variables. Controlling for other variables, manager positive spillover was not related to the log odds of being sleep deficient, $\beta=.23$, Wald $\chi^{2}$ statistic $=1.00, p=.32$. 
To test step two of the mediation, employee positive spillover was regressed on manager positive spillover and the control variables. Similar to the results found using SPSS, manager positive spillover was significantly and negatively related to employee positive spillover, $\beta=-.09, t=-2.50, p=.01$.

To test step three of the mediation, sleep deficiency was regressed on both manager and employee positive spillover. Controlling for other variables, manager positive spillover was not related to the $\log$ odds of being sleep deficient, $\beta=.19$, Wald $\chi^{2}$ statistic $=1.00, p=.84$. Controlling for other variables, employee positive spillover was not related to the log odds of being sleep deficient, $\beta=.04$, Wald $\chi^{2}$ statistic $=1.00, p$ $=.32$.

To test the moderating effect of FSSB on the relationship between manager positive spillover and FSSB, sleep deficiency was regressed on manager positive spillover, FSSB, and the manager positive spillover by FSSB interaction term. Controlling for other variables, manager positive spillover was not related to the log odds of being sleep deficient, $\beta=.16$, Wald $\chi^{2}$ statistic $=.71, p=.39$. Controlling for other variables, FSSB was not related to the log odds of being sleep deficient, $\beta=.02$, Wald $\chi^{2}$ statistic $=.02, p=.88$. Controlling for other variables, the manager positive spillover by FSSB interaction term was not related to the log odds of being sleep deficient, $\beta=-2.07$, Wald $\chi^{2}$ statistic $=.57, p=.45$.

To test the moderating effect of FSSB on the relationship between manager positive spillover and employee positive spillover, employee positive spillover was regressed on manager positive spillover, FSSB, and the manager positive spillover by 
FSSB interaction term. Employee positive spillover was significantly predicted by FSSB when evaluated at the grand mean of supervisor positive spillover $(\beta=.05, t=2.01, p=$ .04 ), supervisor positive spillover when evaluated at the grand mean of employee FSSB ratings ( $\beta=-.09, t=-2.46, p=.02$ ), but not the supervisor positive spillover by FSSB interaction $(\beta=-.81, t=-.99, p=.32)$. These results are in agreement with the prior analyses conducted in SPSS.

To test the moderating effect of FSSB on the relationship between employee positive spillover and employee sleep deficiency, controlling for supervisor positive spillover and the supervisor positive spillover by FSSB interaction term, sleep deficiency was regressed on manager positive spillover, employee positive spillover, FSSB, the manager positive spillover by FSSB interaction term, and the employee positive spillover by FSSB interaction term. Controlling for other variables, manager positive spillover was not related to the log odds of being sleep deficient, $\beta=.18$, Wald $\chi^{2}$ statistic $=.89, p$ $=.34$. Controlling for other variables, employee positive spillover was not related to the $\log$ odds of being sleep deficient, $\beta=.03$, Wald $\chi^{2}$ statistic $=.02, p=.88$. Controlling for other variables, FSSB was not related to the log odds of being sleep deficient, $\beta=-.01$, Wald $\chi^{2}$ statistic $=.01, p=.94$. Controlling for other variables, the manager positive spillover by FSSB interaction term was not related to the log odds of being sleep deficient, $\beta=-1.49$, Wald $\chi^{2}$ statistic $=.29, p=.59$. Controlling for other variables, the employee positive spillover by FSSB interaction term was not related to the log odds of being sleep deficient, $\beta=2.83$, Wald $\chi^{2}$ statistic $=1.25, p=.26$. 
In summary, sleep deficiency was not related to manager or employee positive spillover. The relationship between supervisor positive spillover and employee sleep deficiency was not mediated by employee positive spillover. Furthermore FSSB did not act as a moderator on any of the paths within the mediation model. 


\section{Discussion}

The present research aimed to investigate the moderating effects of FSSB on the crossover of supervisor positive spillover to employee sleep outcomes through employee positive spillover. Results from the multilevel analyses revealed that none of the 8 hypotheses were supported. However, a negative relationship was found between supervisor positive spillover and employee positive spillover. FSSB was also found to moderate the relationship between supervisor positive spillover and employee sleep duration.

\section{Negative Crossover Relationship}

Although supervisor positive spillover was associated with employee positive spillover, the relationship was in the negative direction. This curious finding was contrary to the expectation from hypothesis 1 that high levels of supervisor positive spillover would cross over to employees. Although Carlson and colleagues (2010) previously found evidence for this crossover relationship being mediated by perceptions of schedule control, they also utilized a measure of work-family enrichment (Carlson et al., 2006) rather than work-family positive spillover. In a recent article which compared Hanson et al.'s (2006) measure with Carlson et al.'s (2006) measure, Masuda et al. (2012) found that these two measures are related and have overlapping item content, but are distinct constructs. Specifically, the measure of work-family enrichment (Carlson et al., 2006) measures both the transfer of resources and the resulting beneficial outcomes in the receiving domain, while the measure of positive spillover (Hanson et al., 2006) only measures the transfer of resources. Furthermore, the positive spillover scale measures the 
degree to which the respondent agrees that positive affect can be transferred from work to family domains. It does not, however, measure the frequency with which this happens. As such, positive spillover may beneficially cross over from supervisors to employees, but only when supervisors experience the advantages of the spillover and only when the occurrence of transfer is frequent. Therefore, the discrepancy between the findings of the current study and past research may be the result of differences in the construct being measured.

Carlson et al. (2010) also used an overall scale of work-to-family enrichment, which included dimensions of development and capital, in addition to affect. Because only the affective dimension of Hanson et al.'s (2006) positive spillover scale was used for the current research, it is possible that including the instrumental subscale, which measures the transfer of value-based and behavior-based resources, may add predictive validity over the affective scale. Perhaps positive spillover is more likely to beneficially transfer from supervisors to employees when the resources being transferred include skills, behaviors, and values, as they could be perceived by employees to be especially important for fulfilling responsibilities at home.

An alternative explanation for this negative relationship between supervisor positive spillover and employee positive spillover comes from research conducted by Aderman and Unterberger (1977). The researchers proposed that prior studies had mistakenly assumed that affect is always induced from one individual to another in a concordant fashion. That is, a modeler exhibits positive emotions and the observer empathizes thereby always catching the positive emotions, or the modeler exhibits 
POSITIVE SPILLOVER AND SLEEP

negative emotions and the observer empathizes thereby always catching the negative emotions. Instead, Aderman and Unterberger (1977) suggested that there are two types of empathy: simple empathy (i.e., emotions of the modeler and observer are either both positive or both negative) and contrast empathy (i.e., emotions of modeler and observer are opposite in sign). Findings from their studies suggest that an observer's negative affective response to a modeler's positive affective cues can reduce future modeled behavior. Thus, employees who work under supervisors experiencing high levels of positive spillover may experience some jealousy or resentment because their supervisor experiences the benefits of integrating work and family. Consequently, these employees are actually more likely to avoid those modeled behaviors that facilitate positive spillover than engage in them.

A slightly different alternate explanation concerns the shared resources between supervisors and their employees. Westman, Etzion, and Chen (2009) discovered a similar unexpected finding in their crossover study of spousal dyads where one partner was engaging in business travel. Results showed that there was a negative impact of the employee's business travel satisfaction on their spouse's vigor. The authors suggest that one possibility is that the spouse sacrificed resources for the employee to be able to experience such satisfaction. Similarly, employees' investment of resources towards their work team's goals, and ultimately the supervisor's goals, may mean that their supervisor achieves high levels of positive spillover at their employee's expense. Alternatively, the support and resources that a supervisor invests in accommodating 
employees' work and family lives may ultimately lead to decreased positive spillover for the supervisor.

This negative relationship may also be a characteristic of the white collar population sampled. The skill level required by one's job and substantive complexity of one's job have both been positively related with work-to-family positive spillover (Grzywacz \& Butler, 2005). Descriptive statistics indicated that both supervisors and employees experienced very similar levels, and very high levels on average, of positive spillover. Perhaps the nature of the work in this IT firm allows for high levels of positive affect to be transferred into the family domain on a consistent basis. If this is the case, certain elements of the type of work that one does may moderate the crossover relationship from supervisor to employee.

Supervisors and employees may also interact very differently in this type of industry, given the use of technology. For example, members of the supervisoremployee dyad may interact less frequently in person, but more frequently online over email and conference calls, which may either facilitate or inhibit the crossover of positive spillover. Accordingly, Barsade and Gibson (2007) have called for future research to investigate the organizational implications of emotions being conveyed through textbased means. The authors argue that theories of interpersonal processes, such as emotional contagion, may need to be revised to incorporate the online nature of today's work. Perhaps the negative crossover relationship that was found is partially the result of supervisors and employees interacting primarily through technology, rather than in person. 
POSITIVE SPILLOVER AND SLEEP

\section{Positive Spillover and Sleep Outcomes}

Supervisor positive spillover was not significantly related to employee sleep outcomes despite the presence of a significant supervisor positive spillover by FSSB interaction on employee sleep duration. This suggests that averaging over all individuals in the sample, there was no association between the level of positive spillover that one's supervisor experienced and their own sleep insufficiency, sleep duration, insomnia symptoms, or sleep deficiency as an overall construct. This may indicate true null relationships or the presence of moderators, as seen with sleep duration. It is also possible that sleep insufficiency and insomnia symptoms, given that they are concerning the qualitative aspects of sleep, rather than the quantity of sleep, may be less affected by supervisor experiences of work and family. For example, duration may relate to one's ability to schedule time for sleep while insufficiency and insomnia may both relate to absence of ruminating about work.

Additionally, employee positive spillover was not related to employee sleep outcomes. This is in contrast to previous findings that positive spillover, although in the family-to-work direction, is related to sleep quality (Williams et al., 2006). As suggested by Williams et al. (2006), family-to-work positive spillover may in fact be a better predictor of sleep outcomes due to the saliency of family. The authors interpret their results in light of past research on recovery from work and the effort-recovery model (Meijman \& Mulder, 1998). They suggest that resources in the family domain can spill over into the work domain, facilitating the recovery process. Thus, resources from the 
work domain spilling over into the family domain may not aid in recovery, which in turn could benefit sleep.

Williams and colleagues (2006) also used the Pittsburgh Sleep Quality Index (Buysse et al., 1989) rather than individual measures of sleep insufficiency, sleep duration, and insomnia symptoms or the composite measure of sleep deficiency. The Pittsburgh Sleep Quality Index does not control for sleep apnea and was validated within clinical populations. It is possible that Williams et al.'s (2006) results were influenced by the presence of disordered apneic sleep as they report that $67.3 \%$ of their sample of Canadian hospital workers experienced poor sleep quality, much higher than the Canadian national average. As such, there could be an absence of direct effect relationships between positive spillover and sleep, as was found in this study.

Differential findings may also be the result of Williams et al. (2006) utilizing a female-only sample. The current study included both male and female participants and also controlled for gender. The need to control for gender arises from studies indicating women experience more positive spillover than men (e.g., Grzywacz et al., 2002; Powell \& Greenhaus, 2010). Gender may moderate the relationship between positive spillover and certain sleep outcomes. Although range restriction typically reduces correlations between variables, it has been shown to increase correlations between variables when outlier-prone distributions are involved (Zimmerman \& Williams, 2000). This may be a plausible explanation given the high frequency of disordered sleep present in William's et al.'s sample, in addition to sleep apnea not being controlled for. 


\section{FSSB as a Moderator}

FSSB was found to moderate the relationship between supervisor positive spillover and employee sleep duration with a positive relationship under conditions of high FSSB and a negative relationship under conditions of low FSSB. However, hypothesis $5 b$ stated that the relationship would be positive, but strengthened under conditions of high FSSB. Findings from this study suggest that when FSSB is low, supervisors who experience high levels of positive spillover work with employees with shorter sleep durations. Work-to-family positive spillover has been positively linked with job performance (e.g., Carlson et al., 2008; van Steenbergen et al., 2007), job effort (Wayne et al., 2004), and organizational commitment (Balmforth \& Gardner, 2006). Thus, supervisors experiencing higher levels of positive spillover are likely to be more engaged in their job and may consequently ask for a higher level of workplace commitment from their employees. This may be detrimental when supervisors additionally give low levels of family-specific support to their employees. Because the number of hours worked was controlled for in these analyses, flexibility, afforded through instrumental support and creative work-family management, may be the driving force behind these relationships. The absence of FSSB in combination with higher demands from one's supervisor may result in employees having difficulty managing both work and family responsibilities and even scheduling enough time to sleep. Conversely, individuals who have family-supportive supervisors experiencing high levels of positive spillover are more likely to be able to manage work and family responsibilities, thus increasing sleep duration. 
The significant interaction between supervisor positive spillover and employee sleep duration may also reflect the abovementioned negative crossover relationship between supervisors and employees. Just as Westman et al. (2009) suggest that a spouse can sacrifice resources for the employee, employees may sacrifice resources, in the form of sleep, for supervisors. When high levels of FSSB are not present, supervisors may experience more positive spillover at the expense of their employees' sleep.

In addition, FSSB was not found to moderate the relationship between employee positive spillover and sleep insufficiency and insomnia symptoms, in addition to the composite measure of sleep deficiency. Other non-work factors may have a greater ability to influence the association between supervisor positive spillover and employee positive spillover with sleep outcomes. In line with Wayne et al.'s (2007) resource-gain development theory, personal characteristics, in addition to support, may enhance system functioning, ultimately facilitating the spillover process and their relationship with potential outcomes. According to the authors, an individual is likely to experience positive spillover when they possess personal characteristics that promote positivity and allow the individual to more easily experience positive emotions and pursue developmental opportunities. For example, positive thinking (Rotondo \& Kincaid, 2008) and positive core self-evaluations (Bhargava \& Baral, 2009) have been related to employees' experiences of work-to-family positive spillover, but may also act as moderators on crossover relationships. 
POSITIVE SPILLOVER AND SLEEP

\section{Contributions and Limitations}

This research aimed to address important gaps in the current work-family literature. First, the study examined the beneficial and reciprocal effects of dual participation in both work and family roles. Work-family scholars have called for research such as this to explore the positive linkages within the work-family interface (Edwards \& Rothbard, 2000; Hanson et al., 2006). Second, this research incorporated and tested the role of FSSB as a moderator in relation to the crossover of positive spillover and health outcomes. As has been suggested by Heller and Watson (2005), little is known about the presence of moderators within the positive spillover process. Third, this study employed sleep outcomes as dependent variables, which have remained largely unexplored in the positive spillover literature, let alone the work-family literature (Williams et al., 2006). Furthermore, past organizational studies that have included a sleep variable have primarily used sleep quality or duration. By incorporating sleep insufficiency, sleep duration, and insomnia symptoms, this study was able to examine the different components of sleep deficiency that may be affected by positive spillover (Buxton et al., in press).

This study is cross-sectional in nature, making it difficult to determine causal influences of variables. It is possible that supervisors and employees simultaneously experience greater levels of positive spillover because they are sharing the same environment, rather than because supervisor positive spillover influences employees' experience of positive spillover. Westman (2004) calls this a spurious effect. Additionally, it may be the case that employees experience greater levels of positive 
spillover because they are in fact less deficient in sleep allowing for the transfer of positive mood between the work and non-work domains.

Another limitation of the current study is the absence of the family-to-work direction of positive spillover. Perhaps supervisor family-to-work positive spillover is related to employee work-to-family positive spillover. For example, supervisors may generate positive emotions at home which are then transferred into the workplace. Consequently, this may then encourage supervisors to create positive experiences for their employees, generating employee positive affect in the workplace, only to be then transferred into the employees' home domain. Alternatively, supervisor family-to-work positive spillover may be related to employee family-to-work positive spillover, given that supervisors act as role senders and modelers in the workplace.

Relatedly, this study utilizes the affective dimension of positive spillover. However, it is possible that the transfer of positive behaviors and values between the work and family domains may crossover between supervisor and employee, and may also be associated with sleep outcomes.

\section{Future Research}

Future research should attempt to examine these relationships in a longitudinal design whereby the direction of transfer of resources, work-to-family or family-to-work, can be determined. The spillover-crossover process is complicated in that it involves intraindividual and interindividual components. As such, data collection at multiple time points with all dimensions and both directions of positive spillover being addressed 
would be beneficial. This could determine the movement of resources, and specify which resources are being transferred, within the dyadic system.

In addition, the cross-sectional nature of the data did not allow for an examination of whether supervisors were influencing employees, or employees were influencing supervisors. Therefore, longitudinal research is needed to determine whether the crossover of positive spillover occurs bidirectionally from supervisor to employee and employee to supervisor, or whether one member of the dyad is more influential than the other.

Furthermore, it may be the case that the effects of work-family positive spillover manifest differentially day to day. Since positive emotions are short-lived and since aspects of sleep can vary depending on the day of the week, work schedule, or family schedule, future studies may include a daily diary component to data collection. Such designs would allow for examination of specific events or types of positive spillover that influence sleep deficiency. They would also allow for an examination of the frequency of positive spillover and how frequency may be negatively associated with sleep. This would address our previously mentioned limitation of using a scale which did not measure frequency of positive spillover.

Studies may also attempt to include other measures of sleep, beyond self-report scales, to further understand sleep outcomes in relation to positive spillover. Actigraphy may be an alternative and more accurate method for assessing sleep. Actigraphy represents a reliable, valid measure of sleep not used for the diagnosis of sleep disorders (Ancoli-Israel et al., 2003). Actigraphy could be used in conjunction with daily diary 
methods to obtain objective daily ratings of sleep across 24-hour periods, capturing both weekend and weekday sleeping habits.

Limited research has been conducted on positive crossover in the workplace between role senders and receivers (Crain \& Hammer, forthcoming; Westman, 2001). As a result further work is needed to determine the ways in which supervisor positive spillover can either negatively or positively influence employee positive spillover. Workfamily scholars should attempt to replicate this study in other organizations and industries to determine under what conditions supervisor positive spillover might negatively influence employee positive spillover. FSSB may also be examined as a mediator within the crossover process, rather than a moderator. Furthermore, future studies should include both subscales and directions of positive spillover. Including work-family conflict within this model may be interesting, in that the effects of positive spillover can be compared to the effects of work-family conflict. It is likely that work-family conflict would also cross over from supervisor to employee, thus negatively affecting employee sleep outcomes. However, FSSB may also attenuate these relationships.

Other moderators of the crossover process should also be investigated. For example, the amount of interaction one has with one's supervisor, the amount of coworker or family support one receives, or individual difference characteristics such as emotional intelligence or trait positive affectivity may play a role in the crossover process. Because past literature indicates that work-family positive spillover has a strong influence on many important individual and organizational outcomes, future research should continue to examine the factors impacting these relationships. 


\section{Conclusion}

The current study contributes to the literature on the positive aspects of work and family by providing an investigation into the crossover effects of supervisor work-family positive spillover on employee sleep outcomes. Furthermore, FSSB was examined as a moderator of these relationships. Supervisor positive spillover was surprisingly negatively related with employee positive spillover. Additionally, the association between supervisor work-family positive spillover and employee sleep duration was moderated by FSSB. These results, although not as hypothesized, extend past workfamily and crossover literature. Future studies should continue to investigate the crossover of positive experiences between role senders and receivers in the workplace, in addition to incorporating sleep constructs into study design. This research is crucial to understanding what organizations can do to facilitate employees' experiences of the mutually beneficial effects of engaging in both work and family, and consequently increases in health. This can ultimately lead to implications not only for organizational success, but also for employees' and their families' long-term well-being. 


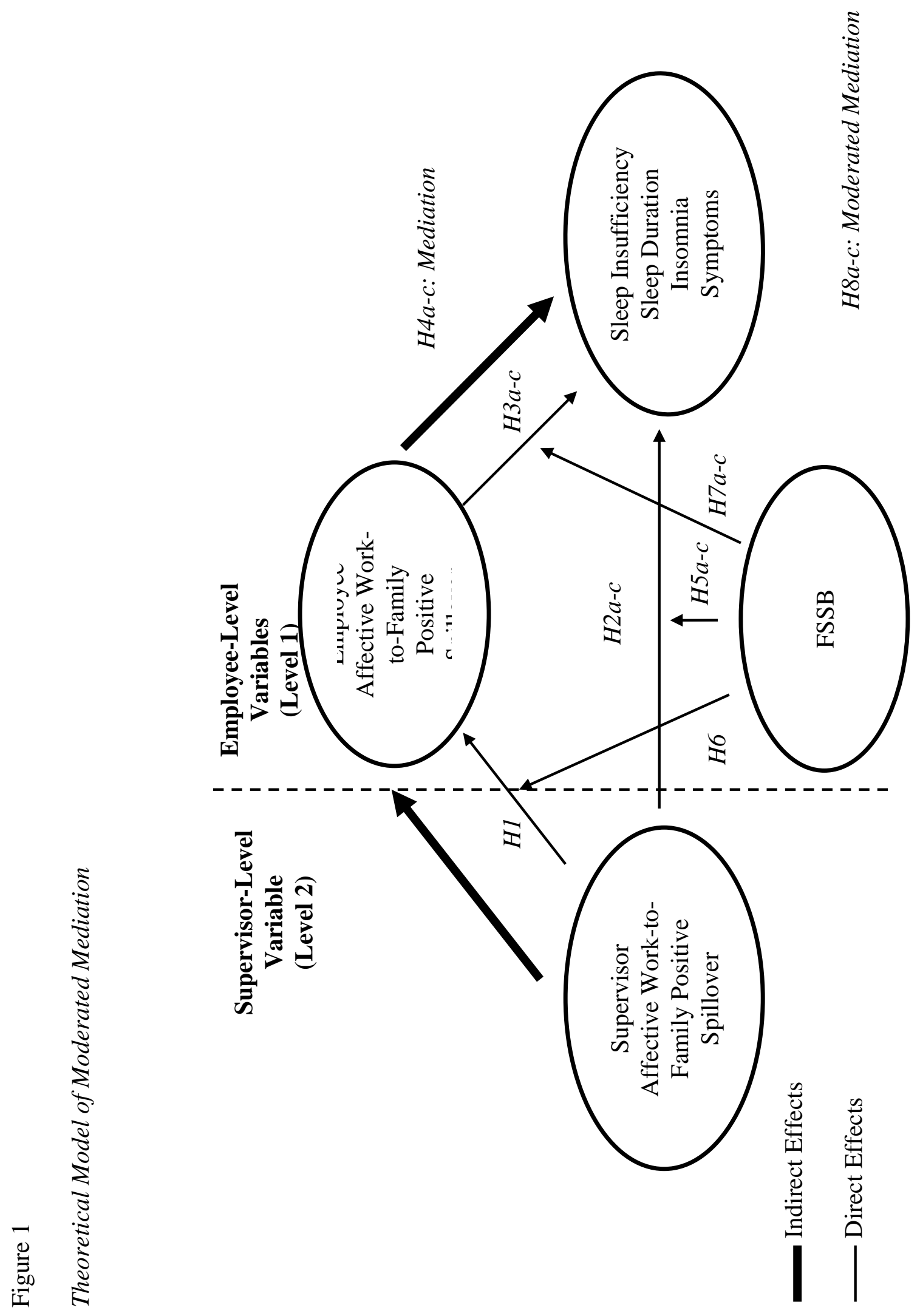




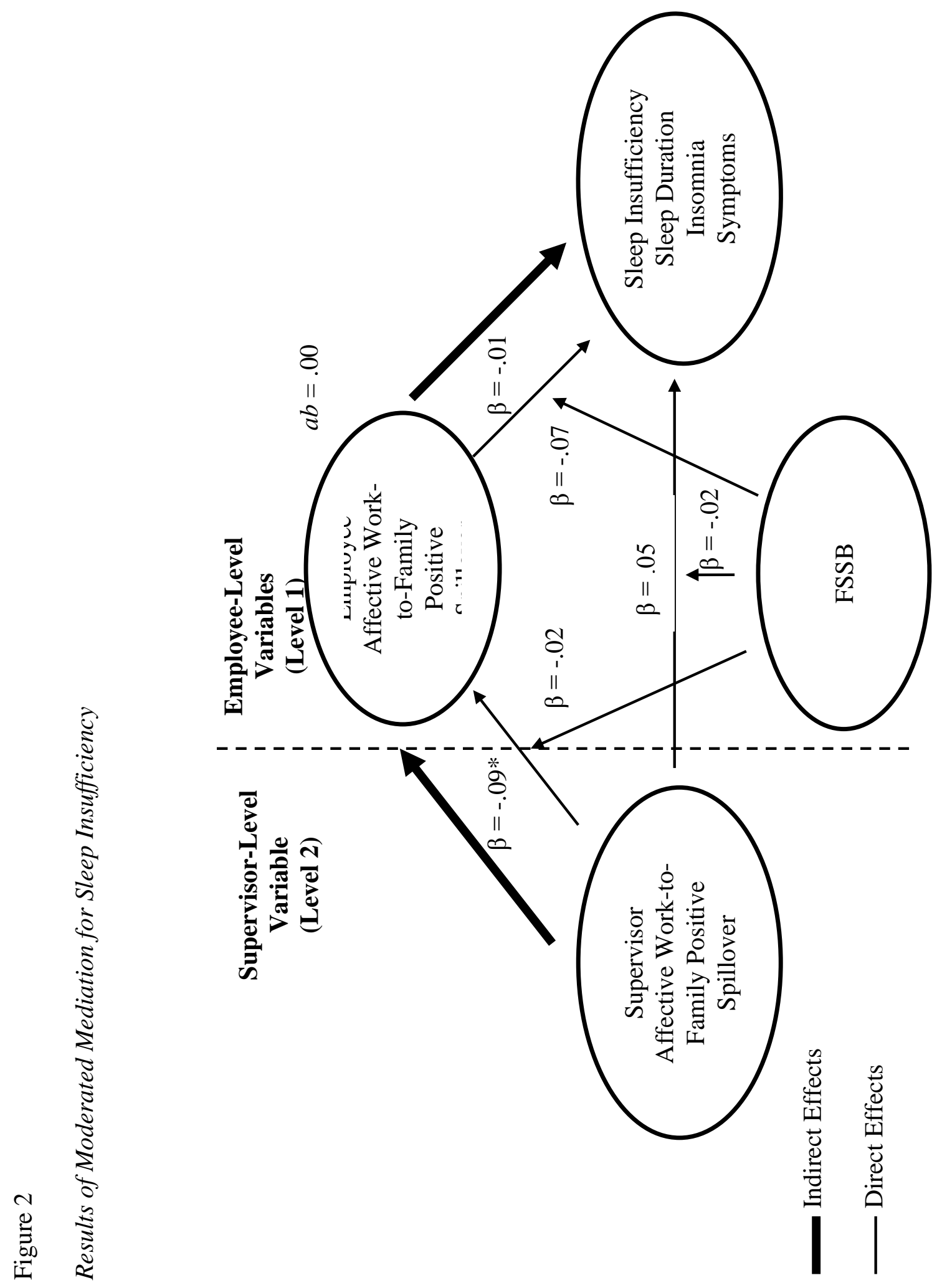




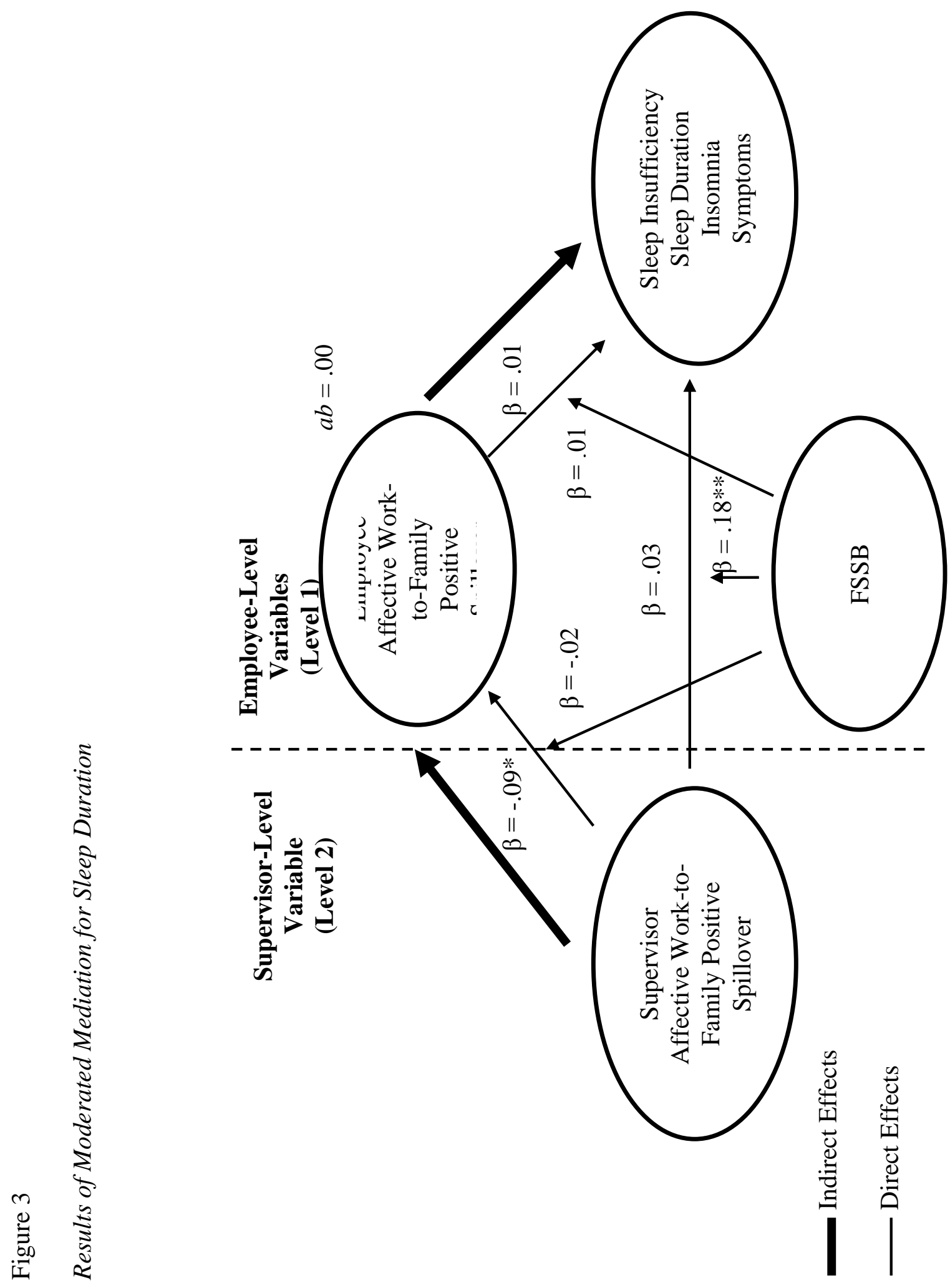




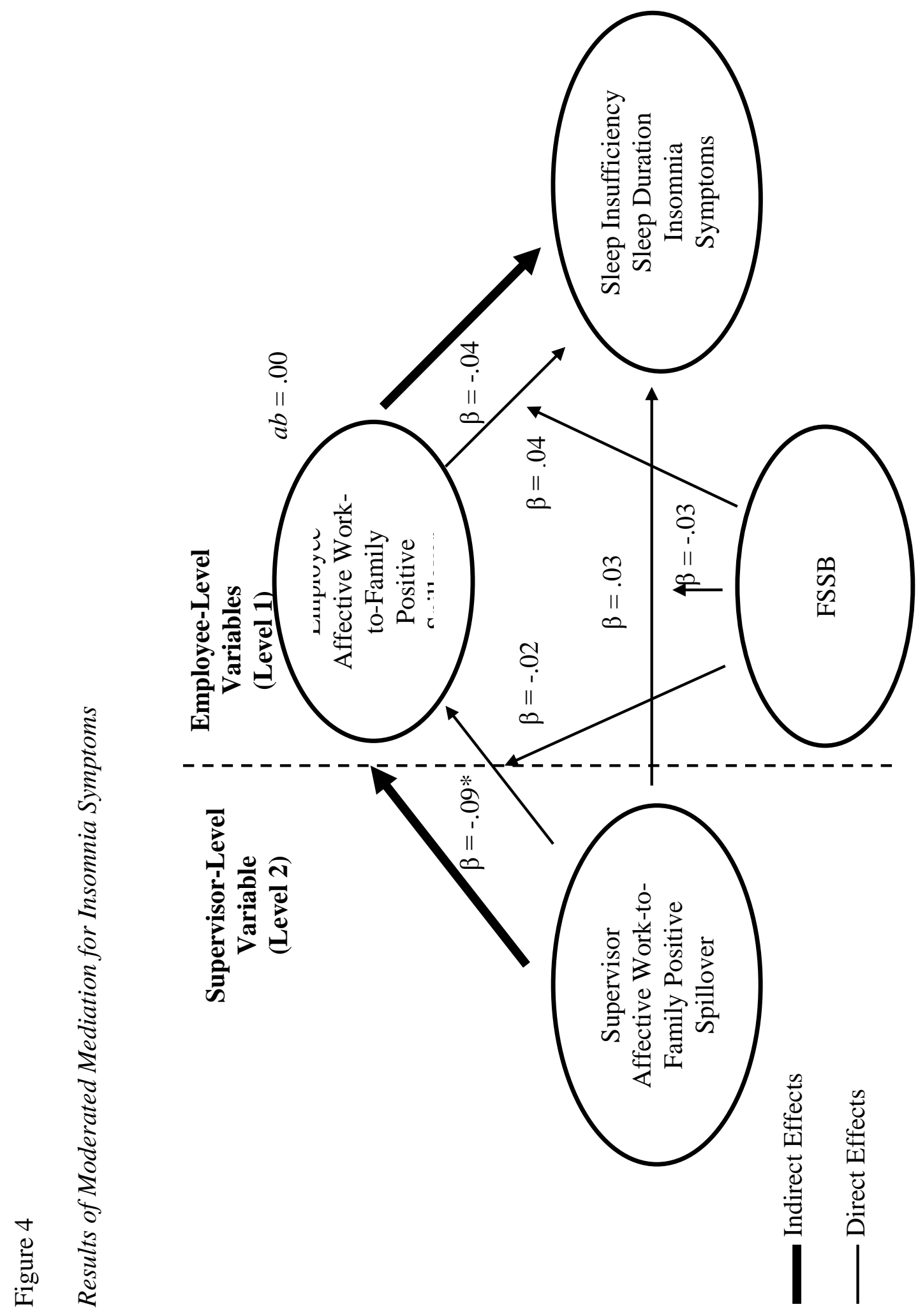


Figure 5

Graph of Supervisor Positive Spillover by FSSB Interaction on Employee Sleep Duration

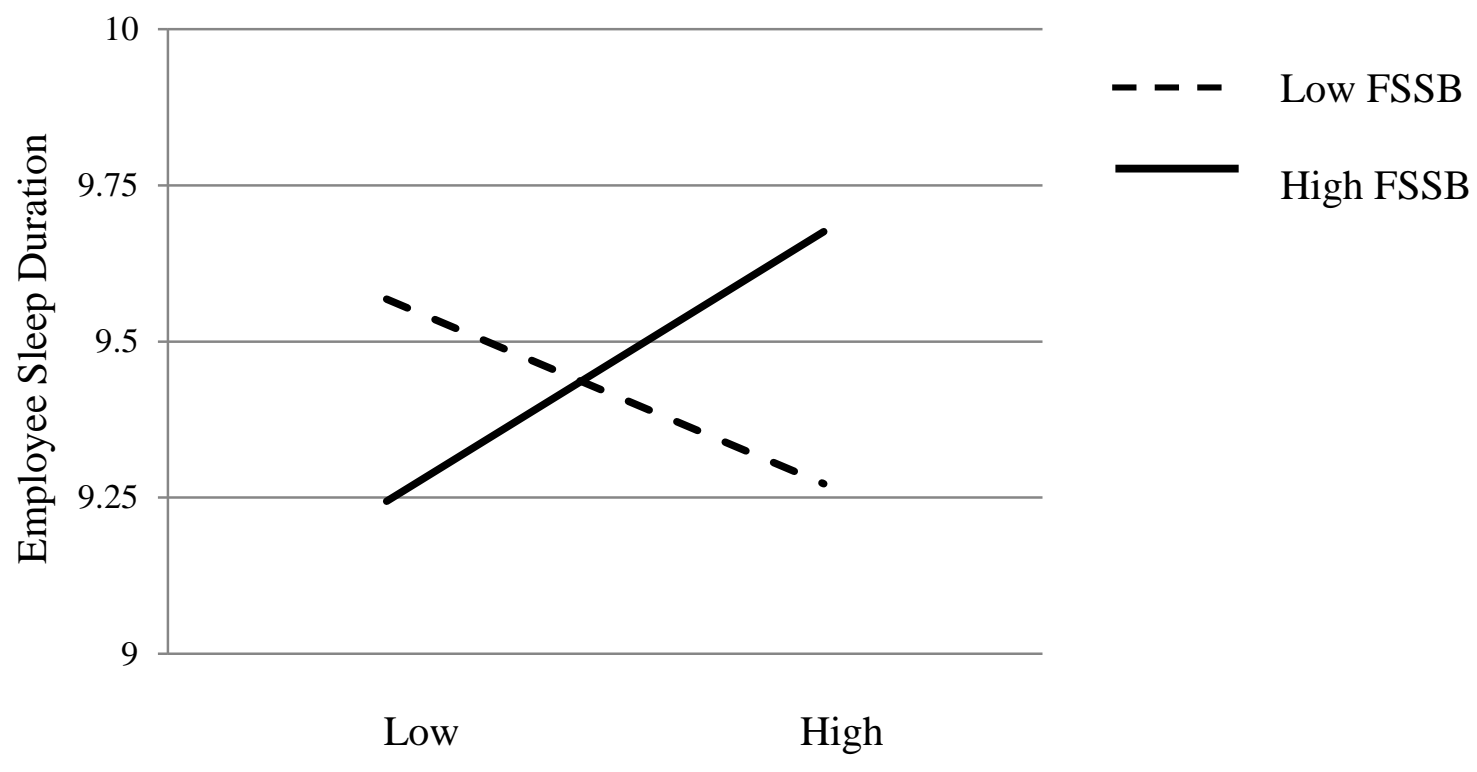

Supervisor Positive Spillover 


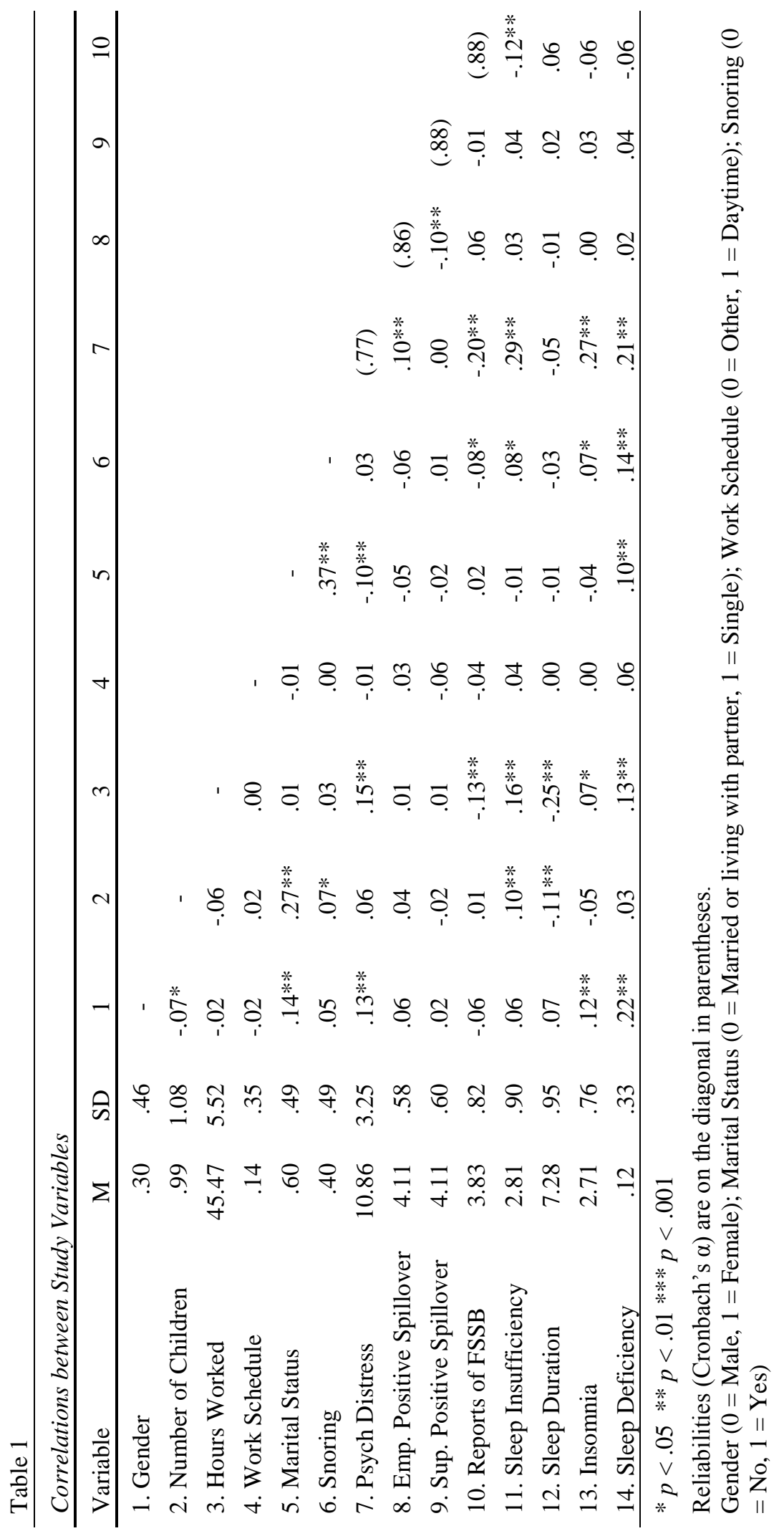


Table 1, cont.

Correlations between Study Variables

\begin{tabular}{lcccc}
\hline Variable & 11 & 12 & 13 & 14 \\
\hline 1. Gender & & & & \\
2. Number of Children & & & & \\
3. Hours Worked & & & & \\
4. Work Schedule & & & & \\
5. Marital Status & & & & \\
6. Snoring & & & & \\
7. Psych Distress & & & & \\
8. Emp. Positive Spillover & & & & \\
9. Sup. Positive Spillover & & & & \\
10. Reports of FSSB & & & & \\
11. Sleep Insufficiency & $-.18^{* * *}$ & - & & \\
12. Sleep Duration & $.28^{* *}$ & $.10^{* * *}$ & $(.34)$ & \\
13. Insomnia & $.29^{* *}$ & $-.29^{* *}$ & $.35^{* *}$ & - \\
14. Sleep Deficiency & & &
\end{tabular}

$* \mathrm{p}<.05 * * \mathrm{p}<.01$

Reliabilities (Cronbach's $\alpha$ ) are on the diagonal in parentheses.

Gender $(0=$ Male, $1=$ Female $)$; Marital Status $(0=$ Married or living

with partner, $1=$ Single $)$; Work Schedule $(0=$ Other, $1=$ Daytime $)$;

Snoring $(0=$ No, $1=$ Yes $)$ 
Table 2

Hypothesis 1: Multilevel Regression Results for Association Between Supervisor Positive Spillover and Employee Positive Spillover

\begin{tabular}{|c|c|c|}
\hline \multirow[b]{3}{*}{ Predictor } & \multicolumn{2}{|c|}{ Outcome } \\
\hline & \multicolumn{2}{|c|}{ Employee Positive Spillover } \\
\hline & $\Delta \chi^{2}$ & $\beta(S E)$ \\
\hline Model 1 & & \\
\hline Intercept & & $4.11(.02)^{* * *}$ \\
\hline Model 2 & $26.79 * * *$ & \\
\hline Gender & & $.04(.04)$ \\
\hline Number of Children & & $.03(.02)$ \\
\hline Hours worked & & $.00(.00)$ \\
\hline Schedule & & $-.02(.05)$ \\
\hline Marital Status & & $-.06(.05)$ \\
\hline Apnea & & $-.06(.04)$ \\
\hline Psych Distress & & $.01(.01)^{*}$ \\
\hline Model 3 & $290.22 * * *$ & \\
\hline Sup. Positive Spillover & & $-.09(.04)^{*}$ \\
\hline
\end{tabular}

$* p<.05 \quad * * p<.01 * * * p<.001$ 


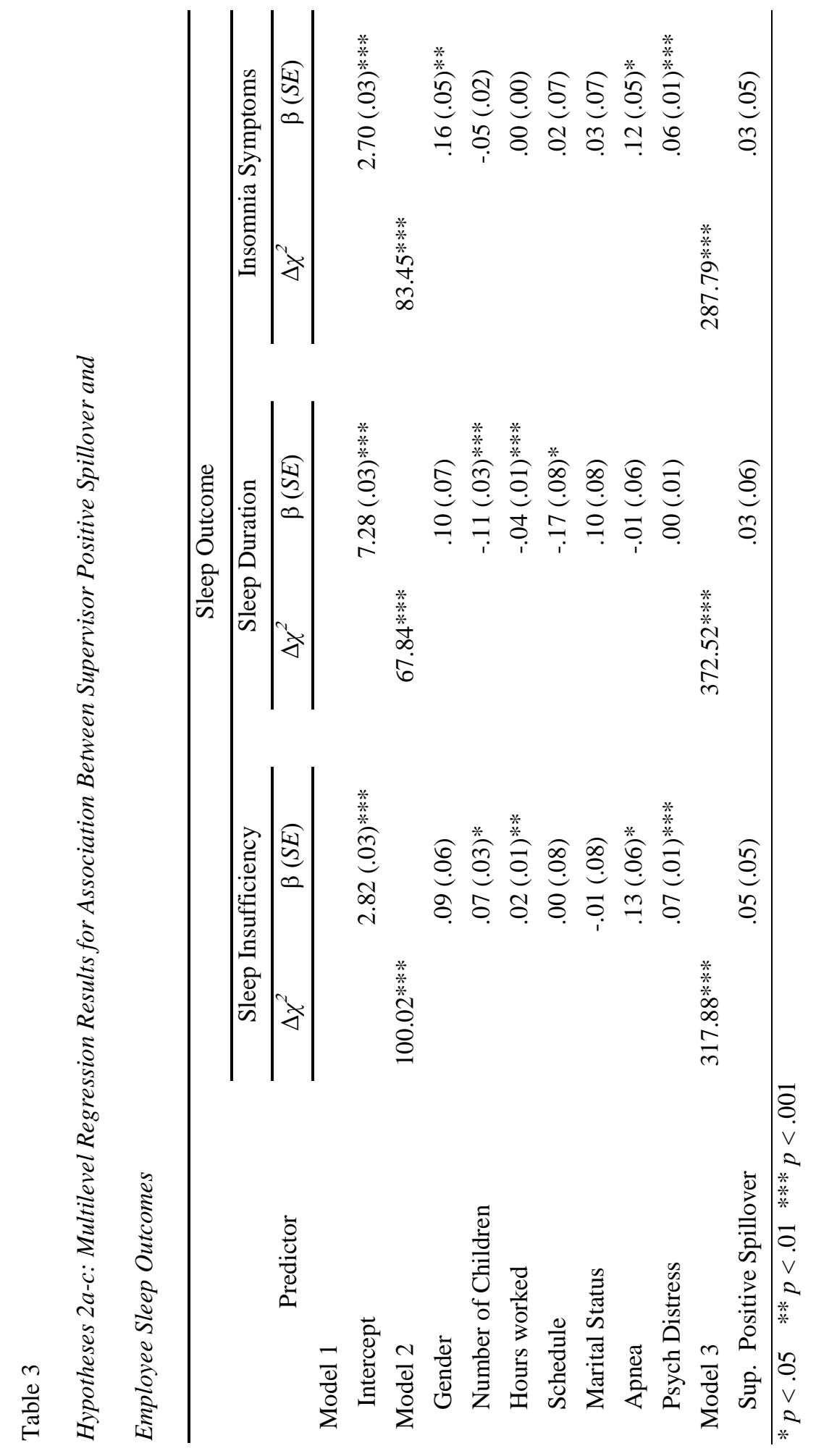




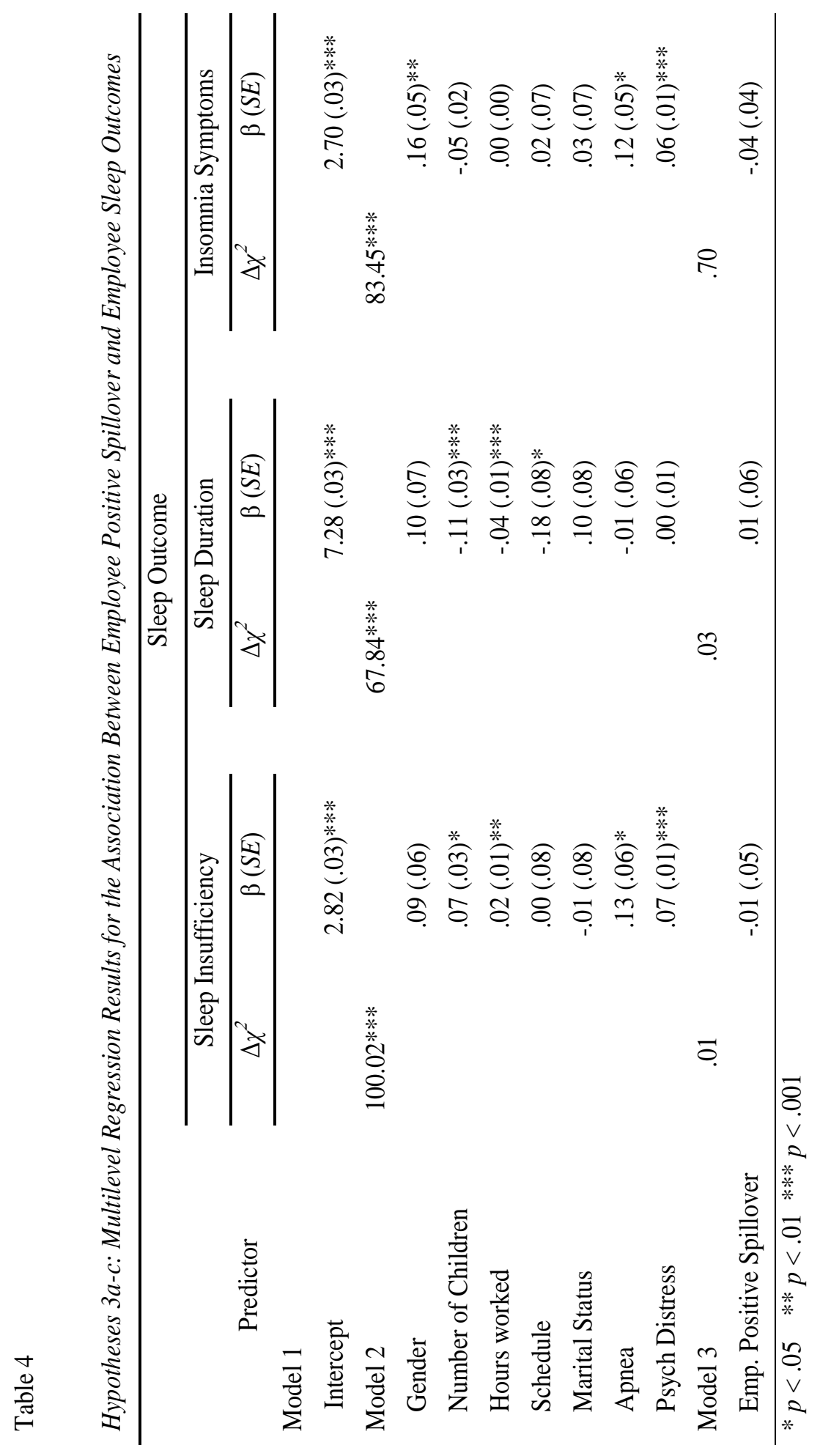




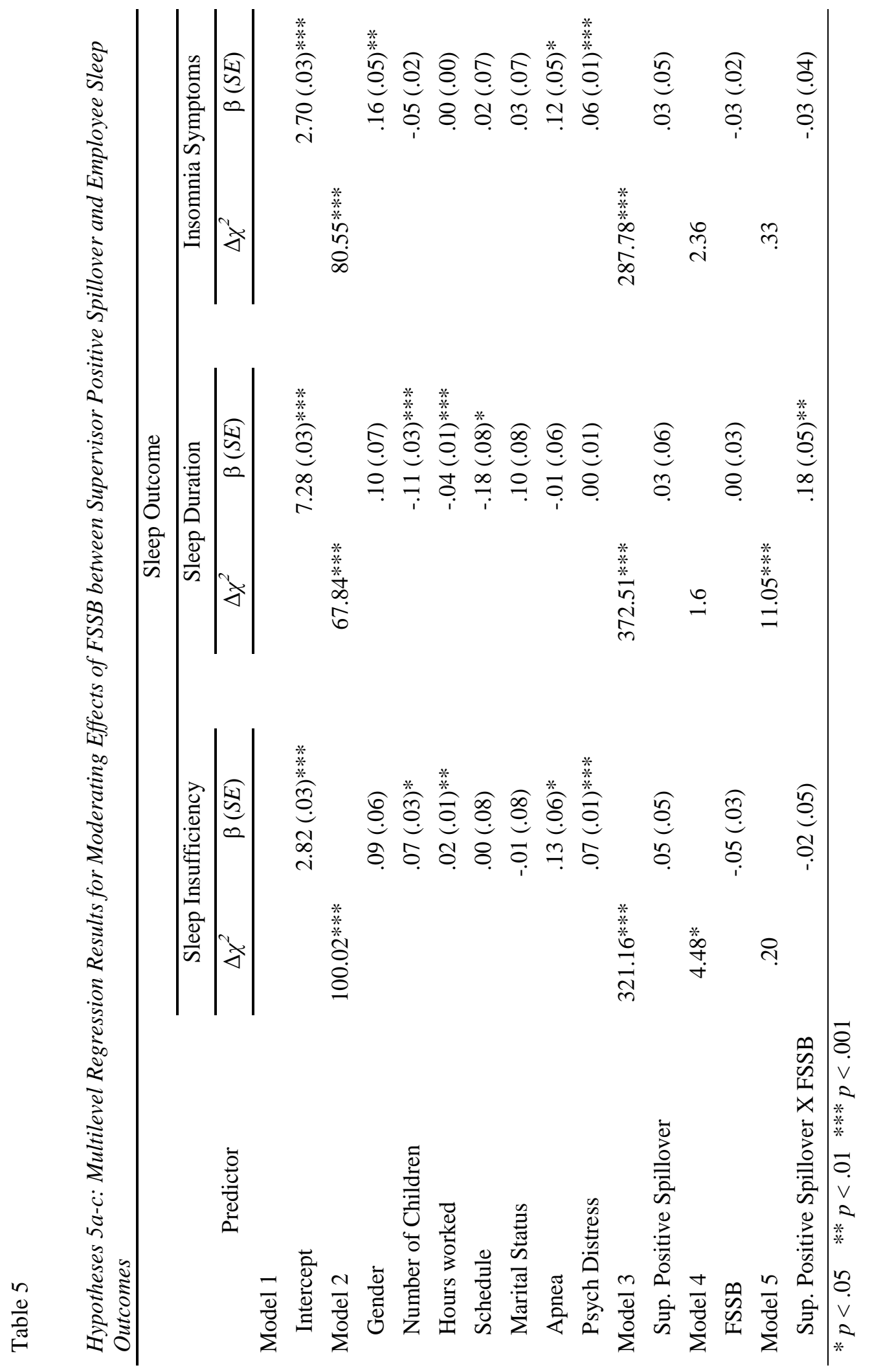


Table 6

Hypothesis 6: Multilevel Regression Results for Moderating Effects of FSSB between Supervisor Positive Spillover and Employee Positive Spillover

\begin{tabular}{|c|c|c|}
\hline \multirow[b]{3}{*}{ Predictor } & \multicolumn{2}{|c|}{ Outcome } \\
\hline & \multicolumn{2}{|c|}{ Employee Positive Spillover } \\
\hline & $\Delta \chi^{2}$ & $\beta(S E)$ \\
\hline Model 1 & & \\
\hline Intercept & & $4.11(.02)^{* * *}$ \\
\hline Model 2 & $14.52 *$ & \\
\hline Gender & & $.04(.04)$ \\
\hline Number of Children & & $.03(.02)$ \\
\hline Hours worked & & $.00(.00)$ \\
\hline Schedule & & $-.02(.05)$ \\
\hline Marital Status & & $-.06(.05)$ \\
\hline Apnea & & $-.06(.05)$ \\
\hline Psych Distress & & $.01(.01)^{*}$ \\
\hline Model 3 & $287.53 * * *$ & \\
\hline Sup. Positive Spillover & & $-.09(.04)^{*}$ \\
\hline Model 4 & 3.55 & \\
\hline FSSB & & $.03(.02)$ \\
\hline Model 4 & .40 & \\
\hline Sup. Positive Spillover X FSSB & & $-.02(.03)$ \\
\hline
\end{tabular}

$* p<.05 \quad * * p<.01 * * * p<.001$ 


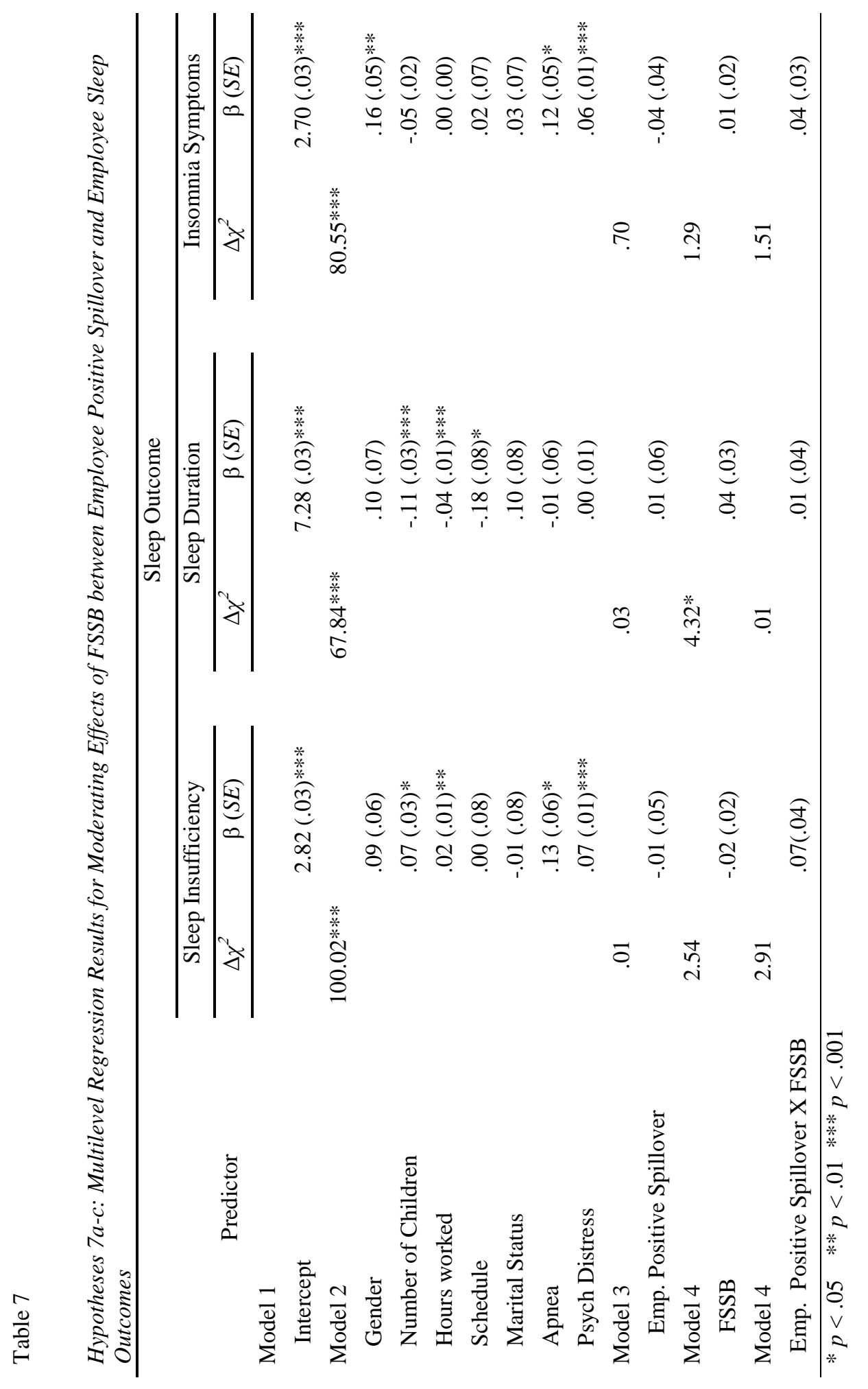




\section{References}

Aderman, D., \& Unterberger, G. L. (1977). Contrast empathy and observer modeling behavior. Journal of Personality, 45, 267-280.

Akerstedt, T. (2003). Shift work and disturbed sleep/wakefulness. Occupational Medicine, 53, 89-94.

Akerstedt, T., Fredlund, P., Gillberg, M. \& Jansson, B. (2002). A prospective study of fatal occupational accidents: Relationship in sleeping difficulties and occupational factors. Journal of Sleep Research, 11, 69-71.

Allen, T. D. (2001). Family-supportive work environments: The role of organizational perceptions. Journal of Vocational Behavior, 58, 414-435.

Allis, P., \& O’Driscoll, M. (2008). Positive effects of nonwork-to-work facilitation on well-being in work, family, and personal domains. Journal of Managerial Psychology, 23(3), 273-291.

American Sleep Disorders Association (1997). International classification of sleep disorders: Diagnostic and coding manual (Rev. ed.). Rochester, MN: American Sleep Disorders Association.

Ancoli-Israel, S., Cole, R., Alessi, C., Chambers, M., Moorcraft, W., \& Pollak, C. P. (2003). The role of actigraphy in the study of sleep and circadian rhythms. SLEEP, 26, 342-392.

Anderson, S. E., Coffey, B. S., \& Byerly, R. T. (2002). Formal organizational initiatives and informal workplace practices: Links to work-family conflict and job-related outcomes. Journal of Management, 28, 787-810. 
Andreassi, J. K., \& Thompson, C. A. (2007). Dispositional and situational sources of control: Relative impact on work-family conflict and positive spillover. Journal of Managerial Psychology, 22, 722-740.

Angus, R. G., \& Heslegrave, R. J. (1985). Effects of sleep loss on sustained cognitive performance during a command and control simulation. Behavior Research Methods, Instruments, \& Computers, 17, 55-67.

Aryee, S., Srinivas, E. S., \& Tan, H. H. (2005). Rhythms of Life: Antecedents and outcomes of work-family balance in employed parents. Journal of Applied Psychology, 90, 132-146.

Ashforth, B. E., \& Humphrey, R. H. (1993). Emotional labor in service roles: The influence of identity. Academy of Management Review, 18, 88-115.

Bakker, A., Demerouti, E., \& Burke, R. (2009). Workaholism and relationship quality: A spillover-crossover perspective. Journal of Occupational Health Psychology, 14, 23-33.

Bakker, A., Demerouti, E., \& Dollard, M. F. (2008). How job demands affect partners' experience of exhaustion: Integrating work-family conflict and crossover theory. Journal of Applied Psychology, 93, 901-911.

Bakker, A. B., Emmerik, H. V., \& Euwema, M. C. (2006). Crossover of burnout and engagement in work teams. Work and Occupations, 33, 464-489.

Bakker, A. B, LeBlanc, P. M., \& Shaufeli, W. B. (2005). Burnout contagion among intensive care nurses. Journal of Advanced Nursing, 51, 276-287. 
Bakker, A. B., Shaufeli, W. B., Sixma, H., \& Bosveld, W. (2001). Burnout contagion among general practitioners. Journal of Social and Clinical Psychology, 20, 8298.

Bakker, A. B., Westman, M., \& van Emmerik, I. J. H. (2009). Advancements in crossover theory. Journal of Managerial Psychology, 24, 206-219.

Balmforth, K., \& Gardner, D. (2006). Conflict and facilitation between work and family: Realizing the outcomes for organizations. New Zealand Journal of Psychology, 35, 69-76.

Bandura, A. Self-efficacy: The exercise of control. New York: Freeman, 1997.

Bardwell, W. A., Berry, C. C., Ancoli-Israel, S., \& Dimsdale, J. E. (1999). Psychological correlates of sleep apnea. Journal of Psychosomatic Research, 47, 583-596.

Barnett, R. C. (1994). Home-to-work spillover revisited: A study of full-time employed women in dual earner couples. Journal of Marriage and Family, 56, 647-656.

Barnett, R. C., \& Baruch, G. K. (1985). Women's involvement in multiple roles and psychological distress. Journal of Personality and Social Psychology, 49, 135145.

Barnett, R. C., \& Hyde, J. S. (2001). Women, men, work, and family. American Psychologist, 56, 781-796.

Barnett, R. C., Raudenbush, S. W., Brennan, R. T., Pleck, J. H., \& Marshall, N. L. (1995). Change in job and marital experiences and change in psychological distress: A longitudinal study of dual-earner couples. Journal of Personality and Social Psychology, 69, 839-850. 
Baron, R. M., \& Kenny, D. A. (1986). The moderator-mediator variable distinction in social psychological research: Conceptual, strategic, and statistical considerations. Journal of Personality and Social Psychology, 51, 1173-1182.

Beehr, T. A., Johnson, L. B., \& Nieva, R. (1995). Occupational stress: Coping of police and their spouses. Journal of Organizational Behavior, 16, 3-25.

Behson, S. J. (2005). The relative contribution of formal and informal organizational work-family support. Journal of Vocational Behavior, 66, 487-500.

Belenky, G., Wesensten, N. J., Thorne, D. R., Thomas, M. L., Sing, H. C., Redmond, D. P., . ., Balkin, T. J. (2003). Patterns of performance degradation and restoration during sleep restriction and subsequent recovery: A sleep dose-response study. Journal of Sleep Research, 12, 1-12.

Berkman, L. F., Buxton, O., Ertel, K., \& Okechukwu, C. (2010). Manager's practices related to work-family balance predict employee cardiovascular risk and sleep duration in extended care settings. Journal of Occupational Health Psychology, 15, 316-329.

Beutell, N. J., \& Wittig-Berman, U. (2008). Work-family conflict and work-family synergy for generation X, baby boomers, and matures: Generational differences, predictors, and satisfaction outcomes. Journal of Managerial Psychology, $23,507-523$.

Bhargava, S., \& Baral, R. (2009). Antecedents and consequences of work-family enrichment among Indian managers. Psychological Studies, 54, 213-225. 
POSITIVE SPILLOVER AND SLEEP

Bogan, E. C. (1991). Economics of the wider family. In T. Marciano and M. Sussman (Eds.), WiderFamilies: New Traditional Family Forms (pp. 9-27). New York: Harworth Press.

Bolger, N., DeLongis, A., Kessler, R. C., \& Wethington, E. (1989). The contagion of stress across multiple roles. Journal of Marriage and Family, 51, 175-183.

Bond, J. T., Galinsky, E.,\& Swanberg, J. E. (1998). The 1997 national study of the changing workforce. NewYork: Families and Work Institute.

Bond, J. T., Thompson, C., Galinsky, J. E., \& Prottas, D. (2003). Highlights of the 2002 National Study of the Changing Workforce. New York: Families and Work Institute.

Bray, J., Buxton, O., Kelly, E., Hammer, L., Almeida, D., \& Dearing, J. W. (under review). An integrative, multi-level, and multi-disciplinary research approach: The work, family, and health network effectiveness study.

Britt, T. W., \& Dawson, C. R. (2005). Predicting work-family conflict from workload, job attitudes, and health: A longitudinal study. Military Psychology, 17, 203-227.

Brockwood, K . J. (2002). An examination of positive work-family spillover among dualearner couples in the sandwiched generation. Unpublished doctoral dissertation. Portland State University.

Bronfenbrenner, U. (1979). The ecology of human development: Experiments by nature and design. Cambridge, MA: Harvard University Press.

Butler, A. B., Grzywacz, J. G., Bass, B. L., \& Linney, K. D. (2005). Extending the demands-control model: A daily diary study of job characteristics, work-family 
POSITIVE SPILLOVER AND SLEEP

conflict and work-family facilitation. Journal of Occupational Health Psychology, 78, 155-169.

Buxton, O. M., Hopcia, K., Sembajwe, G., Porter, J., Dennerlin, J. T., Kenwood, C., et al (in press). Relationship of sleep deficiency to perceived pain and physical disability in hospital patient care workers. Journal of Occupational and Environmental Medicine.

Buxton, O. M., \& Marcelli, E. (2010). Short and long sleep are positively associated with obesity, diabetes, hypertension, and cardiovascular disease among adults in the United States. Social Science and Medicine, 71, 1027-1036.

Buxton, O. M., Pavlova, M., Reid, E. W., Wang, W., Simonson, D. C., \& Adler, G. K. (2010). Sleep restriction for 1 week reduces insulin sensitivity in healthy men. Diabetes, 59, 2126-2133.

Buxton, O. M., Quintiliani, L. M., Yang, M. H., Ebbeling, C. B., Stoddard, A. M., Pereira, L. K., et al. (2009). Association of sleep insufficiency with more healthful food choices and positive workplace experiences among motor freight workers. American Journal of Public Health, 99, s636-s643.

Buysse, D. J., Reynolds, C. F., Monk, T. H., Berman, S. R., \& Kupfer, D. J. (1989). The Pittsburgh sleep quality index: A new instrument for psychiatric practice and research. Psychiatry Research, 28, 193-213.

Cameron, K. S., Dutton, J. E., \& Quinn, R. E. (2003). An introduction to positive organizational scholarship. In K. S. Cameron, J. E. Dutton, \& R. E. Quinn (Eds.), 
POSITIVE SPILLOVER AND SLEEP

Positive Organizational Scholarship (pp. 3-13). San Francisco, CA: BerrettKoehler.

Cappuccio, F. P., D’Elia, L., Strazzullo, P., \& Miller, M. A. (2010). Quantity and quality of sleep and incidence of type 2 diabetes. Diabetes Care, 33, 414-420.

Carlson, D. S., Ferguson, M., Kacmar, K. M., Grzywacz, J. G., \& Whitten, D. (2011). Pay it forward: The positive crossover effects of supervisor work-family enrichment. Journal of Management, 37, 770-789.

Carlson, D. S., Hunter, E. M., Ferguson, M., \& Whitten, D. (in press). Work-Family Enrichment and Satisfaction: Mediating Processes and Relative Impact of Originating and Receiving Domains. Journal of Management.

Carlson, D. S., Kacmar, K. M., Wayne, J. H., Grzywacz, J. G. (2006). Measuring the positive side of the work-family interface: Development and validation of a workfamily enrichment scale. Journal of Vocational Behavior, 68, 131-164.

Carlson, D. S., Witt, L. A., Zivnuska, S., Kacmar, M., \& Grzywacz, J. G. (2008). Supervisor appraisal as the link between family-work balance and contextual performance. Journal of Business Psychology, 23, 37-49.

Carlson, D., Zivnuska, S., Kacmar, K. M., Ferguson, M., Whitten, D. (2011). Workfamily enrichment and job performance: A constructive replication of affective events theory. Journal of Occupational Health Psychology, 16, 297-312.

Casper, L. M., King, R. B., Moen, P., Berkman, L., Davis, K., Durham, M., et al. (under review). Changing work, not workers: A work, family and health conceptual model. 
POSITIVE SPILLOVER AND SLEEP

Center for Disease Control and Prevention. (2011). Unhealthy sleep-related behaviors 12 states, 2009. Morbidity and Mortality Weekly Report, 60, 233-266.

Chen, Z., Powell, G. N., \& Greenhaus, J. H. (2009). Work-to-family conflict, positive spillover, and boundary management: a person-environment fit approach. Journal of Vocational Behavior, 74, 82-93.

Cinamon, R. G., \& Rich, Y. (2010). Work family relations: Antecedents and outcomes. Journal of Career Assessment, 18, 59-70.

Clark, L. A., Watson, D., \& Leeka, J. (1989). Diurnal variation in the positive affects. Motivation and Emotion, 13, 205-234.

Cohen, S., Doye, W. J., Turner, R. B., Alper, C. M., \& Skoner, D. P. (2003). Emotional style and susceptibility to the common cold. Psychosomatic Medicine, 65, 652657.

Cohen, S., \& Pressman, S. D. (2006). Positive affect and health. Current Directions in Psychological Science, 15, 122-125.

Cohen, S., \& Wills, T. A. (1985). Stress, social support, and the buffering hypothesis. Psychological Bulletin, 98, 310-357.

Collijn, D. H., Appels, A., \& Nijuis, F. (1996). Are multiple roles a risk factor for myocardial infarction for women? Journal of Psychosomatic Research, 40, 271279.

Connor, J., Norton, R., Ameratunga, S., Robinson, E., Civil, I., Dunn, J., et al. (2002). Driver sleepiness and risk of serious injury to car occupants: population based case control study. British Medical Journal, 324, 1125-1128. 
POSITIVE SPILLOVER AND SLEEP

Costa, G. (1996). The impact of shift and night work on health. Applied Ergonomics, 27(1), 9-16.

Crain, T. L., \& Hammer, L. B. (forthcoming). Work-family enrichment: A systematic review of antecedents, outcomes, and mechanisms. In A. B. Bakker (Ed.), Advances in positive organizational psychology. Bingley, UK: Emerald.

Crouter, A. C. (1984). Spillover from family to work: The neglected side of the workfamily interface. Human Relations, 37, 425-442.

Culbertson, S. S., Huffman, A. H., \& Alden-Anderson, R. (2010). Leader-member exchange and work-family interactions: The mediating role of self-reported challenge- and hinderance-related stress. The Journal of Psychology: Interdisciplinary and Applied, 144, 15-36.

Dahlgren, A., Kecklund, G., \& Akerstedt, T. (2006). Overtime work and its effects on sleep, sleepiness, cortisol and blood pressure in an experimental field study. Scandanavian Journal of Work and Environmental Health, 32, 318-327.

Demerouti, E., Bakker, A. B., \& Shaufeli, W. B. (2005). Spillover and crossover of exhaustion and life satisfaction among dual-earner parents. Journal of Vocational Behavior, 67, 266-289.

Devine, C. M., Jastran, M., Jabs, J., Wethington, E., Farell, T. J., \& Bisogni, C. A. (2006). "A lot of sacrifices:” Work-family spillover and the food choice coping strategies of low-wage employed parents. Social Science and Medicine, 63, 25912603. 
Dienesch, R. M., \& Liden, R. C. (1986). Leader-member exchange model of leadership: A critique and further development. The Academy of Management Review, 11, 618-634.

Eby, L. T., Casper, W. J., Lockwood, A., Bordeaux, C., \& Brinley, A. (2005). Work and family research in IO/OB: Content analysis and review of the literature (19802002). Journal of Vocational Behavior, 66, 124-197.

Edell-Gustafsson, U. M., Kritz, E. I. K., \& Bogren, I. K. (2002). Self-reported sleep quality, strain and health in relation to perceived working conditions in females. Scandanavian Journal of Caring Sciences, 16, 179-187.

Edwards, J. R., \& Lambert, L. S. (2007). Methods for integrating moderation and mediation: A general analytical framework using moderated path analysis. Psychological Methods, 12, 1-22.

Edwards, J. R., \& Rothbard, N. P. (2000). Mechanisms linking work and family: Clarifying the relationship between work and family constructs. Academy of Management Review, 25, 178-199.

Etzion, D. (1984). Moderation effect of social support on the stress-burnout relationship. Journal of Applied Psychology, 694, 615-622.

Fields, J., \& Casper, L. (2004). America's families and living arrangements: Population characteristics. Washington, DC: U.S. Bureau of the Census.

Franche, R. L., Williams, A., Ibrahim, S., Grace, S. L., Mustard, C., Minore, B., \& Stewart, D. E. (2006). Path analysis of work conditions and work-family spillover 
POSITIVE SPILLOVER AND SLEEP

as modifiable workplace factors associated with depressive symptomology. Stress and Health, 22, 91-103.

Fredrickson, B. L. (1998). What are good positive emotions? Review of general psychology, 2, 1089-2680.

Frone, M. R. (2003). Work-family balance. In J. C. Quick \& L. E. Tetrick (Eds.), Handbook of occupational health psychology (pp. 143-162). Washington, DC: American Psychological Association.

Frone, M. R., Yardley, J. K., \& Markel, K. S. (1997). Developing and testing an integrative model of the work-family interface. Journal of Vocational Behavior, $50,145-167$.

Frye, N., \& Breaugh, J. A. (2004). Family-friendly policies, supervisor support, workfamily conflict, family-work conflict, and satisfaction: A test of a conceptual model. Journal of Business and Psychology, 19, 197-220

Gangwisch, G. E., Malaspina, D., Boden-Albala, B., \& Heymsfield, S. B. (2005). Inadequate sleep as a risk factor for obesity: Analyses of the NHANES I. SLEEP, $28,1289-1296$.

Gareis, K. C.,Barnett, R. C., Ertel, K. A., \& Berkman, L. F. (2009). Work-family enrichment and conflict: Additive effects, buffering, or balance? Journal of Marriage and Family, 71, 696-707.

Gilbreth, B., \& Benson, P. G. (2004). The contribution of supervisor behavior to employee psychological well-being. Work \& Stress, 18, 255-266. 
POSITIVE SPILLOVER AND SLEEP

Glass, J., \& Fujimoto, T. (1995). Employer characteristics and the provision of family responsive policies. Work and Occupations, 22, 380-411.

Goff, S. J., Mount, M. K., \& Jamison, R. L. (1990). Employer supported childcare, work/family conflict and absenteeism: A field study. Personnel Psychology, 43, 793-809.

Goldstein, H. (2010). Multilevel statistical models ( $4^{\text {th }}$ ed.). New York, NY: Wiley.

Goode, W. J. (1960). A theory of role strain. American Sociological Review, 25, 483-496.

Goodstein, J. D. (1994). Institutional pressures and strategic responsiveness: Employer involvement in work-family issues. The Academy of Management Journal, 37, $350-382$.

Gorgievski-Duijvesteijn, M. J., Geisen, C. W. M., \& Bakker, A. B. (2000). Financial problems and health complaints among farm couples: Results of a 10-year followup study. Journal of Occupational Health Psychology, 5, 359-373.

Gottlieb, D. J., Redline, S., Nieto, F. J., Baldwin, C. M., Newman, A. B., Resnick, H. E. (2006). Association of usual sleep duration with hypertension: The sleep heart health study. SLEEP, 29, 1009-1014.

Graen, G., \& Cashman, J. (1975). A role-making model of leadership in formal organizations: A developmental approach. In J. G. Hunt \& L. L. Larson (Eds.), Leadership Frontiers (pp. 143-166). Kent, OH: Kent State University Press.

Graen, G. B., \& Scandura, T. A. (1987). Toward a psychology of dyadic organizing. Research In Organizational Behavior, 9, 175-208. 
Graves, L. M., Ohlott, P. J., \& Ruderman, M. N. (2007). Commitment to family roles: Effects on managers' attitudes and performance. Journal of Applied Psychology, 92, 44-56.

Greenberg, J. (2006). Losing sleep over organizational injustice: Attenuating insomniac reactions to underpayment inequity with supervisory training in interactional justice. Journal of Applied Psychology, 91, 58-69.

Greenhaus, J. H., \& Beutell, N. J. (1985). Sources of conflict between work and family roles. Academy of Management Review, 10, 76-88.

Greenhaus, J. H. \& Parasuraman, S. (1999). Research on work, family, and gender: Current status and future directions. In G. Powell (Ed.), Handbook of gender and work (pp. 391-412). Thousand Oaks, CA: Sage Publications, Inc.

Greenhaus, J. H., Parasuraman, S., Granrose, C. S., Rabinowitz, S., \& Beutell, N. J. (1989). Sources of work-family conflict among two-career couples. Journal of Vocational Behavior, 34, 133-153.

Greenhaus, J. H., \& Powell, G. N. (2006). When work and family are allies: A theory of work-family enrichment. Academy of Management Review, 31, 72-92.

Greenhaus, J. H., \& Powell, G. N. (2010). Sex, gender, and the work-to-family interface: Exploring negative and positive interdependencies. Academy of Management Journal, 53, 513-534.

Grossi, G., Perski, A., Ekstedt, M., Johansson, T., Lindstrom, M., Holm, K. (2005). The morning salivary cortisol response in burnout. Journal of Psychosomatic Research, 59, 103-111. 
POSITIVE SPILLOVER AND SLEEP

Grzywacz, J. G. (2000). Work-family positive spillover and health during midlife: Is managing conflict everything? American Journal of Health Promotion, 14, 236243.

Grzywacz, J. G., Almeida, D. M., \& McDonald, D. A. (2002). Work-family spillover and daily reports of work and family stress in the adult labor force. Family Relations, $51,28-36$.

Grzywacz, J. G., \& Bass, B. L. (2003). Work, family, and mental health: Testing different models of work-family fit. Journal of Marriage and Family, 65, 248-262.

Grzywacz, J. G., \& Butler, A. B. (2005). The impact of job characteristics on workfamily facilitation: Testing a theory and distinguishing a construct. Journal of Occupational Health Psychology, 10, 97-109.

Grzywacz, J. G., Carlson, D. S., Kacmar, K . M., \& Holliday, W. (2007). A multi-level perspective on the synergies between work and family. Journal of Occupational and Organizational Psychology, 80, 559-574.

Grzywacz, J. G., \& Marks, N. F. (2000). Family, work, work-family positive spillover, and problem drinking during midlife. Journal of Marriage and Family, 62, 336348.

Grzywacz, J. G., \& Marks, N. F. (2000). Reconceptualizing the work-family interface: An ecological perspective on the correlates of positive and negative spillover between work and family. Journal of Occupational Health Psychology, 5, 111126.

Guilleminault C., van den Hoed, J., \& Mitler, M.M. (1978). Clinical overview 
POSITIVE SPILLOVER AND SLEEP

of the sleep apnea syndromes. In C. Guilleminault, W. C. Dement (Eds.), Sleep Apnea Syndromes. New York, NY: Alan R. Liss.

Haar, J. M., \& Bardoel, E. A. (2008). Positive spillover form the work-family interface: A study of Australian employees. Asia Pacific Journal of Human Resource, 46, 275-287.

Hahn, V. C., Binnewies, C., Sonnentag, S., \& Mojza, E. J. (2011). Learning how to revover from job stress: Effects of a recovery training program on recovery, recovery-related self-efficacy, and well-being. Journal of Occupational Health Psychology, 16, 202-216.

Hakanen, J. J., Peeters, M. C. W., \& Perhoniemi, R. (2011). Enrichment processes and gain spirals at work and at home: A 3-year cross-lagged panel study. Journal of Occupational and Organizational Psychology, 84, 8-30.

Hammer, L. B., Allen, E., \& Grigsby, T. D. (1997). Work-family conflict in dual-earner couples: Within-individual and crossover effects of work and family. Journal of Vocational Behavior, 50, 185-203.

Hammer, L. B., Bauer, T. N., \& Grandey, A. A. (2003). Work-family conflict and workrelated withdrawal behaviors. Journal of Business Psychology, 17, 419-436.

Hammer, L.B., Colton, C. L., Caubet, S., \& Brockwood, K. B. (2002). The unbalanced life: Work and family conflict. In J. C. Thomas \& M. Hersen (Eds.), Handbook of Mental Health In the Workplace (pp. 83-101). Newbury Park: Sage Publications.

Hammer, L. B., Cullen, J. C., Neal, M. B., Sinclair, R. R., \& Shafiro, M. V. (2005). The longitudinal effects of work-family conflict and positive spillover on depressive 
POSITIVE SPILLOVER AND SLEEP

symptoms among dual-earner couples. Journal of Occupational Health Psychology, 10, 138-154.

Hammer, L. B., Kossek, E. E., Bodner, T., \& Crain, T. L. (under review). Measurement development and validation of the family supportive supervisor behavior shortform.

Hammer, L. B., Kossek, E. E., Yragui, N. L., Bodner, T. E., \& Hanson, G. C. (2009). Development and validation of a multidimensional measure of family supportive supervisor behaviors (FSSB). Journal of Management, 35, 837-856.

Hammer, L. B., Kossek, E. E., Zimmerman, K.., \& Daniels, R. (2007). Clarifying the Construct of Family-Supportive Supervisory Behaviors (FSSB): A Multilevel Perspective. In P.L. Perrewe, \& D. C. Ganster (Eds.). Exploring the Work and Non-work Interface (pp. 165-204). Oxford, UK: Elsevier Ltd.

Hammer, L. B., \& Zimmerman, K. L. (2011). Quality of work life. In S. Zedeck (Ed.), APA Handbook of Industrial and Organizational Psychology (pp. 399-431). Washington, DC: American Psychological Association.

Hanson, G. C., Hammer, L. B., \& Colton, C. L. (2006). Development and validation of a multidimensional scale of perceived work-family positive spillover. Journal of Occupational Health Psychology, 11, 249-265.

Harris, E. A.. (2011, April 16). F.A.A. to change air traffic controllers' schedules. New York Times. Retrieved May 3, 2011, from http://www.nytimes.com 
POSITIVE SPILLOVER AND SLEEP

Hecht, T. D., \& Boies, K. (2009). Structure and correlates of spillover from nonwork to work: An examination of nonwork activities, well-being, and work outcomes. Journal of Occupational Health Psychology, 14, 414-426.

Hecht, T. D., \& McCarthy, J. M. (2010). Coping with employee, family, and student roles: Evidence of dispositional conflict and facilitation tendencies. Journal of Applied Psychology, 95, 631-647.

Heller, D., \& Watson, D. (2005). The dynamic spillover of satisfaction between work and marriage: The role of time and mood. Journal of Applied Psychology, 90, 12731279.

Hill, J. E. (2005). Work-family facilitation and conflict, working fathers and mothers, work-family stressors and support. Journal of Family Issues, 26, 793-819.

Hill, J. E., Allen, S., Jacob, J., Bair, A. F., Bikhazi, S. L., Langeveld, A. V., et al. (2007). Work-family facilitation: Expanding theoretical understanding through qualitative exploration. Advances in Developing Human Resources, 9, 507-526.

Hobfoll, S. E. (1989). Conservation of resources: A new attempt at conceptualizing stress. American Psychologist, 44, 513-524.

Horowitz, B. N., Luong, G., \& Charles, S. T. (2008). Neuroticism and extraversion share genetic and environmental effects with negative and positive mood spillover in a national representative sample. Personality and Individual Differences, 45, 636642. Health Psychology, 11, 249-265.

House, J. S. (1981). Work stress and social support. Reading, MA: Addison-Wesley. 
Howe, G. W., Levy, M. L., \& Caplan, R. D. (2004). Job loss and depressive symptoms in couples: Common stressors, stress transmission, or relationship disruption. Journal of Family Psychology, 18, 639-650.

Hox, J. J. (2010). Multilevel analysis: Techniques and applications ( $2^{\text {nd }}$ ed.). New York, NY: Routledge.

Huffman, A. H., Adler, A. B., Calhoun, M., \& Castro, C. A. (2001). Measuring sleep and work demands in U.S. Army senior leaders. Washington, DC: U. S. Government Printing Office.

Hunter, E. M., Perry, S. J., Carlson, D. S., \& Smith, S. A. (2010). Linking team resources to work-family enrichment and satisfaction. Journal of Vocational Behavior, 77, 304-312.

Ilies, R., Wilson, K. S., \& Wagner, D. T. (2009). The spillover of daily job satisfaction onto employees' family lives: The facilitating role of work-family integration. Academy of Management Journal, 52, 87-102.

Ingram, P., \& Simmons, T. (1995). Institutional and resource dependence determinants of responsiveness to work-family issues. The Academy of Management Journal, 38, 1466-1482.

Innstrand, S. T., Langballe, E. M., Espnes, G. A., Falkum, E., \& Aasland, O. G. (2008). Positive and negative work-family interaction and burnout: A longitudinal study of the reciprocal relations. Work \& Stress, 22, 1-15.

Innstrand, S. T., Langballe, E. M., Espnes, G. A., Aasland, O. G., \& Falkum, E. (2010). Personality vulnerability and work-home interaction: The effect of job 
POSITIVE SPILLOVER AND SLEEP

performance-based self-esteem on work/home conflict and facilitation.

Scandanavian Journal of Psychology, 51, 480-487.

Innstrand, S. T., Langballe, E. M., \& Falkum, E. (2010). Exploring occupational differences in work-family interaction: Who is at risk? International Journal of Stress Management, 17, 38-55.

Innstrand, S. T., Langballe, E. M., Falkum, E., Espnes, G. A., \& Aasland, O. G. (2009). Gender-specific perceptions of four dimensions of the work/family interaction. Journal of Career Assessment, 17, 402-415.

Innstrand, S. T., Langballe, E. M., Espnes, G. A., Aasland, O. G., \& Falkum, E. (2010). Work-home conflict and facilitation across four different family structures in Norway. Community, Work \& Family, 13, 231-249.

Ispa, J. M., Gray, M. M., \& Thornburg, K. R. (1984). Childrearing attitudes of parents in person oriented and thing oriented occupations: A comparison. Journal of Psychology, 117, 245-250.

Jacques, C., Lynch, J. C., \& Samkoff, J. S. (1999). The effects of sleep loss on cognitive performance of resident physicians. Journal of Family Practice, 30, 223-229.

Jacquinet-Salford, M. C., Lang, T., Fouriaud, C., Nicoulet, I., \& Bingham, A. (1993). Sleeping tablet consumption, self-reported quality of sleep, and working conditions. Journal of Epidemiology and Community Health, 47, 64-68.

Johnson, J. V., \& Hall, E. M. (1988). Job strain, work place social support, and cardiovascular disease: A cross-sectional study of a random sample of the Swedish working population. American Journal of Public Health, 78, 1336-1342. 
Jones, F., \& Fletcher, B. C. (1993). An empirical study of occupational stress transmission in working couples. Human Relations, 46, 881-903.

Judge, T. A., \& Ilies, R. (2004). Affect and job satisfaction: A study of their relationship at work and at home. Journal of Applied Psychology, 89, 661-673.

Kahn, R. L., Wolfe, D. M., Quinn, R., Snoek, J. D., \& Rosenthal, R. A. (1964). Organizational Stress. New York: Wiley.

Kalimo, R., Tenkanen, L., Harma, M., Poppius, E., \& Heinsalmi, P. (2000). Job stress and sleep disorders: Findings from the Helskinki heart study. Stress Medicine, 16, $67-75$.

Karambayya, R., \& Reilly, A. H. (1992). Dual earner couples: Attitudes and actions in restructuring work for family. Journal of Organizational Behavior, 13, 585-601.

Karasek, R. A. (1979). Job demands, job decision latitude, and mental strain: Implications for job redesign. Administrative Science Quarterly, 24, 285-308.

Karasek, R. A., Triantis, K. P., \& Chaudhry, S. S. (1982). Coworker and supervisor support as moderators of associations between task characteristics and mental strain. Journal of Occupational Behavior, 3, 181-200.

Karatepe, O. M., \& Bekteshi, L. (2008). Antecedents and outcomes of work-family facilitation and family-work facilitation among frontline hotel employees. International Journal of Hospitality Management, 27, 517-528.

Karatepe, O. M., \& Kilic, H. (2009). The effects of two directions of conflict and facilitation on frontline employees' job outcomes. The Service Industries Journal, 29, 977-993. 
Karatepe, O. M., \& Magaji, A. B. (2008). Work-family conflict and facilitation in the hotel industry: A study in Nigeria. Cornell Hospitality Quarterly, 49, 395-412.

Karimi, L., \& Nouri, A. (2009). Do work demands and resources predict work-to-family conflict and facilitation? A study of Iranian male employees. Journal of Family and Economic Issues, 30, 193-202.

Katz, D., \& Kahn, R. L. (1978). The social psychology of organizations. New York: Wiley.

Kelly, E. L. (2006). Work-family policies: The United States in international perspective. In M. Pitt-Catsouphes, E. E. Kossek, \& S. Sweet (Eds.), The work and family handbook: Multi-disciplinary perspectives and approaches (99-123). Mahwah, NJ: Lawrence Erlbaum.

Kelly, E. L., \& Dobbin, F. (1999). Civil rights law at work: Sex discrimination and the rise of maternity leave policies. American Journal of Sociology, 105, 455-449.

Kessler, R. C., Berglund, P. A., Coulouvrat. C., Hajak, G., Roth, T., .. Walsh, J. K. (2011). Insomnia and the performance of US workers: Results from the America Insomnia Survey. SLEEP, 34, 1161-1171.

King, E. B., Botsford, W. E., Huffman, A. H. (2009). Work, family, and organizational advancement: Does balance support the perceived adcancement of mothers? Sex Roles, 61, 879-891.

King, R. B., Karuntzos, G., Casper, L., Moen, P., Davis, K., Berkman, L., Durham, M. \& Kossek, E. (2012). Work-family balance issues and work-leave policies. In R. 
POSITIVE SPILLOVER AND SLEEP

J. Gatchel \& Izabela Z. Schultz (Eds.), Handbook of occupational health and wellness. New York: Springer.

Kinnunen, U., Feldt, T., Geurts, S., \& Pulkkinen, L. (2006). Types of work-family interface: Well-being correlates of negative and positive spillover between work and family. Scandinavian Journal of Psychology, 47, 149-162.

Kirchmeyer, C. (1992a). Nonwork participation and work-attitudes: A test of scarcity vs. expansion models of personal resource. Human Relations, 45, 775-795.

Kirchmeyer, C. (1992b). Perceptions of nonwork-to-work spillover: Challenging the common view of conflict-ridden domain relationships. Basic \& Applied Social Psychology, 13, 231-249.

Kirchmeyer, C. (1993). Nonwork-to-work spillover: A more balanced view of the experiences and coping of professional women and men. Gender Roles, 28, 531552.

Knudsen, H. K., Ducharme, L. J., \& Roman, P. M. (2007). Job stress and poor sleep quality: Data from an American sample of full-time workers. Social science \& Medicine, 64, 1997-2007.

Kohatsu, N. D., Tsai, R., Yong, T., VanGilder, R., Burmeister, L. F., Stromquist, A. M., et al. (2006). Sleep duration and body mass index in a rural population. Archives of Internal Medicine, 166, 1701-1705.

Kohn, M. L. (1963). Social class and parent-child relationships: An interpretation. American Journal of Sociology, 68, 471-480. 
Kossek, E. (2005). Workplace policies and practices to support work and families. In S. Bianchi, L. Casper, \& R. King (Eds.), Work, Family, Health \& Well-being (pp. 97-116). Mahwah, NJ: LEA Press.

Kossek, E. E., \& Nichol, V. (1992). The effects of on-site child care on employee attitudes and performance. Personnel Psychology, 45, 485-509.

Krauss, A. D., Chen, P. Y., DeArmond, S., \& Moorcroft, B. (2003). Sleepiness in the workplace: Causes, consequences, and countermeasures. In C. L. Cooper \& I. T. Robertson (Eds.), International Review of Industrial and Organizational Psychology (pp. 81-129). West Sussex, England: John Wiley \& Sons Ltd.

Kwan, H. K., \& Mao, Y. (2011). The role of citizenship behavior in personal learning and work-family enrichment. Fronteirs of Business Research in China, 5, 96-120.

Kwan, H. K., Mao, Y., \& Zhang, H. (2010). The impact of role modeling on protégés personal learning and work-to-family enrichment. Journal of Vocational Behavior, 77, 313-322.

Lallukka, T., Rahkonen, O., Lahelma, E., \& Arber, S. (2010). Sleep complaints in middle-aged women and men: The contribution of working conditions and workfamily conflicts. Journal of Sleep Research, 19, 466-477.

Lapierre, L. M., \& Allen, T. D. (2006). Work-supportive family, family-supportive supervision, use of organizational benefits, and problem-focused coping: Implications for work-family conflict and employee well-being. Journal of Occupational Health Psychology, 11, 169-181. 
LaRocco, J. M., House, J. S., \& French, J. R. P. (1980). Social support, occupational stress, and health. Journal of Health and Social Behavior, 21, 202-218.

Lockwood, C. M., \& MacKinnon, D. P. (1998). Bootstrapping the standard error of the mediated effect. In Proceedings of the $23^{\text {rd }}$ Annual SAS Users Group International Conference (pp. 997-1002).

Lourel, M., Ford, M. T., Gamassou, C. E., Gueguen, N., \& Hartmann, A. (2009). Negative and positive spillover between work and home. Journal of Managerial Psychology, 24, 438-449.

Lu, J. F., Siu, O. L., Spector, P. E., \& Shi, K. (2009). Antecedents and outcomes of a fourfold taxonomy of work-family balance in Chinese employed parents. Journal of Occupational Health Psychology, 14, 182-192.

Luna, T. D., French, J., \& Mitcha, J. L. (1997). A study of usaf air traffic controller shiftwork: Sleep, fatigue, activity, and mood analyses. Aviation, space, and environmental medicine, $68,18-23$.

MacKinnon, D. P. (2008). Introduction to statistical mediation analysis. New York, NY: Lawrence Erlbaum Associates.

MacKinnon, D. P., Lockwood, C. M., Hoffman, J. M., \& West, S. G. (2002). A comparison of methods to test mediation and other intervening variable effects. Psychological Methods, 7, 83-104.

Mallon, L., Broman, J. E., \& Hetta, J. (2005). High incidence of diabetes in men with sleep complaints. Diabetes Care, 28, 2762-2767. 
Marks, S. R. (1977). Multiple roles and role strain: Some notes on human energy and time commitment. American Sociological Review, 2, 921-936.

Marks, S. R., \& MacDermid, S. M. (1996). Multiple roles and the self: A theory of role balance. Journal of Marriage and Family, 58, 417-432.

Masuda, A. D., McNall, L. A., Allen, T. D., \& Nicklin, J. M. (2012). Examining the constructs of work-to-family enrichment and positive spillover. Journal of Vocational Behavior.

McNall, L. A., Nicklin, J. M., \& Masuda, A. (2010). A meta-analytic review of the consequences associated with work-family enrichment. Journal of Business Psychology, 25, 381-396.

Mead, G. H. (1934). Mind, Self, and Society. Chicago: University of Chicago Press. Meijman, T. F., \& Mulder, G. (1998). Psychological aspects of workload. In P. J. D. Drenth \& H. Thierry (Eds.), Handbook of work and organizational psychology, Vol. 2: Work psychology (pp. 5-33). Hove, England: Psychology Press.

Melamed, S., \& Oksenberg, A. (2002). Excessive Daytime Sleepiness and Risk of Occupational Injuries in Non-Shift Daytime Workers. Journal of Sleep and Sleep Disorders Research, 25, 315-321.

Melamed, S., Ugarten, U., Shirom, A., Kahana, L., Lerman, Y., \& Froom, P. (1999). Chronic burnout, somatic arousal and elevated salivary cortisol levels. Journal of Psychosomatic Research, 46, 591-598. 
Mezick, E. J., Matthews, K. A., Hall, M., Strollo, P. J., Buysse, D. J., Karmack, T. W., et al. (2008). Influence of race and socieoeconomic status on sleep: Pittsburgh SleepScore project. Journal of Biobehavioral Medicine, 70, 410-416.

Michel, J. S., Clark, M. A., \& Jaramillo, D. (2011). The role of the five factor model of personality in the perceptions of negative and positive forms of work-nonwork spillover: A meta-analytic review. Journal of Vocational Behavior, 79, 191-203.

Milliken, F. J., Martins, L. L., \& Morgan, H. (1998). Explaining organizational responsiveness to work-family issues: The role of human resource executives as issue interpreters. Academy of Management Journal, 41, 580-592

Mitler, M. M., Carskadon, M. A., Czeisler, C. A., Dement, W. C., Dinges, D. F., \& Graeber, R. C. (1988). Catastrophes, sleep, and public policy: Consensus Report. SLEEP, 11, 100-109.

Muller, D., Judd, C. M., \& Yzerbyt, V. Y. (2005). When moderation is mediated and mediation is moderated. Journal of Personality and Social Psychology, 89, 852863.

Mulvaney, M. K., McNall, L. A., \& Morrissey, R. A. (2011). A longitudinal investigation of work-family strains and gains, work commitment, and subsequent employment status among partnered working mothers. Journal of Family Issues, 32, 292-316.

Muthén, L., \& Muthén, B. (1998-2010). Mplus user's guide. Los Angeles: Muthen \& Muthen. 
Nakata, A., Ikeda, T., Takahashi, M., Haratani, T., Fukui, S., Swanson, N. G., et al. (2005). Sleep-related risk of occupational injuries in Japanese small and mediumscale enterprises. Industrial Health, 43, 89-97.

Nasermoaddeli, A., Sekine, M., Kumari, M., Chandola, T., Marmot, M., \& Kagamimori, S. (2005). Association of sleep quality and free time leisure activities in Japanese and British civil servants. Journal of Occupational Health, 47, 384-390.

National Center on Sleep Disorders Research. (2011). National Institutes of Health Sleep disorders research plan (NIH Publication No. 11-7820).

National Sleep Foundation (2011, March 7). Sleepy connected Americans: National sleep foundation releases annual sleep in America poll exploring connections with communications technology use and sleep. National Sleep Foundation. Retrieved August, 22, 2011, from http://www.sleepfoundation.org/article/pressrelease/annual-sleep-america-poll-exploring-connections-communicationstechnology-use-.

Neal, M. B., \& Hammer, L. B. (2007). Working couples caring for children and aging parents: Effects on work and well-being. Mahwah, NJ: Lawrence Erlbaum Associates.

National Heart, Lung, and Blood Institute Working Group on Insomnia. (1999). Insomnia: Assessment and management in primary care. American Family Physician, 59, 3029-3038. 
Nomura, K., Nakao, M., Takeuchi, T., \& Yano, E. (2009). Associations of insomnia with job strain, control, and support among male Japanese workers. Sleep Medicine, $10,626-629$.

NTSB. (1990). Fatigue, alcohol, other drugs, and medical factors in fatal-to-thedriver heavy truck crashes (Safety Study NTSB/SS-90/01). Washington, DC: National Transportation Safety Board.

NTSB. (1999). Evaluation of U.S. Department of Transportation: efforts in the 1990s to address operation fatigue (No. Safety Report NTSB/SR-99/01). Washington, DC: National Transportation Safety Board.

O’Driscoll, M. P., Poelmans, S., Spector, P. E., Kalliath, T., Allen, T. D., Cooper, C. L., et al. (2003). Family-responsive interventions, perceived organizational and supervisor support, work-family conflict, and psychological strain. International Journal of Stress Management, 210, 326-344.

O’Neill, J. W., Harrison, M. M., Cleveland, J., Almeida, D., Stawski, R., \& Crouter, A. C. (2009). Work-family climate, organizational commitment, and turnover: Multilevel contagion effects of leaders. Journal of Vocational Behavior, 74, 1829.

Osterman, P. (1995). Work-family programs and the employment relationship. Administrative Science Quarterly, 40, 681-700

Parasuraman, S., \& Greenhaus, J. H. (2002). Toward reducing some critical gaps in the work-family research. Human Resource Management Review, 12, 299-312. 
Parasuraman, S., Greenhaus, J. H., \& Granrose, C. S. (1992). Role stressors, social support, and well-being among two-career couples. Journal of Organizational Behavior, 13, 339-356.

Patel, S. R., \& Hu, F. B. (2008). Short sleep duration and weight gain: A systematic review. Obesity, 16, 643-653.

Pearlin, L., \& Kohn, M. (1966). Social class, occupational and parental values: A cross national study. American Sociological Review, 31, 466-479.

Pedersen, D. E., Minnote, K. L., Kiger, G., \& Mannon, S. E. (2009). Workplace policy and environment, family role quality, and positive family-to-work spillover. Journal of Family and Economic Issues, 30, 80-89.

Philibert, I. (2005). Sleep loss and performance in residents and nonphysicians: A metaanalytic examination. SLEEP, 28, 1392-1402.

Pictromanoco, P. R., Manis, J., \& Frohardt-Lane, K. (1986). Psychological consequences of multiple social roles. Psychology of Women Quarterly, 10, 373-382.

Poppleton, S., Briner, R. B., \& Kiefer, T. (2008). The roles of context and everyday experience in understanding work-non-work relationships: A qualitative diary study of white- and blue-collar workers. Journal of Occupational and Organizational Psychology, 81, 481-502.

Powell, G. N. \& Greenhaus, J. H., (2010). Sex, gender, and the work-to-family interface: Exploring negative and positive interdependencies. Academy of Management, 53, 513-534. 
POSITIVE SPILLOVER AND SLEEP

Powell, G. N., \& Greenhaus, J. H. (2006). Is the opposite of positive negative? Untangling the complex relationship between work-family enrichment and conflict. Career development international, 11, 650-659.

Preacher, K. J., Rucker, D. D., \& Hayes, A. F. (2007). Addressing moderated mediation hypotheses: Theory, methods, and prescriptions. Multivariate Behavioral Research, 42, 185-227.

Pressman, S. D., \& Cohen, S. (2005). Does positive affect influence health? Psychological Bulletin, 131, 925-971.

Prince, M., Manolis, C., \& Minetor, R. (2007). Life satisfaction crossover among couples. In R. J. Estes (Ed.). Advancing quality of life in a turbulent world (pp. 191-208). Netherland: Springer.

Raabe, P. H. (1990). The organizational effects of workplace family policies: Past weaknesses and recent progress toward improved research. Journal of Family Issues, 11, 477-487.

Rafaeli, A., \& Sutton, R. I. (1987). Busy stores and demanding customers: How do they affect the display of positive emotion? Academy of Management Review, 33, 623637.

Raggat, P. T. F. (1991). Work stress among long-distance coach drivers: A survey and correlational study. Journal of Organizational Behavior, 12, 565-579.

Rajaratnam, S. M. W., Barger, L. K., Lockley, S. W., Shea, S. S., Wang, W., Landrigan, C. P., .. C Czeisler, C. A. (2011). Sleep disorders, health, and safety in police officers. Journal of the American Medical Association, 23, 2567-2578. 
Reyner, L. A., Horne, J. A., \& Reyner, A. (1995). Gender- and age-related differences in sleep determined by home-recorded sleep logs and actimetry from 400 adults. SLEEP, $18,127-134$.

Ribet, C., \& Derriennic, F. (1999). Age, working conditions, and sleep disorders: A longitudinal analysis in the French cohort E.S.T.E.V. Journal of Sleep Research and Sleep Medicine, 22, 491-504.

Riemann, D., Berger, M., \& Voderholzer, U. (2001). Sleep and depression - results from psychobiological studies: an overview. Biological Psychology, 57, 67-10.

Roche, M., \& Haar, J. M. (2010). Work-family interface predicting needs satisfaction: The benefits for senior management. E-Journal of Social and Behavioral Research in Business, 1(1), 12-23.

Rogers, S. J., \& May, D. C. (2003). Spillover between marital quality and job satisfaction: Long-term patterns and gender differences. Journal of Marriage and family, 65, 482-495.

Roth, T., Coulouvrat, C., Hajak, G., Lakoma, M. D., Sampson, N. A., Shahly, V., ... Kessler, R. C. (2011). Prevalence and perceived health associated with insomnia based on DSM-IV-TR; International Statistical Classification of Diseases and Related Health Problems, Tenth Revision; and Research Diagnostic Criteria/International Classification of Sleep Disorders, Second Edition Criteria: Results from the America insomnia survey. Biological Psychiatry, 69, 592-600. Rothausen, T. J. (1999). "Family" in organizational research: A review and comparison of definitions and measures. Journal of Organizational Behavior, 20, 817-836. 
POSITIVE SPILLOVER AND SLEEP

Rothbard, N. P. (2001). Enriching or depleting? The dynamics of engagement in work and family roles. Administrative Science Quarterly, 46, 655-684.

Rotondo, D. M., \& Kincaid, J. F. (2008). Conflict, facilitation, and individual coping styles across the work and family domains. Journal of Managerial Psychology, 23, 484-506.

Rozario, P. A., Morrow-Howell, N., \& Hinterlong, J. E. (2004). Role enhancement or role strain: Assessing the impact of multiple productive roles on older caregiver well-being. Research on Aging, 26, 413-428.

Ruderman, M. N., Ohlott, P. J., Panzer, K., \& King, S. N. (2002). Benefits of multiple roles for managerial women. Academy of Management Journal, 45, 369-386.

Salovey, P., \& Birnbaum, D. (1989). Influence of mood on health-relevant cognitions. Journal of Personality and Social Psychology, 57, 539-551.

Salovey, P., Rothman, A. J., Detweiler, J. B., \& Steward, W. T. (2000). Emotional states and physical health. American Psychologist, 55, 110-121.

Sanz-Vergel, A. I., Demerouti, E., Mayo, M., \& Moreno-Jimenez, B. (2011). Work-home interaction and psychological strain: The moderating role of sleep quality. Applied Psychology: An International Review, 60, 210-230.

Schneewind, K. A., Reeb, C., \& Kupsch, M. (2010). Bidirectional work-family spillover and work-family balance: How are they related to personal distress and global stress? Family Science, 1, 123-134. 
Schwarz, N., \& Clore, G. L. (1983). Mood, misattribution, and judgments of well-being: Informative and directive functions of affective states. Journal of Personality and Social Psychology, 45, 513-523.

Schwarz, N.,\& Clore, G. L. (1996). Feelings and phenomenal experiences. In E. T. Higgins \& A. Kruglanski (Eds.), Social psychology:Handbook of basic principles (pp. 433-465). New York:Guilford.

Scott, B. A., \& Judge, T. A. (2006). Insomnia, emotions, and job satisfaction: A multilevel study. Journal of Management, 32, 622-645.

Seery, B. L., Corrigall, E. A., \& Harpel. T. (2008). Job-related emotional labor and its relationship to work-family conflict and facilitation. Journal of Family Economic Issues, 29, 461-477.

Sekine, M., Chandola, T., Martikainen, P., Marmot, M., \& Kagamimori, S. (2006). Work and family characteristics as determinants of socioeconomic and sex inequalities in sleep: The Japanese civil servants study. SLEEP, 29, 206-216.

Seligman, M. E. P. (1998). Learned optimism: How to change your mind and your life ( $2^{\text {nd }}$ ed.). New York: Pocket Books.

Seligman, M. E. P., \& Csikszentmihalyi, M. (2000). Positive psychology: An introduction. American Psychologist, 55, 5-14.

Shimizu, T., Eto, R., Horiguchi, I., Obata, Y., Feng, Q., Nagata, S. (2005). Relationship between turnover and periodic health check-up data among Japanese hospital nurses: A three-year follow-up study. Journal of Occupational Health, 47, 327333. 
Shockley, K. M., \& Singla, N. (2011). Reconsidering work-family interactions and satisfaction: A meta-analysis. Journal of Management, 37, 861-886.

Sieber, S. D. (1974). Toward a theory of role accumulation. American Sociological Review, 39, 467-478.

Siu, O., Lu, J., Brough, P., Lu, C., Bakker, A. B., Kalliath, T., et al. (in press). Role resources and work-family enrichment: the role of work engagement. Journal of Vocational Behavior.

Sobel, M. E. (1982). Asymptotic confidence intervals for indirect effects in structural equation models. In S. Leinhardt (Ed.), Sociological methodology (pp. 290-212). San Francisco, CA: Jossey-Bass.

Soderstrom, M., Ekstedt, M., Akerstedt, T., Nilsson, J., \& Axelsson, J. (2004). Sleep and sleepiness in young individuals with high burnout scores. Sleep in Psychiatric Disease, 27, 1369-1377.

Sonnentag, S., \& Fritz, C. (2007). The recovery experience questionnaire: Development and validation of a measure for assessing recuperation and unwinding from work. Journal of Occupational Health Psychology, 3, 204-221.

Sorenson, G., Stoddard, A. M., Stoffel, S. S., Buxton, O., Sembajwe, G., Hashimoto, D., et al. (2011). The role of the work context in multiple wellness outcomes for hospital patient care workers. Journal of Occupational and Environmental Medicine, 53, 899-910.

Spector, P. E., \& Jex, S. M. (1998). Development of four self-report measures of job stressors and strain: Interpersonal conflict at work scale, organizational 
POSITIVE SPILLOVER AND SLEEP

constraints scale, quantitative workload inventory, and physical symptoms inventory. Journal of Occupational Health Psychology, 3, 356-367.

Srivastava, S., Srivastava, U. R., \& Srivastava, A. K. (2009). Qualitative Exploration into the phenomenon of work-family facilitation in Indian context. Indian Journal of Social Science Research, 6, 92-102.

Steptoe, A., O’Donnell, K., Marmot, M., \& Wardle, J. (2008). Positive affect, psychological well-being, and good sleep. Journal of Psychosomatic Research, 64, 409-415.

Stevanovic, P., \& Rupert, P. A. (2009). Work-family spillover and life satisfaction among professional psychologists. Professional Psychology: Research and Practice, 40, $62-68$.

Stevens, D. P., Minnotte, K. L., Mannon, S. E., \& Kiger, G. (2007). Examining the "neglected side of the work-family interface": Antecedents of positive and negative family-to-work spillover. Journal of Family Issues, 28(2), 242-262.

Stoddard. M., \& Madsen, S. R. (2007). Toward an understanding of the link between work-family enrichment and individual health. Journal of Behavioral and Applied Management, 9, 2-15.

Stotland, E. Exploratory investigations of empathy. In L. Berkowitz (Ed.), Advances in experimental social psychology, Vol. 4. New York: Academic Press, 1969, pp. 271-314.

Strine, T. W., \& Chapman, D. P. (2005). Associations of frequent sleep insufficiency with health-related quality of life and health behaviors. Sleep Medicine, 6, 23-27. 
Stryker, S. (1968). Identity salience in role performance: The relevance of symbolic interaction theory for family research. Journal of Marriage and the Family, 30, 558-564.

Sumer, H. C., \& Knight, P. A. (2001). How do people with different attachment styles balance work and family? A personality perspective on work-family linkage. Journal of Applied Psychology, 86, 653-663.

Tabachnick, B. G., \& Fidell, L. S. (2007). Using multivariate statistics (5th ed.). Boston, MA: Pearson Education.

Taheri, S., Lin, L., Austin, D., Young, T., \& Mignot, E. (2004). Short sleep duration is associated with reduced leptin, elevated ghrelin, and increased body mass index. PLoS Medicine, 1, 210-217.

Takeuchi, R., Yun, S., \& Teslu, P. T. (2002). An examination of crossover and spillover effects of spouse and expatriate cross cultural adjustment on expatriate outcomes. Journal of Applied Psychology, 85, 655-666.

Taylor, B. L., Delcampo, R. G., \& Blancero, D. M. (2009). Work-family conflict/facilitation and the role of workplace supports for U.S. Hispanic professionals. Journal of Organizational Behavior, 30, 643-664.

Tepas, D. I., \& Carvalhais, A. B. (1990). Sleep patterns and shiftworkers. Occupational Medicine,5, 199-208.

Tetrick, L. E., \& Quick, J. C. (2003). Prevention at work: Public health in occupational settings. In J. C. Quick, \& L. E. Tetrick (Eds.), Handbook of Occupational Health Psychology (pp. 3-17). Washington, DC: American Psychological Association. 
Thoits, P. A. (1986). Multiple identities: Examining gender and marital status differences in distress. American Sociological Review, 51, 259-272.

Thomas, L. T., \& Ganster, D. C. (1995). Impact of family-supportive work variables on work-family conflict and strain: A control perspective. Journal of Applied Psychology, 80, 6-15.

Thompson, C. A., Beauvais, L. L., \& Lyness, K. S. (1999). When work-family benefits are not enough: The influence of work-family culture on benefit utilization, organizational attachment, and work-family conflict. Journal of Vocational Behavior, 54, 392-415

Thompson, C. A., \& Prottas, D. J. (2005). Relationships among organizational family support, job autonomy, perceived control, and employee well-being. Journal of Occupational Health Psychology, 11, 100-118.

U.S. Bureau of Labor Statistics. (2006). Women in the labor force: A databook. Report 996. Retrieved from http://www.bls.gov/cps/ wlf-databook2006.html van Amelsvoort, L. G. P. M., Jansen, N. W. H., Swaen, G. M. H., van den Brandt, P. A., \& Kant, I. (2004). Direction of shift rotation among three-shift workers in relation to psychological health and work-family conflict. Scandanavian Journal of Work and Environmental Health, 30, 149-156.

Van Dongen, H. P. A., Maislin, G., Mullington, J. M., \& Dinges, D. F. (2003). The cumulative cost of additional wakefulness: Dose-response effects on 
POSITIVE SPILLOVER AND SLEEP

neurobehavioral functions and sleep physiology from chronic sleep restriction and total sleep deprivation. SLEEP, 26, 117-126.

van Steenbergen, E. F., Ellemers, N., \& Mooijart, A. (2007). How work and family can facilitate each other: Distinct types of work-family facilitation and outcomes for women and men. Journal of Occupational Health Psychology, 12, 279-300.

van Steenbergen, E. F., \& Ellemers, N. (2009). Is managing the work-family interface worthwhile? Benefits for employee health and performance. Journal of Organizational Behavior, 30, 617-642.

Vela-Bueno, A., Moreno-Jimenez, B., Rodriguez-Munoz, A., Olavarrietta-Bernardino, S., Fernandez-Mendoza, J., De la Cruz-Troca, J. J., et al. (2008). Insomnia and sleep quality among primary care physicians with low and high burnout levels. Journal of Psychosomatic Research, 64, 435-442.

Voydanoff, P. (2004a). Implications of work and community demands and resources for work-to-family conflict and facilitation. Journal of Occupational Health Psychology, 9, 275-285.

Voydanoff, P. (2004b). The effects of work demands and resources on work-to-family conflict and facilitation. Journal of Marriage and Family, 66, 398-412.

Voydanoff, P. (2005a). The differential salience of family and community demands and resources for family-to-work conflict and facilitation. Journal of Family and Economic Issues, 26, 395-417. 
POSITIVE SPILLOVER AND SLEEP

Voydanoff, P. (2005b). The effects of community demands, resources, and strategies on the nature and consequences of the work-family interface: An agenda for future research. Family Relations, 54, 583-595.

Wadsworth, L. L., \& Owens, B. P. (2007). The effects of social support on work-family enhancement and work-family conflict in the public sector. Public Administration Review, 67, 75-87.

Walsh, J. K., Coulouvrat, C., Hajak, G., Lakoma, M. D., Petukhova, M., Roth, T., ... Kessler, R. C. (2011). SLEEP, 34, 997-1011.

Wayne, J. H., Grzywacz, J. G., Carlson, D. S., \& Kacmar, K. M. (2007). Work-family facilitation: A theoretical explanation and model of primary antecedents and consequences. Human Resource Management Review, 17, 63-76.

Wayne, J. H., Musisca, N., \& Fleeson, W. (2004). Considering the role of personality in the work-family experience: Relationships of the big five to work-family conflict and facilitation. Journal of Vocational Behavior, 64, 108-130.

Wayne, J. H., Randel, A. E., \& Stevens, J. (2006). The role of identity and work-family support in work-family enrichment and its work-related consequences. Journal of Vocational Behavior, 69, 445-461.

Westman, M. (2001). Stress and strain crossover. Human Relations, 54, 717-751.

Westman, M., \& Etzion, D. (2005). The crossover of work-family conflict from one spouse to the other. Journal of Applied Social Psychology, 35, 1936-1957.

Westman, M., \& Etzion, D. (1999). The crossover of strain from school principals to teachers and vice versa. Journal of Occupational Health Psychology, 4, 269-278. 
POSITIVE SPILLOVER AND SLEEP

Westman, M., Etzion, D., \& Chen, S. (2009). Crossover of positive experiences from business travelers to their spouses. Journal of Managerial Psychology, 24, 269284.

Westman, M., Etzion, D., \& Horovitz, S. (2004). The toll of unemployment does not stop with the unemployed. Human Relations, 57, 823-844.

Westman, M., Keinan, G., Roziner, I., \& Benyamini, Y. (2008). The crossover of perceived health between spouses. Journal of Occupational Health Psychology, $13,168-180$.

Westman, M., \& Vinokur, A. D. (1998). Unraveling the relationship of distress levels within couples: Common stressors, empathic reactions, or crossover via social interaction? Human Relations, 51, 137-156.

Westman, M., Vinokur, A. D., Hamilton, V. L., \& Roziner, I. (2004). Crossover of marital dissatisfaction during military downsizing among Russian army officers and their spouses. Journal of Applied Psychology, 89, 769-779.

Williams, A., Franche, R., Ibrahim, S., Mustard, C. A., \& Layton, F. R. (2006). Examining the relationship between work-family spillover and sleep quality. Journal of Occupational Health Psychlogy, 11, 27-37.

Williams, K. J., \& Alliger, G. M. (1994). Role stressors, mood spillover, and perceptions of work-family conflict in employed parents. Academy of Management Journal, $37,837-868$.

Williams, T. (2011, April 14). Official in charge of air traffic control resigns. New York Times. Retrieved May 3, 2011, from http://www.newyorktimes.com 
POSITIVE SPILLOVER AND SLEEP

Wingard, D. L., \& Berkman, L. F. (1986). Mortality risk associated with sleeping patterns among adults. SLEEP, 6, 102-107.

Yanchus, N. J., Eby, L. T., Lance, C. E., \& Drollinger, S. (2010). The impact of emotional labor on work-family outcomes. Journal of Vocational Behavior, 76, 105-117.

Zimmerman, K. L. (2009). Operationalizing the antecedents of work-family positive spillover: A longitudinal study. Unpublished doctoral dissertation. Portland State University.

Zimmerman, K. L., \& Hammer, L. B. (2010). Work-family positive spillover. Where have we been and what lies ahead? In J. Houdmount \& S. Leka (Eds.). Contemporary Occupational Health Psychology (pp. 273-295). West Sussex, UK: John Wiley and Sons Ltd.

Zimmerman, D. W., \& Williams, R. H. (2000). Restriction of range and correlation in outlier-prone distributions. Applied Psychological Measurement, 24, 267-280. 
Appendix

Survey Items

\section{Gender}

1. What is your gender?

$$
\begin{aligned}
& 1=\text { MALE } \\
& 2=\text { FEMALE }
\end{aligned}
$$

Age

1. How old are you?

\section{Race}

1. How would you describe your race? Please select all that apply.

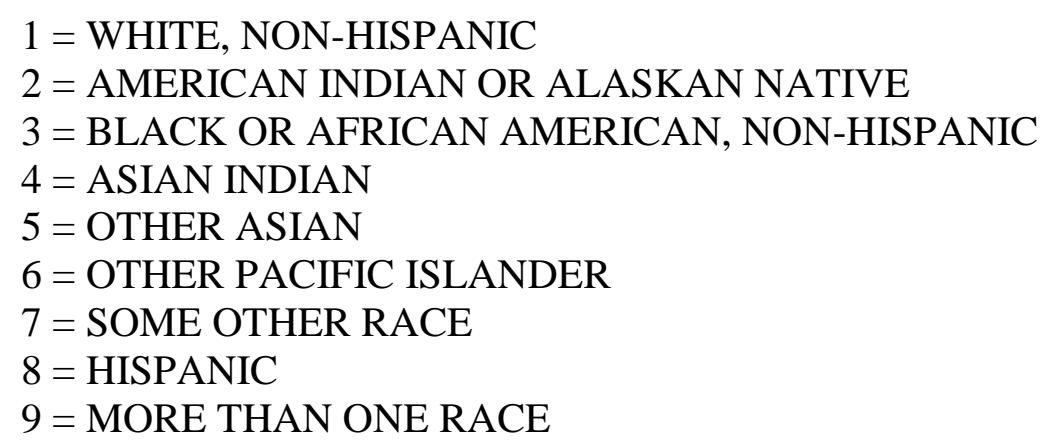

\section{Marital Status}

1. Are you currently married or do you have a permanent romantic partner that lives with you?

$$
\begin{aligned}
& 1=\text { YES, CURRENTLY MARRIED } \\
& 2=\text { YES CURRENTLY LIVING WITH A ROMANTIC PARTNER } \\
& 3=\text { NO }
\end{aligned}
$$

\section{Number of Children}


1. How many children live in your home for 4 or more days a week?

\section{Regular Night Work}

1. Which of the following best describes your work schedule at this job?

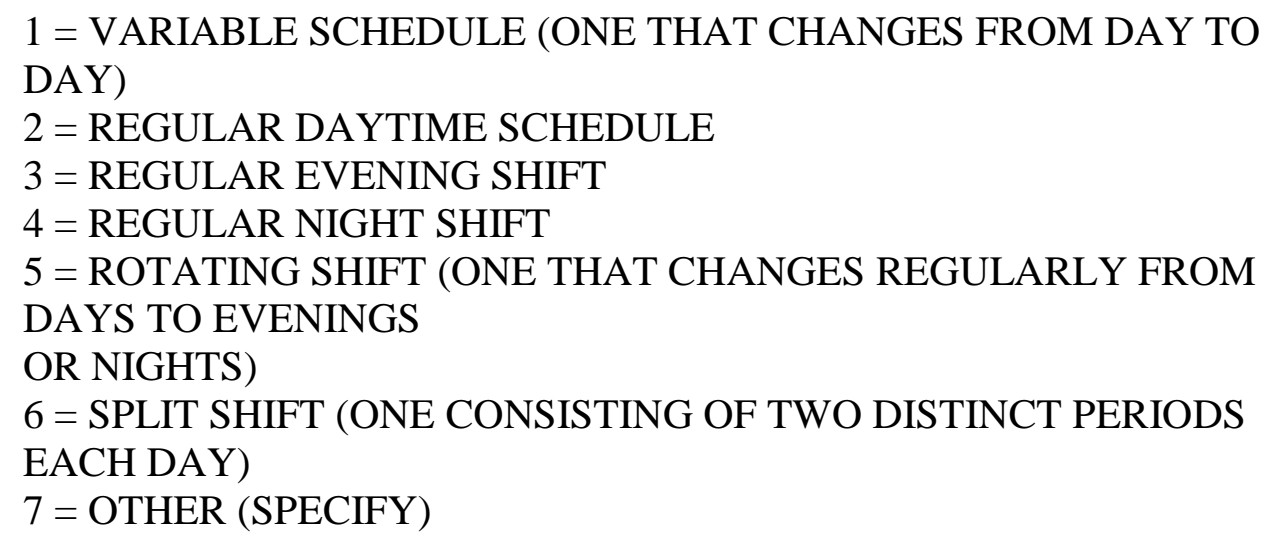

\section{Hours Worked}

1. About how many hours do you work in a typical week in this job?

\section{Chronic Conditions}

Instructions: The next section will ask some basic questions about your physical health. Please respond to these questions with a "yes" or "no".

1. Has a doctor ever told you that you had cancer?

2. Has a doctor ever told you that you had a stroke?

3. Are you currently doing nothing special for your diabetes?

4. Are you currently using some other treatment for your diabetes?

5. Are you currently trying to lose or control your weight?

6. Are you currently using insulin to lower your blood sugar?

7. Are you currently taking medication by mouth?

8. Are you currently following a special diet? 
9. Has a doctor ever told you that you had diabetes, sugar in your urine, or high blood sugar?

10. Are you currently taking medication for your cholesterol?

11. Are you currently taking medication for your heart?

12. Has a doctor ever told you that you had a heart attack, or coronary or myocardial infarction?

13. Are you currently taking medication for your high blood pressure?

14. Has a doctor ever told you that you had high blood pressure?

$$
\begin{aligned}
& 1=\text { YES } \\
& 2=\text { NO }
\end{aligned}
$$

\section{Apnea}

Instructions: The next set of questions will ask about your behavior while sleeping, trying to sleep, or while feeling sleepy during the last month. You can answer "yes" or "no" to these questions.

1. During the past month, have you snored, or ever been told that you were snoring?

$$
\begin{aligned}
& 1=\mathrm{YES} \\
& 2=\mathrm{NO}
\end{aligned}
$$

\section{Health Behaviors}

Instructions: The next set of questions will ask about your use of tobacco and alcohol.

1. Do you smoke tobacco cigarettes every day, some days or not at all?

$$
\begin{aligned}
& 1=\text { EVERY DAY } \\
& 2=\text { SOME DAYS } \\
& 3=\text { NOT AT ALL }
\end{aligned}
$$

2. On average, in a week, on how many days do you smoke? 
3. On the days you do smoke, how many tobacco cigarettes do you smoke on an average day?

4. On average, in one week, how many days do you drink any type of alcohol?

5. On the days you do drink alcohol, how many drinks do you have on the average day?

6. How many times in the past 4 weeks did you engage in exercise for at least 20 minutes that caused you to break a sweat?

7. How many times in the past 4 weeks have you eaten a meal from a fast food restaurant? By a fast food restaurant, we mean places like McDonald's, Wendy's, Taco Bell, Burger King or Kentucky Fried Chicken.Would you say never, 1 to 3 times, 1 or 2 times a week, 3 or 4 times a week, 5 or 6 times a week, 1 time per day, or 2 or more times per day?

$$
\begin{aligned}
& 1=\text { NEVER } \\
& 2=1-3 \text { TIMES } \\
& 3=1-2 \text { TIMES A WEEK } \\
& 4=3-4 \text { TIMES A WEEK } \\
& 5=5-6 \text { TIMES A WEEK } \\
& 6=1 \text { TIME PER DAY } \\
& 7=2 \text { OR MORE TIMES PER DAY }
\end{aligned}
$$

\section{Psychological Distress}

Instructions: The next set of questions asks about happy and sad feelings you experienced during the past 30 days.

1. During the past 30 days, how much of the time did you feel so sad nothing could cheer you up?

2. During the past 30 days, how much of the time did you feel nervous? 
3. During the past 30 days, how much of the time did you feel restless or fidgety?

4. During the past 30 days, how much of the time did you feel hopeless?

5. During the past 30 days, how much of the time did you feel worthless?

6. During the past 30 days, how much of the time did you feel that everything was an effort?

$$
\begin{aligned}
& 1=\text { ALL OF THE TIME } \\
& 2=\text { MOST OF THE TIME } \\
& 3=\text { SOME OF THE TIME } \\
& 4=\text { A LITTLE OF THE TIME } \\
& 5=\text { NONE OF THE TIME }
\end{aligned}
$$

\section{Work-to-family positive spillover}

Instructions: The next section will ask you some questions about how your job relates to your family or personal life.

1. When things are going well at work, your outlook regarding your family or personal life is improved.

2. Being in a positive mood at work helps you to be in a positive mood at home.

3. Being happy at work helps you to be happy at home.

4. Having a good day at work allows you to feel positive with your family.

$$
\begin{aligned}
& 1=\text { STRONGLY AGREE } \\
& 2=\text { AGREE } \\
& 3=\text { NEITHER } \\
& 4=\text { DISAGREE } \\
& 5=\text { STRONGLY DISAGREE }
\end{aligned}
$$

\section{Family Supportive Supervisor Behaviors}

Instructions: I'm now going to read some statements about your experiences with your direct supervisor at "company name". 
1. Your supervisor makes you feel comfortable talking to him/her about my conflicts between work and non-work.

2. Your supervisor works effectively with employees to creatively solve conflicts between work and non-work.

3. Your supervisor demonstrates effective behaviors in how to juggle work and nonwork issues.

4. Your supervisor organizes the work in your department or unit to jointly benefit employees and the company.

$$
\begin{aligned}
& 1=\text { STRONGLY AGREE } \\
& 2=\text { AGREE } \\
& 3=\text { NEITHER } \\
& 4=\text { DISAGREE } \\
& 5=\text { STRONGLY DISAGREE }
\end{aligned}
$$

\section{Sleep Insufficiency}

Instructions: The next section will ask some basic questions about your physical health.

1. How often during the past four weeks did you get enough sleep to feel rested upon waking up?

$$
\begin{aligned}
& 1=\text { NEVER } \\
& 2=\text { RARELY } \\
& 3=\text { SOMETIMES } \\
& 4=\text { OFTEN } \\
& 5=\text { VERY OFTEN }
\end{aligned}
$$

\section{Sleep Duration}

1. Over the past 4 weeks, what time did you usually turn the lights off to go to sleep? 
2. Over the past 4 weeks, what time did you usually get out of bed?

\section{Insomnia Symptoms}

1. During the past 4 weeks, how often could you not get to sleep within 30 minutes?

2. During the past 4 weeks, how often did you wake up in the middle of the night or early morning?

$$
\begin{aligned}
& 1=\text { NEVER } \\
& 2=\text { LESS THAN ONCE A WEEK } \\
& 3=\text { ONCE OR TWICE A WEEK } \\
& 4=\text { THREE OR MORE TIMES A WEEK }
\end{aligned}
$$

